\title{
MODELO DE SUPERFICIE DE RESPOSTA COM ALGUMAS VARIÁVEIS AUXILIARES
}

\author{
AUGUSTO RAMALHO DE MORAIS \\ Engenheiro Agrônomo
}

Orientador: Prof. VIVALDO FRANCISCO DA CRUZ

\begin{abstract}
Dissertação apresentada à Escola Superior de Agricultura "Luiz de Queiroz", da Universidade de São Paulo, para obtenção do título de Mestre em Agronomia - Área de Concentração: Estatística e Experimentação Agronômica.
\end{abstract}

PIR A C ICABA

Estado de São Paulo - Brasil

Outubro, 1982 


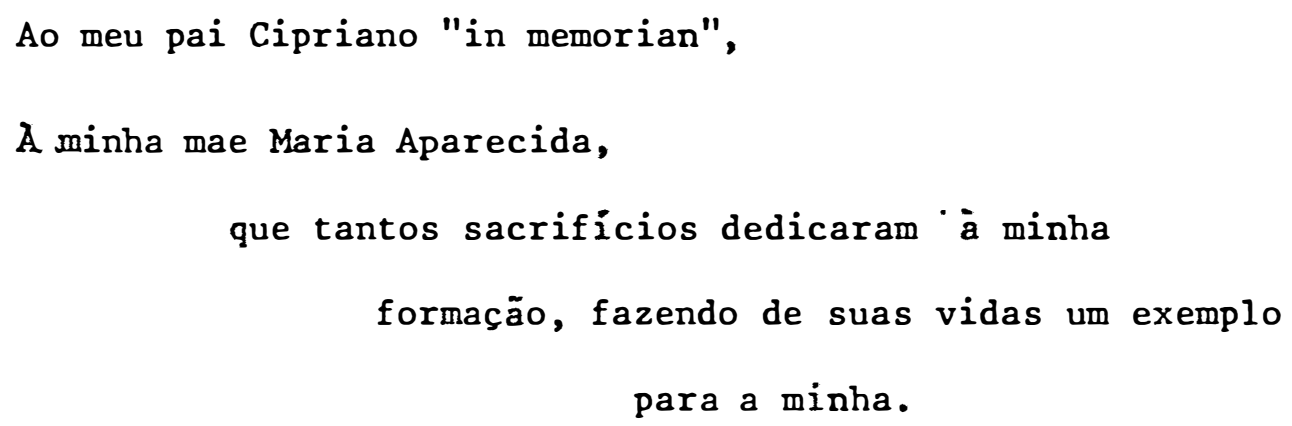

Aos meus avōs Joaquim, Adalgiza, Manoel "in memorian" e Umbelina, que plantaram na terra,

DEDICO.

"Através do conhecimento e do Amor até a perfeição iremos chegar". (Ronaldò)

"A maior recompensa è a consciēncia tranqüila do dever cumprido" (Alexandre)

Ao meu irmão, cunhada, sobrinha, aos meus tios, amigos e à minha noiva, OFEREÇO • 


\section{AGRADECIMENTOS}

A vida.

A EMBRAPA - EMPRESA BRASILEIRA DE PESQUISA AGROPECUARIA, pelo suporte financeiro e colaboração no nosso desempenho profissional.

A ESALQ - Escola Superior de Agricultura "Luiz de Queiroz", que possibilitou a realização do curso.

Ao Corpo Docente do Departamento de Matemática e Esta tística, da ESALQ, pelos ensinamentos ministrados durante o curso de pós-graduação.

Ao Professor Dr. Vivaldo Francisco da Cruz pela orienta ção e amizade.

Ao CNPMS - Centro Nacional de Pesquisa de Milho e Sorgo que nos acolheu.

Aos colegas que de vārias formas me incentivaram e apoiaram.

A todos que, mesmo sem eu o saber, auxiliaram para a realização do curso de Mestrado. 
LISTA $\mathrm{DE}$ TABELAS........................... v

LISTA DE APENDICE.................................. vii

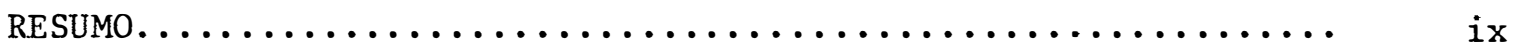

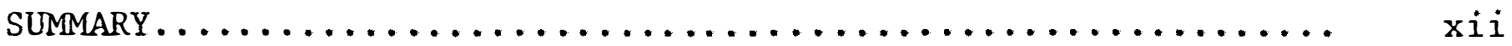

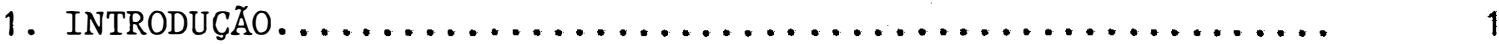

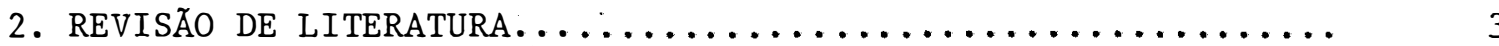

2.1. Anālise de covariāncia..................... 3

2.2. Ajustamento de superficies de resposta............. 9

3. MATERIAL E MÉTODO............................ 24

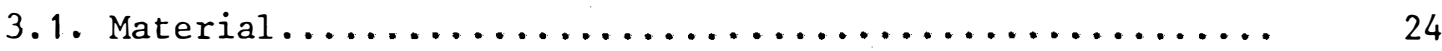

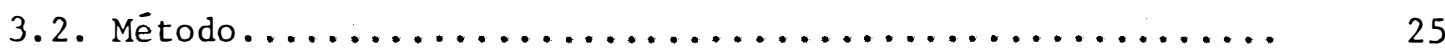

4. RESULTADOS E DISCUSSAO.......................... 60

4.1. Modelo sem as variäveis auxiliares adicionais......... 60

4.2. Modelo com as variäveis auxiliares adicionais......... 65

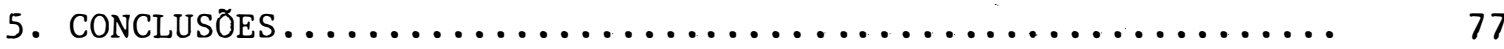

6. Literatura CitAdA.......................... 80

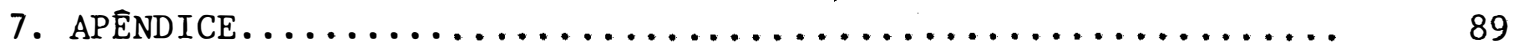




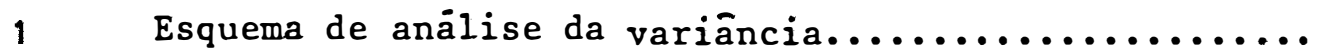

2 Esquema de anālise da variạncia para os efeitos de tratamento ajustados de acädo com a regressão 1 inear, com suas respectivas esperanças matemäticas

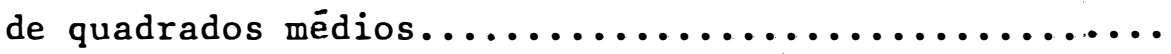

3 Matriz de dispersão dos efeitos de tratamentos ajusdos pela regressão linear, caso de uma variável auxi-

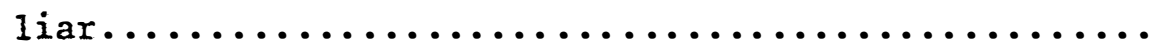

4 Estimativas dos parāmetros, desvios padröes e valores de $t$ da variāyel dependente produção, relativos aos e-

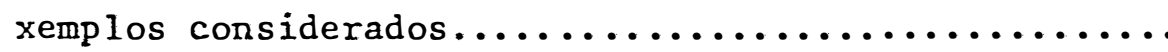

5 Anālise da variāncia relativa aos dados de produção pa

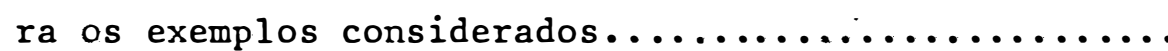

6 Valores de quadrados médios e teste $F$ para produção e produção ajustada pelas variáveis auxiliares:altura da planta, diāmetro da copa e número de internódios, e-

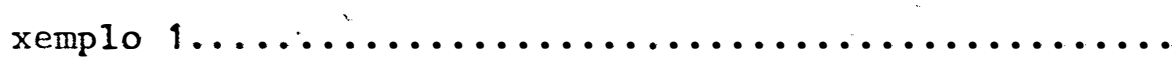


7 Valores de quadrados médios e teste $\mathbf{F}$ para producão $e$ producão ajustada pelas variāveis auxiliares: altura da planta, diāmetro da copa e número de internódios, e-

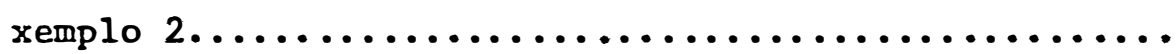

8 Valores de quadrados médios e teste $\mathrm{F}$ para producão $\mathrm{e}$ producão ajustada pelas variäveis auxiliares:altura da planta, diāmetro da copa e nümero de internódios,

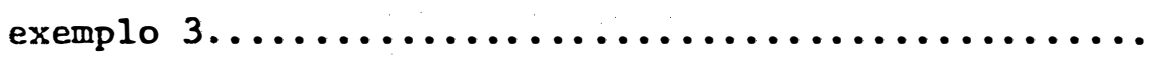

9 Estimativas ajustadas dos parāmetros, desvios padröes, e valores de $t$, no exemplo $1 . . . . \ldots \ldots \ldots . .$. Estimativas ajustadas dos parāmetros, desvios padrões e valores de $t$, no exemplo $2 \ldots \ldots \ldots \ldots \ldots \ldots \ldots$ Estimativas ajustadas dos parāmetros, desvios padrões e valores de $t$, no exemplo $3 \ldots \ldots \ldots \ldots \ldots \ldots \ldots$ dos parämetros.......................... 
vii.

\section{LISTA DE APENDICE}

Apēndice

Pägina

1 Valores observados, relativos às variáveis auxiliares

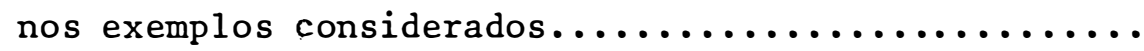

2 Matriz de dispersão das estimativas dos parāmetros ajustadas pelas três variāveis auxiliares, no exem-

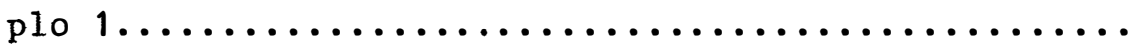

3 Matriz de dispersão das estimativas dos parāmetros ajustadas pelas trēs variāveis auxiliares, no exem-

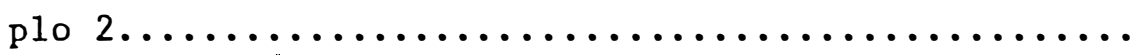

4 Matriz de dispersão das estimativas dos parāmetros ajustadas pelas très variáveis auxiliares, no exem-

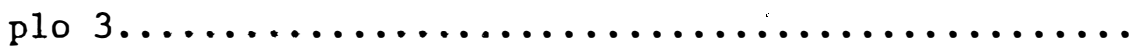

5 Matrizes de dispersão das estimativas dos coeficientes de regressão, nos exemplos em questão...

6 Representação gräfica das produções médias nos trēs niveis de $\mathrm{N}, \mathrm{P}_{2} \mathrm{O}_{5}$ e $\mathrm{K}_{2} \mathrm{O} \ldots \ldots \ldots \ldots \ldots \ldots \ldots \ldots \ldots$

7 Valores observados e estimados da produção, no exem

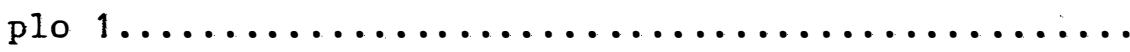


viii.

Apēndice

Pägina

8 Valores observados e estimados da produção, no exem-

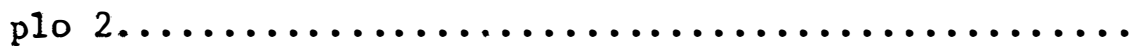

9 Valores observados e estimados da produção, no exem-

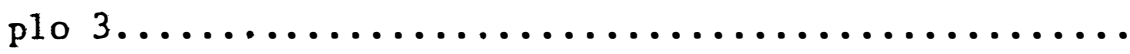


ix.

\section{MODELO DE SUPERFICIE DE RESPOSTA COM ALGUMAS VARIÁVEIS AUXILIARES.}

AUGUSTO RAMALHO DE MORAIS

Prof. VIVALDO FRANCISCO DA CRUZ

- Orientador -

\section{RESUMO}

A procura de delineamentos que possibilitassem estudos mais eficientes de respostas à variação de - fatores aplicados a determinado fenómeno, iniciou-se com R.A. Fisher e, prolonga-se pelos anos, nos vários campos de pesquisa.

Com o objetivo de se verificar a relação entre a produ ção e niveis de adubação, através do uso da metodologia de superfície de resposta, estudou-se um modelo de regressāo polinomial quadrático, tendo-se a preocupação de considerar algumas variāveis auxiliares adicionais ao modelo, com vistas à obtenção de förmulas que permitam avaliar o comporta mento da produção ante à inclusão destas ūltimas.

Desenvolveu-se, usando o método dos quadrados minimos, a seqüēncia de operações para a realização das anālises estatísticas considerando-se o modelo adaptado a um esquema fatorial completo, para trés fä tores em trēs níveis eqüidistantes. São dados: o cálculo das estimativas dos parâmetros do modelo, de suas variāncias e covariāncias; a análise da 
variāncia e os testes de hipöteses, os intervalos de confiança para os pārametros e as respostas esperadas.

Em seguida, foi aplicada a metodologia a dados provenientes de um experimento de adubação N-P-K, em cafeeiro onde, se conside rou a produção como variável dependente e, altura da planta, diāmetro da copa e número de internödios como variáveis auxiliares adicionais.

$$
\text { As principais conclusões obtidas foram: }
$$

1. Os parâmetros ( $\left.a_{i i}, i^{\prime} i^{\prime}=0,1,2,3\right)$ do modelo com uma variávẹl auxiliar, serão estimados com maior precisão do que no modelo original (sem a variāvel auxiliar) quando a redução da variāncia residual deste, dada por $\left(\sigma^{2}-\sigma_{1}^{2}\right)$, for maior do que o acréscimo [SQa $\left.{ }_{i}^{\prime}, / R\left(z^{2}\right)\right] \sigma_{1}^{2}$, dado pela inclusão da variável auxiliar ao modelo; ou seja,

$$
\frac{\sigma^{2}}{\sigma_{1}^{2}}>1+\frac{\text { SQa }^{\prime}{ }_{i i^{\prime}}}{R\left(z^{2}\right)} \text {, }
$$

onde: SQa' ${ }_{i i^{\prime}}$ : é a soma de quadrados dos parāmetros $\left(a^{\prime}{ }_{i i}{ }^{\prime}, i, i^{\prime}=0\right.$, $1,2,3)$, relativa à variável auxiliar;

$R\left(z^{2}\right)$ : è a soma de quadrados de resíduo, relativa à variável auxiliar;

$\sigma^{2}$ e $\sigma_{1}^{2}$ : são asvariāncias residuais dos modelos sem e com a variāvel auxiliar, respectivamente.

2. As variáveis auxiliares que mais contribuiram para a redução da variân cia residual $\left(\sigma^{2}\right)$ foram: altura da planta seguida de diāmetro da copa nos exemplos considerados. 
3. As estimativas da variāncia dos parāmetros $\left(a_{i i}{ }^{\prime}, i, i^{\prime}=0,1,2,3\right)$, são dados pela expressão:

$$
\bar{v}\left(a_{i i^{\prime}}\right)=\frac{1}{c_{j}}\left[1+\frac{Q M a a_{i i^{\prime}}^{\prime}}{R\left(z^{2}\right)}\right] \hat{\sigma}_{2}^{2},
$$

onde: QMa!'’' : quadrado mëdio do parāmetro $\left(a_{i i}^{\prime}{ }^{\prime}\right)$ relativo à variável auxiliar;

$C_{j}$ : coeficiente dos termos quadráticos, lineares e interações, respectivamente 6,18 e 12 .

$\hat{\sigma}_{1}^{2}$ : estimativa da variāncia residual. 
xii.

\title{
RESPONSE SURFACE MODEL WITH SOME AUXILIARY VARIABLES
}

\author{
Augusto Ramalho de Morais \\ -Author
}

Vivaldo Francisco da Cruz

-Adviser-

\section{SUMMARY}

The development of designs that provide more efficient approach studies to investigate response by variation of other factors was initiated by R.A. Fisher in agronomy, and extended to other research areas.

In order to study the relationships between yield and fertilization levels, the response surface methodology was applied to a type of quadratic polynomial regression model, with orthogonal polynomials of first and second degree, considering somes auxiliary vàriables for the obtention of formulae for the evaluation of their effect in the model.

The least square procedure used in order to statistical analysis according to a model adaptate to factorial design, for three factors at three equally spaced levels. The estimates of parameters in the model, their variances and covariances, the analysis 
of variance and the tests of hypothesis, the confidence intervals for parameters and expected values are given.

The methodology was applied on $\mathrm{N}, \mathrm{P}_{2} \mathrm{O}_{5}$, and $\mathrm{K}_{2} \mathrm{O}$ experiment with coffee-tree fertilization, where dependent variable is yield and auxiliary variables are plant height, treetop diameter and internode number.

The principal conclusions obtained were:

1. The parameters ( $a_{i i}, i^{\prime} i^{\prime}=0,1,2,3$ ) of the model with one auxi liary variable will be estimated with greater precision than those in the original model when the reduction of the residual variance, given by $\left(\sigma^{2}-\sigma_{1}^{2}\right)$, were greater than the quantity $\left|S Q a_{i}^{\prime}, / R\left(z^{2}\right)\right| \hat{\sigma}_{1}^{2}$ due to the inclusion of the auxiliary variable in the model; that is, when

where:

$$
\frac{\sigma^{2}}{\sigma_{1}^{2}}>1+\frac{S Q a^{\prime}}{R\left(z^{2}\right)}
$$

$$
\begin{aligned}
& \mathrm{SQa}_{i i^{\prime}}^{\prime}: \text { sum of squares of parameters }\left(a_{i i^{\prime}}^{\prime}, i^{\prime}=0,1,2,3\right), \\
& \text { relative the auxiliary variable; } \\
& \mathrm{R}\left(\mathrm{z}^{2}\right): \text { sum of squares of residual, relative the auxiliary } \\
& \text { variable; } \\
& \sigma^{2} \text { e } \sigma_{1}^{2} \text { : residual variances of the models without and with } \\
& \text { auxiliary variable. }
\end{aligned}
$$

2. The additional auxiliary variables that contributed to decrease the reduction in residual variance were: treetop, diameter and height plant.

3. The expression of the estimated parameters variance are:

$$
\hat{v}\left(a_{i i^{\prime}}\right)=\frac{1}{c_{j}}\left|I+\frac{Q M a_{i i^{\prime}}^{\prime}}{R\left(z^{2}\right)}\right| \hat{\sigma}_{1}^{2},
$$


xiv.

where: QMa! ${ }_{i i^{\prime}}^{\prime}$ : mean square of parameters $\left(a_{i i}^{\prime}\right)$, relative the auxiliary variable;

$c_{j}$ : quadratic, linear and interaction terms coefficient 6,18 , and 12 , respectively.

$\hat{\sigma}_{1}^{2}$ : residual variance estimative. 


\section{INTRODUCÃO}

A metodologia de superficie de resposta è essencialmen te um conjunto de técnicas estatísticas usada em pesquisas com a finalida de de determinar as melhores condições, e tambëm, dar maior conhecimento

sobre a natureza de certos fenōmenos. $\vec{E}$ composta por planejamento e análi se de experimentos, que procura relacionar respostas com niveis de fatores quantitativos.

Sua aplicação deu-se iniciálmente na indūstria química. No campo agronōmico, o uso se concentrou no estudo do rendimento de culti vares como efeito de niveis de fertilizantes aplicados ao solo; posterior mente incluem-se outros fatores como densidade de plantio, controle de doenças, etc.

Com o crescente aumento do uso de fertilizantes, pesqui sadores e economistas tēm-se preocupado em buscar solução racional de ut lização destes pelos agricultores. Pesquisa-se, também, quais os modos mais eficientes para planejar a procura dessas soluções a partir de deli- 
neamentos experimentais que utilizem todas as combinações dos fatores em estudo ou parte delas.

Desenvolveu-se, no presente trabalho, a análise de um modelo de regressão polinomial quadrático adaptado a um esquema fato rial completo, para trēs fatores em trēs niveis eqüidistantes, consideran do-se algumas variáveis auxiliares adicionais, através da metodologia de superficie de resposta, com vistas à abtenção de förmulas que permitam avaliar o comportamento da produção (variável dependente) diante da inclusão das variáveis auxiliares ao modelo.

E dada a seqüéncia de operaçōes para a realização da análise estatística, com soluções específicas para esse delineamento.

Como exemplo, estudou-se a relação entre a produção de cafeeiro e niveis de adubação $\mathrm{N}-\mathrm{P}-\mathrm{K}$ onde, se considerou altura da planta, o diāmetro da copa e o número de internódios como variáveis auxiliares adicionais na explicação das produções observadas.

De modo especifico incluiu-se nos objetivos a verificação da hipōtese relativa à influência das variáveis auxiliares adicionais na variável dependente. No caso de rejeição da hipōtese da não influēncia das variáveis, determinar quais delas devem ser consideradas em futuros experimentos desse tipo. 


\section{REVISÃO DE LITERATURA}

Apresentar-se-à nesse capítulo, primeiramente, uma revi são de trabalhos referentes ao uso da anälise de covariāncia e, em seguida outra relacionada ao ajustamento de superfícies de resposta a dados ex perimentais. Isto tendo em vista que não encontrou-se, na literatura disponivel, referencias sobre ajuste de modelos de superficie de resposta que tratassem do modelo proposto neste trabalho.

\subsection{ANÁlise DE COVARIÂNCIA}

A anālise de covariāncia tem sido muito bem estudada, principalmente nos delineamentos experimentais inteiramente casualizados

e blocos casualizados. A seguir apresenta-se algumas referéncias sobre a técnica e uso da anālise de covariāncia. 
A primeira ilustração do método da covariāncia na literatura, foi apresentada por Fisher (1932), segundo COCHRAN (1957), onde a variāvel auxiliar (x) constituía a produção de chá por parcela, obtida num período preliminar e a variávèl dependente (y) constituiu a produção de chā no final do ensaio, após aplicação dos tratamentos.

KEMPTHORNE (1952) fazendo um estudo sobre a anälise da covariāncia, apresentou um modelo matemático com dois critérios de classi ficação, com uma observação por parcela e ausenncia de interação. Supōs a presença de um atributo (x) sujeito à variação associada a cada parcela experimental, e admitiu a seguir a auséncia do efeito de tratamentos levantando a hipótese de que os efeitos de tratamentos sejam nulos e, a seguir testa o modelo matemático completo.

OSTLE (1954) apresentou um estudo teörico sobre a anälí se da covariáncia, onde abordou um modelo matemático de um experimento fa torial com dois fatores no delineamento em blocos completos casualizados, apresentando förmulas para cálculo das somas de quadrados e de produtos, teste $\mathrm{F}$ para os fatores e sua interação e para variāncias das médias ajus tadas. Considerou um exemplo, obtido de Wishart (1950) onde comparou o fornecimento de trēs rações a leitões de ambos os sexos medindo o peso inicial (x) e o ganho de peso (y).

As principais finalidades do uso da análise da covariān cia, segundo COCHRAN (1957), são:

a) aumentar a precisão nos experimentos casualizados;

b) remover os efeitos de variáveis perturbadoras;

c) contribuir para esclarecer a natureza dos efeitos de tratamentos; 
d) ajustar regressões em classificações múltiplas;

e) analisar dados quando algumas observações são perdidas.

O mesmo autor considerou que as pressuposições básicas requeridas para que o uso da anālise de covariāncia seja vālido, são uma extensão daquelas necessārias para uma anālise da variāncia, que podem ser resumidas em:

a) os efeitos dos tratamentos, dos blocos e da regressão devem ser aditivos;

b) os erros experimentais devem ser independentes e normalmente distribuí dos, com média zero e variāncia constante.

ZELLEN (1957) e DIAS (1981) estudando a anālise de cova riāncia intrablocos, com $\mathbf{p}$ variāveis auxiliares, para delineamentos em blocos incompletos equilibrados, consideraram o seguinte modelo matemático:

$$
Y_{i j}=m+t_{i}+b_{j}+\sum_{w=1}^{p} a_{w} x_{i j}^{(w)}+e_{i j} \text {, }
$$

onde :

$$
\begin{aligned}
\mathrm{Y}_{i j} & =\text { valor observado da variável dependente; } \\
\mathrm{m} & =\text { média geral; } \\
\mathrm{t}_{i} & =\text { efeito do i-ésimo tratamento; } \\
\mathrm{b}_{j} & =\text { efeito do j-ésimo bloco; } \\
a_{w} & =\text { efeito do w-ésimo coeficiente de regressão linear; }
\end{aligned}
$$




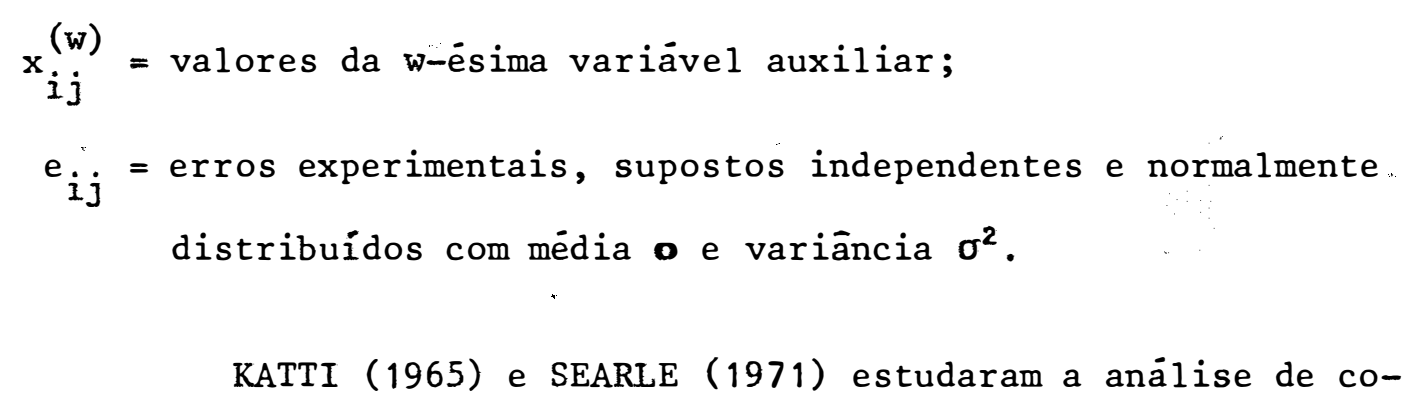
variāncia para qualquer tipo de delineamento, com $\mathbf{p}$ variāveis auxiliares, utilizando o seguinte modelo matemático:

$$
\mathrm{Y}=\mathrm{X} \beta+\mathrm{Zb}+\mathrm{E},
$$

onde:

$$
\begin{aligned}
& Y= \\
X= & \text { matriz de incidéncia correspondente ao delineamento em } \\
& \text { questão; } \\
B= & \text { vetor dos parāmetros correspondentes aos efeitos envolvi- } \\
& \text { dos no modelo proposto; } \\
Z= & \text { matriz dos valores das } \mathbf{p} \text { variäveis auxiliares; } \\
\mathbf{b}= & \text { vetor dos coeficientes de regressão; } \\
\mathrm{E}= & \text { vetor dos erros experimentais, onde } \mathrm{E} \sim \mathrm{N}\left(\Phi, \sigma^{2} \mathrm{I}\right) .
\end{aligned}
$$

Para obterem as soluções, os autores consideraram o modelo acima reescrito, da seguinte maneira:

$$
Y=X \beta *+(Z-X \Delta) \mathbf{b}+E,
$$

onde $\Delta e^{e}$ uma matriz escolhida tal que $X^{\prime}(Z-X \Delta)=\Phi$. 
veis independentes estão relacionadas linearmente com a variável dependen te, o uso da análise da covariancia pode conduzir a estimativas mais precisas, podendo assim obter-se comparações mais eficientes entre médias dos tratamentos; tais considerações foram também feitas por WINER (1970) e MONTGOMERY (1976).

WINER (1970) desenvolveu a anālise de covariāncia para uma experimento fatorial pxq, com n observações por parcela, onde conside rou o seguinte modelo matemático:

$$
Y_{i j k}=\mu+\alpha_{i}+\beta_{j}+\alpha \beta_{i j}+\beta\left(X_{i j k}-\bar{X}\right)+e_{i j k},
$$

onde:

$$
\begin{aligned}
& Y_{i j k} \text { : são os valores observados; } \\
& \mu: \text { média geral; } \\
& \alpha_{i}: \operatorname{com} i=1,2, \ldots, p, e ́ \text { o efeito do fator } \alpha ; \\
& \beta_{j}: \operatorname{com} j=1,2, \ldots, q, e ́ \text { o efeito do fator } \beta ; \\
& \alpha \beta_{i j}: \text { é o efeito da interação } \alpha \text { x } \beta ; \\
& \beta: \text { é o coeficiente de regressão; } \\
& X_{i j k}: \text { são os valores da variável auxiliar; } \\
& \bar{X}: \text { média dos valores da variável auxiliar; } \\
& e_{i j k}: \text { são os erros experimentais. }
\end{aligned}
$$

PIMENTEL GOMES (1978) para as anālises de covariāncia nos delineamentos em blocos completos casualizados, com uma variável auxi liar, sugeriu, para o cálculo da soma de quadrados de tratamentos ajusta- 
da para regressão, o seguinte procedimento:

$$
S Q T^{*}=R^{\prime}\left(y^{2}\right)-\frac{\left[R^{\prime}(x y)\right]^{2}}{R^{\prime}\left(x^{2}\right)}-\operatorname{SQRES*},
$$

onde :

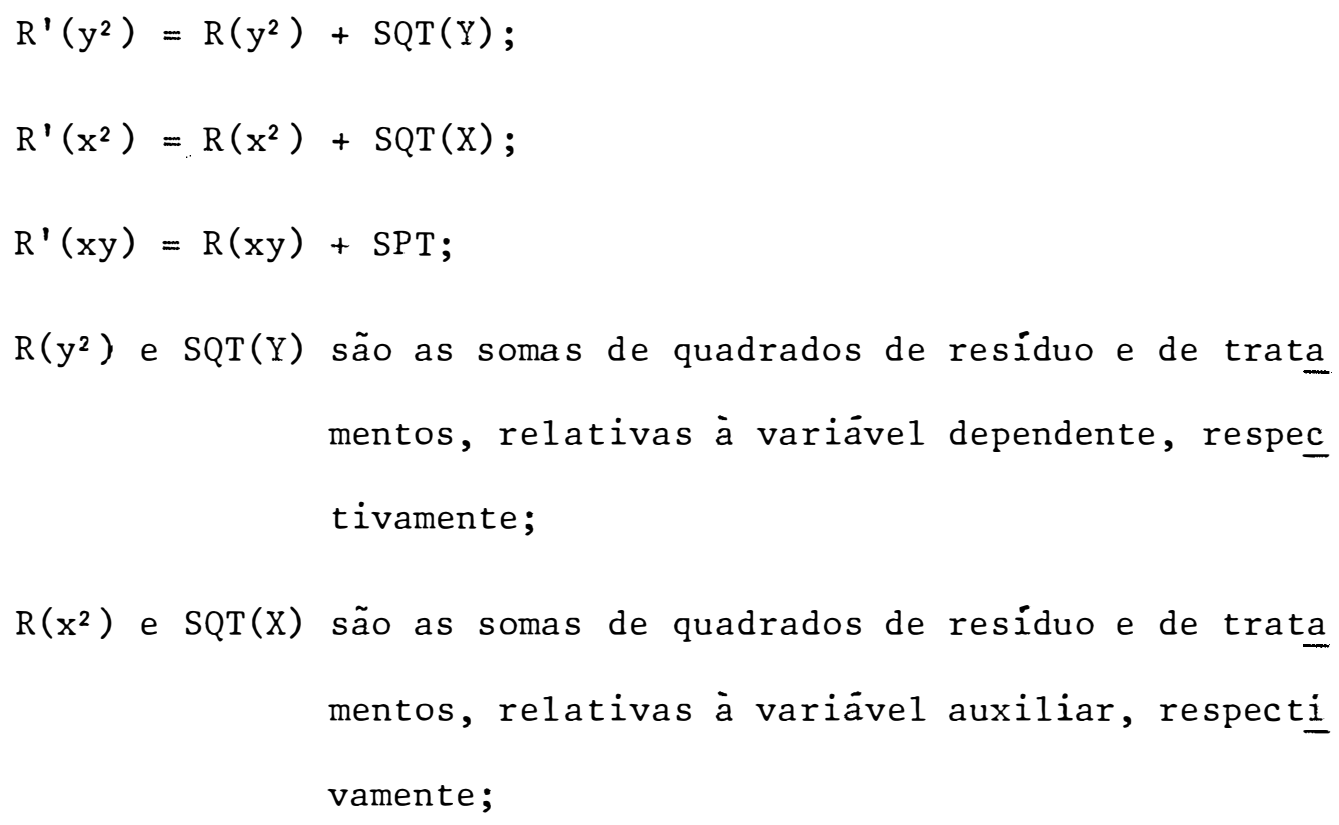




\subsection{AJustamento DE SUPERFícies DE RESPOSta}

Não obstante ser desconhecida a forma matemätica da fun ção que melhor se ajuste aos dados de produção, è possivel, utilizar mode los estatísticos que dela se aproximam com precisão razoável. A seguir são apresentados alguns trabalhos que mostram o uso dos modelos de superficies de resposta.

Segundo N.A.S.-N.R.C. (1961) a primeira tentativa de se explicar a produção como uma função da fertilidade é considerada com a "lei do mínimo" proposta por Justus von Liebig, em 1855; mas segundo revi são apresentada por MEAD e PIKE (1975) surgiu com Fechner, em 1860, no campo de pröbites.

Mitscherlich (1909) segundo N.A.S.-N.R.C. (1961) foi um dos primeiros a especificar que a relação funcional entre aplicações de fertilizantes e resposta na produção è curvilínea, acrescentando que o crescimento de plantas segue uma curva baseada em aumentos decrescentes. Também, W.J. Spillman, em 1923, chegou a uma função de crescimento exponencial, equivalente à de Mitscherlich, estudando resultados de experimen tos de adubação em algodoeiro, na Carolina do Norte.

Nas ūltimas décadas, grande tēm sido a contribuição da estatistica por intermédio do uso dos delineamentos experimentais, nas pesquisas, de um modo geral. Segundo Abeywardena (1966), citado por DAVILA e BENITES (1979), ANDRADE (1977) e ARNOLD et alii (1979), a utilização de modelos matemáticos para expressar a resposta de nutrientes, sob a for ma de superficie, teve um grande progresso a partir da década de cinqüenta, após a publicação dos artigos de Box e Wilson (1951) e de Box e 
Hunter (1957).

BOX e WILSON (1951) estudaram delineamentos com a finalidade de determinar o ponto de resposta mäxima, em ensaios com diferentes níveis de $\mathbf{k}$ fatores, usando o menor número possível de observações. Discutiram o comportamento de alguns delineamentos experimentais propostos, denominados "Planejamentos Compostos", que a princípio foram utiliza dos na indústria química e, atualmente são usados em outros campos de pes quisa, dos quais destaca-se a agricultura. A suposição predominante neste artigo, è que a resposta pode ser aproximada, em uma região de interesse, por um polinōmio, nos níveis dos värios fatores ou variáveis envolvidas. BOX e HUNTER (1957) desenvolveram os delineamentos rota cionais para $\mathbf{k}$ fatores, considerando a propriedade de que è constante a variância da resposta estimada em pontos eqüidistantes do centro. Propuse ram os seguintes requisitos para um delineamento de superficie de resposta:

- deve permitir o ajustamento de um polinómio que se considera adequado, para representar a função verdadeira, tanto quanto possível, dentro da região de interesse;

- deve permitir a verificação da adequada representatividade do polinómio;

- não deve conter um excessivo número de pontos experimentais;

- deve permitir a disposição em blocos;

- deve possibilitar a extensão a um polinómio de grau mais elevado.

HADER et alii (1957) apresentaram um estudo de delineamentos e métodos estatísticos para caracterizar a superficie de resposta, 
onde consideraram um ensaio de produção de alface afetada por trēs micronutrientes: cobre, molibdēnio e ferro, em cinco concentrações diferentes, em delineamento rotativo de segunda ordem. A análise da varianncia mostrou efeito altamente significativo para os componentes lineares e quadráticos; entretanto, os parāmetros apresentaram erros padrões relativamente grandes.

COCHRAN e COX (1957) consideraram que o método mais informativo para analisar os resultados de um experimento fatorial depende da natureza dos fatores. Se todos estes, representam variáveis quantitatí vas, o método mais informativo de anālise consiste em relacionar as respostas como função dessas variāveis.

Box e Draper (1959), citados por MEAD e PIKE (1975) di $\underline{\mathbf{s}}$ cutiram várias razões na escolha de um delineamento para estudar a superfície de resposta. As razões incluem simples interesse na superfície, estimação eficiente dos parāmetros do modelo e possivel discriminação entre diferentes modelos e, consideraram ainda, que diferentes delineamentos po deriam ser usados para diferentes objetivos.

HEADY et alii (1961) ajustaram quatro funções de produção aos dados de trēs ensaios de adubação: a) N e P em milho; b) P e $\quad K$ em trevo vermelho e c) $P$ e $K$ em alfafa,

Os autores verificaram que a função de raiz quadrada re presentou melhor os dados, pois a ela correspondeu o menor desvio de re- 
gressão e o maior coeficiente de determinação, para os trēs ensaios. CAMPOS (1967) estudou a regressão polinomial quadrática ajustada aos dados de ensaios fatoriais $3^{3}$, de adubação NPK, na cultura do milho, usando o seguinte modelo matemático:

$$
\begin{aligned}
Y= & a_{0}+a_{11} x_{1}^{2}+a_{22} x_{2}^{2}+a_{33} x_{3}^{2}+a_{12} x_{1} x_{2}+a_{13} x_{1} x_{3}+a_{23} x_{2} x_{3}+ \\
& +a_{14} x_{1}+a_{24} x_{2}+a_{34} x_{3}+e,
\end{aligned}
$$

onde:

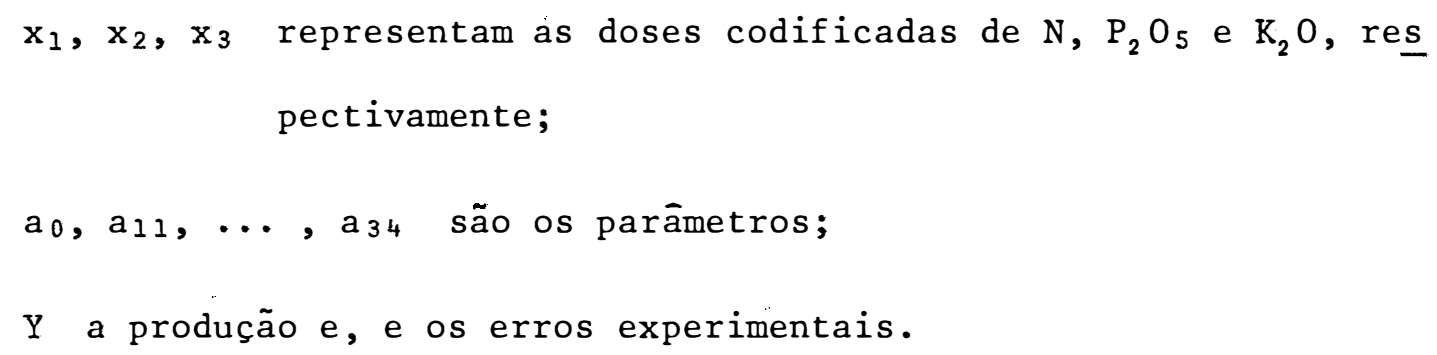
intervalos de confiança das produções. Mostrou também, os cortes da super fície quando dois nutrientes são fixados nas doses padrões.

Seguindo ao estudo teórico, foi aplicado o método a 50 ensaios de adubação em milho, estudados isoladamente e reunidos em diversos grupos.

Algumas das principais conclusões obtidas pelo autor foram as seguintes:

a) Os parāmetros da equação da superfície de resposta apresentaram intervalos de confiança muito amplos, e conseqüentemente uma imprecisão nas 
estimativas dos rendimentos.

b) Hả maior evidéncia de aparecimento de ponto de máximo, à medida que se agrupam os ensaios.

c) Não houve concordāncia dos resultados obtidos para as doses econōmicas aconselháveis, nos diversos casos estudados, não permitindo assim reco mendações de förmulas de adubação.

d) Os resultados obtidos através de cortes de superfície, foram concordan tes com os obtidos no seu estudo completo.

e) A aplicação da regressão polinomial aos ensaios fatoriais $3^{3}$ de adubação foi recomendada apenas para grupos de ensaios e de boa precisão.

Segundo ESCOBAR e CADY (1967) muitos delineamentos para o estudo das superfícies de resposta têm sido propostos, apresentando algumas vantagens relativas de uns sobre os outros, mas parece não existir um critério ünico, definido como indice de eficiência de um delineamento sobre outro, pois o conjunto de fatores envolvidos em um experimento de a dubação é vasto e complexo, incluindo, variações de solo, de cultura e de clima (Heady, 1956, citado por VIEIRA, 1970).

$\mathrm{Na}$ comparação entre delineamentos experimentais usados para obtenção de superfícies de resposta polinomiais de segundo grau, BOX e WILSON (1951) levaram em consideração a precisão na estimativa dos parâ metros da função e o vício que pode surgir pela não adequação do modelo.

Os delineamentos compostos centrais podem ser compara dos com os fatoriais $3^{k}$ ou com quaisquer outros delineamentos que visem o ajustamento dos dados a um polinōmio de segundo grau, com base na eficiēncia (MYERS, 1971). A eficiēncia de um delineamento é considerada para 
cada coeficiente do polinômio do segundo grau, podendo portanto, um delineamento ser mais eficiente do que outro para determinado coeficiente e ao mesmo tempo ser menos eficiente levando em consideração outro coeficiente.

PIMENTEL GOMES e CAMPOS (1972) baseando na comparação de variâncias, demonstraram a eficiência do fatorial $3^{3}$ sobre o delinea mento composto central rotativo. A mesma metodologia tinha sido usada anteriormente por CAMPOS (1967) e, posteriormente por OLIVEIRA (1974) para comparar a precisão das estimativas dos coeficientes dos modelos do grupo fatorial $3^{k}$ relativamente ao delineamento composto central para $k=2,3$ e 4 .

DÁvila (1979) apresentou características e grä́icos de alguns delineamentos usados em experimentos com fertilizantes. Comparou a eficiēncia desses delineamentos com base no maior tamanho de seu determinante $\left|X^{\prime} X\right|$ e observou que os fatoriais $3^{2}$ e $3^{3}$ foram mais eficientes, apesar de terem somente três níveis para cada fator.

PIMENTEL GOMES (1968) considerou a necessidade da carac terização dos pontos críticos, chamando a atenção para o fato de que, a simples solução de equações, formadas com as derivadas parciais de prime ra ordem da função de receita líquida, não implica, necessariamente ra ob tenção de máximo, sendo necessário, portanto, verificar se a matriz das derivadas parciais de segunda ordem é definida negativa. 0 autor mencionou a existência de vários trabalhos onde o aparecimento de pontos de minimo e de sela não têm sido considerados e mostrou que, pelo fato dos coe ficientes dos termos quadráticos serem todos negativos, não necessariamen te se obtēm um ponto de máximo, sendo preciso, a diagonalização e poste- 
rior interpretação dos elementos dessa matriz, mesmo nesse caso. Lembrou ainda, que esses pontos críticos somente terão validade se estiverem dentro da região explorada pelo ensaio experimental.

MORAES (1969) estudando a regressão polinomial quadrátí ca ajustada para um ensaio fatorial $3^{3}$ de adubação em milho, realizado na Venezuela, com niveis não eqüidistantes de $\mathrm{N}, \mathrm{P}_{2} \mathrm{O}_{5}$ e $\mathrm{K}_{2} \mathrm{O}$, determinou as estimativas dos parāmetros, as estimativas das produções a partir da equa ção de regressão que foram consideradas relativamente boas e os respecti vos intervalos de confiança. Foi feita a anālise da variāncia da regres são que mostrou efeito altamente significativo, obtido o coeficiente de determinação $\left(r^{2}=0,949\right)$ e estudada a função de receita líquida que possui ponto de sela. Mas, considerando somente os valores contidos dentro do intervalo estudado no experimento, o autor determinou o máximo absoluto e recomendou doses de nutrientes.

TEIXEIRA (1969) analisou economicamente, experimentos que relacionam produção de grãos com populações de planta na cultura do milho, para os municipios de Sete Lagoas e Capinópolis, no Estado de Minas Gerais, empregando o modelo de superfície de resposta em termos quadräticos, e concluiu que o efeito do nitrogênio sobre a produção foi menor que o efeito de população de plantas, em todos os ensaios usados.

VIEIRA (1970) estudou quatro funções de produção aplica das a ensaios fatoriais $3^{3}$ de adubação $N, P$ e $K$, na cultura do milho. As principais conclusões obtidas foram:

a) Os parāmetros das quatro funções ajustadas possuem intervalos de confiança bastante amplos. Entretanto a precisão das estimativas dos ren- 
dimentos depende da grandeza relativa das variāncias e covariāncias das estimativas dos parāmetros. Isto explica porque, apesar da amplitude dos intervalos de confiança dos parämetros, obteve-se estimativas razoáveis para os rendimentos.

b) Nos casos estudados, as doses económicas de nutrientes, apresentaram diversificação, de tal ordem, que não permitiram a recomendação de uma fórmula de adubação.

c) No caso de regressões polinomiais, à medida que se procede ao agrupa mento dos ensaios apareceram maior nümero de pontos de máximos; isto se justifica pela maior precisão das médias dos tratamentos. Para a regressão assintótica o valor de c, da equação de Mitscherlich, obtido de grupos de ensaios merecem maior confiança.

d) Dos trēs modelos de regressão polinomial ajustados, dois revelaram-se praticamente iguais nos resultados: o modelo quadrático e o de grau 3/2; o mesmo resultado obteve COSTA (1977) e indicaram o uso do modelo quadrático, pois apresenta maior facilidade de cálculos.

e) Dos trēs modelos polinomiais, o modelo de raiz quadrada ... apresentou maior coeficiente de determinação.

f) A aplicação de regressão polinomial aos ensaios fatoriais de adubação foi recomendada para grupos de ensaios, cuja anālise estatistica dos experimentos fatoriais mostre efeitos quadráticos significativos.

g) Para determinar a dose econömica de nutrientes, no caso de trēs níveis, recomendou o uso da lei de Mitscherlich. Mas, se existirem interações significativas de nutrientes ou queda da produção devido à adu- 
bação excessiva, recomendou a regressão polinomial, preferencialmente o modelo de raiz quadrada.

CAMPOS e ARAUJO (1971) estudaram o ajuste de uma superficie de resposta, considerando o modelo quadrätico com e sem as interações lineares, a dados de ensaios fatoriais de adubação NPK, na cultura do milho. Verificaram que as estimativas dos parāmetros correspondente as interações, não sendo significativas, dão suporte metodológico para o estudo das superficies desprezando-as, fato esse evidenciado por apresentarem, ambos os modelos, coeficiente de determinação de $98 \%$.

Observaram que, embora os intervalos de confiança dos parāmetros sejam relativamente amplos, há um estreitamento muito acentuado, no caso dos rendimentos culturais. Esse estreitamento é mais acentuado no caso do modelo sem as interações, em decorréncia das förmulas que estimam as variāncias para os dois modelos.

As pressuposições bāsicas, segundo MYERS (1971) para o estudo de superficie de resposta, podem ser resumidas em:

- a função existe, mas é muito complicada ou desconhecida, sendo as variā veis envolvidas quantitativas e continuas;

- a função pode ser aproximada, dentro de uma região de interesse;

- as variāveis independentes são controladas pelo experimento e, medidas sem erro.

o autor considerou que o sucesso dos modelos de superfície de resposta dependem de que a função de produção seja aproximada $\underline{\text { a }}$ travēs de uma regressão polinomial de baixo grau, e, que se as interações 
lineares entre os nutrientes forem poucó expressivas, o modelo polinomial quadrático pode ser simplificado, conforme estudos de CAMPOS e ARAUJO (1971) e LIMA (1980).

BALAAM (1973) considerou quatro tipos básicos de deli neamentos experimentais como delineamentos de superficie de resposta, que são: fatorial completo, fatorial fracionado, composto central e delinea mento rotacional. Apresentou uma breve revisão sobre anālise de regressão polinomial, seguida de uma caracterização dos delineamentos em questão.

VIEIRA et alii (1971) fizeram um estudo comparativo de trēs funções na interpretação econométrica de experimentos de ... adubação NPK, na cultura do milho. As principais conclusões obtidas pelos autores foram:

- as variâncias das estimativas dos parāmetros são amplas;

- quando a análise estatística de ensaios fatoriais não mostrar interações significativas dos nutrientes devem ser pesquisadas as regressões a uma só variảvel, que considerem o efeito de cada nutriente isoladamente;

- os resultados deste trabalho, bem como os obtidos por CAMPOS (1967) e VIEIRA (1970), para os mesmos dados experimentais, confirmam a observa ção de Heady (1956), citado por VIEIRA (1970), de que as respostas das culturas aos diferentes nutrientes não obedecem sempre a uma função de forma algébrica particular. Assim, o modelo matemático da função ajustą da deve exprimir o fonómeno biológico de variação da produção com a variação da adubação. 
MENEGUELLI (1976) estudando o ajustamento das funções quadrática, raiz quadrada, Mitscherlich e linear a um ensaio de adubação, na cultura do milho, com os nutrientes $\mathrm{N}$ e $\mathrm{P}_{2} \mathrm{O}_{5}$, nas doses $0,125,250$, 375 e $500 \mathrm{~kg} / \mathrm{ha}$, através da técnica de simulação para a geração de experî mentos constatou que a função raiz quadrada foi a que apresentou melhores resultados, pois suas rendas líquidas forneceram menores erros médios, se guida da função quadrática.

ANDRADE (1977) apresentou um estudo sobre a metodologia de superficie de resposta, baseando em trabalhos desenvolvidos por Box e outros autores. Concluiu que para o uso do método de máxima inclinação as cendente, os tipos de planejamentos mais adequados são os Compostos Rotacionários, devido ao fato de que não se conhecendo a verdadeira função de resposta, deve-se usar um planejamento que permita verificar qual o grau mais adequado do polinómio a ser ajustado e, também, faça com que as variāncias das respostas estimadas, por pontos eqüisdistantes do centro, se jam iguais.

COSTA (1977) fez um estudo comparativo de très modelos de regressão polinomial ajustados aos dados experimentais de 27 ensaios fatoriais $3^{3}$ de adubação NPK na cultura do arroz, conduzidos no Estado de Goiás. Os modelos de regressão foram: polinomial quadrático, de grau $3 / 2$ e de raiz quadrada.

Considerando os ensaios individuais e os ensaios dis postos em cinco grupos, e somente os modelos quadrático e raiz quadrada, o autor concluiu que tanto os valores de $F$ das regressões como os coeficientes de determinação, foram concordantes em ambos os modelos, em todos os casos estudados. As doses económicas obtidas nos cortes, foram bastan- 
te próximas das encontradas através das superfícies, e seus intervalos de confiança muito amplos. Em alguns casos os modelos apresentaram doses eco nômicas fora do intervalo estudado, dificultando a recomendação de adubação.

MONTEIRO (1978) estudou o comportamento de três funções de produção usadas em ensaios fatoriais $3^{3}$, de adubação NPK, na cultura do amendoim. Para os modelos polinomial quadrático, polinomial de grau $1 / 2$ e lei de Mitscherlich, determinou as estimativas dos parāmetros, dose económica dos nutrientes e suas respectivas variāncias. Para os modelos polinomiais determinou as variâncias, intervalos de confiança para os parāmetros e rendimentos e ainda, fez cortes nas superfícies.

As principais conclusões obtidas pelo autor foram:

- os valores do teste $\mathrm{F}$ e os coeficientes de determinação, apresentaram concordāncia nos dois modelos polinomiais;

- as doses económicas obtidas através dos cortes da superfície foram bastante semelhantes às obtidas pela lei de Mitscherlich;

- com o grupamento dos ensaios, houve um melhor ajuste das funções aos da dos experimentais;

- recomenda-se o uso da regressão polinomial quadrática ou a lei de Mitscherlich, para grupos de ensaios de boa precisão, na determinação das doses económicas de nutrientes, para o caso de três niveis.

MORAIS e GONTIJO (1978) estudaram o efeito da adubação NPK, na cultura do arroz, em quatro diferentes localidades do Estado de Minas Gerais, usando um fatorial $5^{3}$ adaptável a um delineamento composto 
central modificado. Determinaram para trēs locais as equações de superfí cie de resposta para diversas características como produção de grãos, altura da planta, etc. Obtiveram as equações de superfície para cada nutriente, considerando o corte das superficies para os outros dois nutrientes em suas doses padrão $(60 \mathrm{~kg} / \mathrm{ha})$, e ainda, os pontos de máximos.

SHIROSE et alii (1978) apresentaram uma aplicação da me todologia de superfície de resposta com a finalidade de determinar a melhor combinação de níveis de açúcar e sal, na paçoca de soja, usando o de lineamento composto central rotacional. Obtiveram um coeficiente de deter minação de $97,43 \%$ e, os níveis $84,96 \%$ e $0,48 \%$ de açúcar e sal, respectiva mente.

SILVA (1978) estudando a interpretação económica de ensaios de adubação na cultura do milho, no Estado de Pernambuco, através do uso da superficie de resposta em ensaios fatoriais $3^{3}$, obteve resul-? tados nosquais os parāmetros das interações do modelo polinomial quadrätico raramente apresentaram significāncia; na maioria das vezes as produções observadas situam-se dentro do intervalo de confiança dos rendi mentos, principalmente quando o coeficiente de determinação é alto.

Obteve as doses economicamente aconselhäveis de $\mathrm{N}, \mathrm{P}_{2} \mathrm{O}_{5}$ e $\mathrm{K}_{2} \mathrm{O}$ através dos cortes da superfície; considerou que a obtenção de máxi mos torna-se problemātica quando os grupos são constituídos de poucos ensaios, e ainda, que os intervalos de confiança para doses economicamente aconselhāveis quando os termos quadrāticos são não significativos deram resultados absurdos.

VIEIRA (1978) considerou que as quantidades económicas de nutrientes, recomendadas com base em ensaios de boa precisão, conduzí 
dos no mesmo local e no mesmo ano agrícola, variam grandemente, sugerindo que é razoável admitir que a variāncia da quantidade económica de nutriente é relativamente alta, mesmo para ensaios conduzidos em condições bastante homogèneas.

RIBOLDI (1978) estudou o ajuste dos modelos de regressão polinomiais, raiz quadrada e raiz $3 / 4$ utilizando o método dos polinōmios ortogonais, a dados experimentais de ensaios fatoriais $3^{3}$ incomple tos, na cultura do milho, e constatou que:

- as produções médias dos tratamentos estimadas, foram concordantes com as produções médias observadas, para ambos os modelos;

- ambos os modelos podem conduzir a equações com número diferente de parâ metros;

- omitindo o tratamento testemunha obteve-se equações de regressão diferentes das obtidas quando o mesmo foi considerado;

- nos casos de extrapolações, as equações obtidas conduziram a previsões satisfatörias.

NAGAI et alii (1979) estudando o modelo polinomial quadrático com vistas à interpretação econōmica de ensaios de adubação em al godoeiro, no Estado de São Paulo, obtiveram resultados onde o coeficiente de determinação foi de $95 \%$ para um grupo de oito ensaios, sendo significa tivos os coeficientes lineares para $\mathrm{N}$ e $\mathrm{K}_{2} \mathrm{O}$ e quadrático para $\mathrm{K}_{2} \mathrm{O}$ e, ainda observaram desvios padrões muito elevados.

Com os dados de um ensaio de competição de variedades de milho, adubação e densidade de plantio no município de Governador Vala 
dares, no Estado de Minas Gerais, PIRES (1979) estudou economicamente os niveis ótimos dos fatores de adubação e densidade e o comportamento de dois conjuntos de variedades. Verificou que pelas equações de rendimentos, em condições semelhantes às do experimento, as variedades híbridas tendem a gerar melhores resultados que as variedades de polinização aberta e, o ní vel ótimo de densidade gira em torno de 60 mil plantas por hectare. Devido a não significāncia dos termos quadráticos nas equações estimadas não obteve-se os niveis ötimos dos nutrientes.

LIMA (1980) estudando 22 ensaios fatoriais $3^{3}$ incompletos de adubação NPK, na cultura da mandioca, observou que apenas houve efeito linear dos nutrientes; que os niveis ötimos dos nutrientes foram bastante discrepantes de um ensaio para outro, e ainda, que os intervalos de confiança obtidos para as doses econōmicas foram amplos.

ROJAS (1980) discutiu as caracteristicas bäsicas que de vem reunir os ensaios de fertilizantes, analisou os critérios desenvolvidos para a obtenção de delineamentos ótimos e apresentou recomendações para experimentos $\operatorname{com} \mathrm{k}=2,3, \ldots, 8$ fatores, nos quais a função de resposta é quadrātica.

NICOLELLA (1981) estudou a utilização de superfície de resposta na interpretação de ensaios de adubação NPK, conduzidos em plantações de cacau, variedade Catongo. Considerou o ajuste do modelo polino mial quadrätico com e sem interações e âbordou, principalmente as estimativas dos parämetros e dos rendimentos, seus intervalos de confiança, e ainda, os niveis ötimos de nutrientes através de cortes das superfícies fixando dois dos nutrientes. 
24.

\section{MATERIAL E MÉTODO}

\subsection{MATERIAL}

0 material experimental usado como exemplo de aplicação è proveniente de um ensaio de adubação mineral (NPK) e orgānica em cafeei ros (Coffea arabica L.) foi cedido por GUIMARĀES et alii (1976). O expe rimento foi instalado no município de Machado, MG, em Latossolo VermelhoEscuro, fase cerrado, usando-se a variedade Catuai $\mathrm{CH}$ 2077-2-5-44 a um es paçamento de $4 \times 1 \mathrm{~m}$, uma planta por cova e o delineamento experimental usa do foi inteiramente casualizado em esquema fatorial $3^{3}$. Foi feita uma calagem em toda a ārea e os níveis de adubação foram: 10 ano - 0; 15 e $30 \mathrm{~g}$ de $\mathrm{N}, 0 ; 78$ e $156 \mathrm{~g}$ de $\mathrm{P}_{2} \mathrm{O}_{5}$ e $0 ; 15$ e $30 \mathrm{~g}$ de $\mathrm{K}_{2} \mathrm{O}$ por cova. A adubação de 29 ano de $0 ; 30$ e $60 \mathrm{~g}$ de $\mathrm{N}$ e $0 ; 30$ e $60 \mathrm{~g}$ de $\mathrm{P}_{2} \mathrm{O}_{5}$ por cova. A adubação do 39 ano de $0 ; 60$ e $120 \mathrm{~g}$ de $\mathrm{N}$ e $0 ; 60$ e $120 \mathrm{~g}$ de $\mathrm{K}_{2} \mathrm{O}$ por cova. As fontes fo ram sulfato de amōnio e nitrocálcio alternadamente, superfosfato simplese 
apatita de Araxá com $50 \%$ de cada um e, cloreto de potássio.

Foi considerada como variável resposta, a produção em gramas de café em coco por quatro plantas, e como variáveis independentes os niveis de nitrogēnio $(\mathrm{N})$, fósforo $\left(\mathrm{P}_{2} \mathrm{O}_{5}\right)$ e potássio $\left(\mathrm{K}_{2} \mathrm{O}\right)$, e como variáveis auxiliares: altura da planta $(\mathrm{cm})$, diāmetro da copa $(\mathrm{cm})$ e número de internōdios, medidas na época da ültima adubação.

\subsection{MÉTODO}

Apresenta-se, nesse capitulo, o desenvolvimento da meto dologia de superficie de resposta, em forma matricial, aplicada a um ensaio fatorial completo $3^{3}$, com níveis eqüidistantes.

\section{a. MODELO MATEMÁTICO}

Apresentar-se-á o método de superfície polinomial de resposta usado em ensaios de adubação $\mathrm{N}-\mathrm{P}-\mathrm{K}$, em esquema fatorial $3 \times 3 \times 3$, com doses eqüidistantes, levando-se em consideração algumas variāveis auxiliares adicionais, usando o seguinte modelo matemático:

$$
\begin{aligned}
y= & a_{00}+a_{11} x_{1}^{2}+a_{22} x_{2}^{2}+a_{33} x_{3}^{2}+a_{12} x_{1} x_{2}+a_{13} x_{1} x_{3}+a_{23} x_{2} x_{3}+a_{10} x_{1}+ \\
& +a_{20} x_{2}+a_{30} x_{3}+b_{1} z+\ldots+b_{t} t+e
\end{aligned}
$$


onde: $\mathrm{x}_{1}$ : representa as doses reduzidas de nitrogēnio (N);

$\mathrm{x}_{2}$ : representa as doses reduzidas de fósforo $\left(\mathrm{P}_{2} \mathrm{O}_{5}\right)$;

$\mathrm{x}_{3}$ : representa as doses reduzidas de potássio $\left(\mathrm{K}_{2} \mathrm{O}\right)$;

$b_{t}, \operatorname{com} t=1,2, \ldots, t$, são os coeficientes de regressão da variāvel dependente sobre a t-ésima variável auxiliar;
$z_{i j k}, \ldots, t_{i j k}$ : são os valores reduzidos assumidos pelas variáveis auxiliares.

Para facilidade de cálculos os valores das doses de $\mathrm{N}$, $\mathrm{P}_{2} \mathrm{O}_{5}$ e $\mathrm{K}_{2} \mathrm{O}$ foram codificados como sendo $-1,0,1$, através da seguinte transformação:

$$
\frac{D_{i}-\bar{D}}{q}
$$

onde: $\mathrm{D}_{i}$ : são os valores das doses de nutrientes;

$\overline{\mathrm{D}}$ : média desses valores;

$\mathrm{q}$ : diferença entre as doses.

Fez-se tambēm:

$$
z_{i j k}=v_{i j k}-\bar{v} \quad(i, j, k=0,1,2),
$$

sendo:

$v_{i j k}$, com $i, j, k=0,1,2$, valores da primeira variável auxiliar;

$\overline{\mathrm{V}}$ : média desses valores;

e,

$$
t_{i j k}=U_{i j k}-\bar{U}
$$


sendo: $\mathrm{U}_{i j k}$ : valores da t-ésima variävel auxiliar;

$\overline{\mathrm{U}}$ : média desses valores.

Pelas características desse modelo (a.1) os parämetros correspondentes aos efeitos quadráticos puros não são independentes da mé dia, sendo necessäria nova parametrização para que se tenha tal indepen dência (DAVIES, 1960; JORGE, 1980).

Assim, o modelo geral em que a variävel $x_{m}(m=1,2,3)$ é $\underline{a}$ gora uma variảvel reduzida e os componentes quadráticos ficam ortogonais à média, será:

$$
\begin{aligned}
y= & a_{0}^{\prime}+a_{11}\left(x_{1}^{2}-\frac{\sum x_{1}^{2}}{n}\right)+a_{22}\left(x_{2}^{2}-\frac{\sum x_{2}^{2}}{n}\right)+a_{33}\left(x_{3}^{2}-\frac{\sum x_{3}^{2}}{n}\right)+a_{12} x_{1} x_{2}+ \\
& +a_{13} x_{1} x_{3}+a_{23} x_{2} x_{3}+a_{10} x_{1}+a_{20} x_{2}+a_{30} x_{3}+b_{1} z+\cdots+b_{t} t+e,
\end{aligned}
$$

sendo: n: número de doses de cada nutriente;

$\mathrm{y}$ : variável aleatória dependente das variáveis $\mathrm{x}_{1}, \mathrm{x}_{2}, \mathrm{x}_{3}, \mathrm{z}, \ldots, \mathrm{t}$; $a_{0}^{\prime}, a_{11}, a_{22}, \ldots, a_{30}, b_{1}, \ldots, b_{t}$, são parämetros a determinar; e: erro experimental, suposto e $\sim \mathrm{N}\left(0, \sigma_{1}^{2}\right)$.

o desenvolvimento da metodologia do modelo de superfície polinomial de resposta, linear nos parāmetros, está baseado principal mente em definições, fórmulas e conceitos extraídos de BOX e WILSON (1951), GRAYBILL (1961), MYERS (1971), CAMPOS (1967), HOFFMANN e VIEIRA (1977), JORGE (1980) e DRAPER e SMITH (1981).

Em forma matricial, o modelo apresentado (a.2), serā: 


$$
Y=X \beta+\varepsilon,
$$

onde:

Y: vetor das observações, de dimensão (Nx1);

$\mathrm{X}$ : matriz dos coeficientes, de dimensão $(\mathrm{Nxp}+\mathrm{t})$;

$\beta$ : vetor dos parāmetros, de dimensão $(p+t \times 1)$;

$\varepsilon:$ vetor dos erros experimentais, de dimensão $(\mathrm{Nx} 1)$.

Observação: Para facilidade de notação considerou-se nos modelos que

$$
z_{i j k}=z, t_{i j k}=t \text { e } y_{i j k}=y .
$$

A matriz $\mathrm{X}$, também chamada "matriz das variāveis independentes", fica sendo: 


\begin{tabular}{|c|c|c|c|c|c|c|c|c|c|c|c|c|}
\hline 1 & $1 / 3$ & $1 / 3$ & $1 / 3$ & 1 & 1 & 1 & -1 & -1 & -1 & $z_{0} 000$ & $\cdots$ & $t_{0} 00$ \\
\hline 1 & $1 / 3$ & $-2 / 3$ & $1 / 3$ & 0 & 1 & 0 & -1 & 0 & -1 & 2010 & $\cdots$ & $t_{010}$ \\
\hline 1 & $1 / 3$ & $1 / 3$ & $1 / 3$ & -1 & 1 & -1 & -1 & 1 & -1 & $z_{0} 20$ & $\cdots$ & $t_{020}$ \\
\hline 1 & $1 / 3$ & $1 / 3$ & $-2 / 3$ & 1 & 0 & 0 & -1 & -1 & 0 & $\mathbf{z}_{0} 001$ & $\cdots$ & $t_{001}$ \\
\hline 1 & $1 / 3$ & $-2 / 3$ & $-2 / 3$ & 0 & 0 & 0 & -1 & 0 & 0 & $z_{0} 11$ & $\cdots$ & $t_{011}$ \\
\hline 1 & $1 / 3$ & $1 / 3$ & $-2 / 3$ & -1 & 0 & 0 & -1 & 1 & 0 & $z_{021}$ & $\cdots$ & $t_{021}$ \\
\hline 1 & $1 / 3$ & $1 / 3$ & $1 / 3$ & 1 & -1 & -1 & -1 & -1 & 1 & $z_{0} 02$ & $\cdots$ & $t_{002}$ \\
\hline 1 & $1 / 3$ & $-2 / 3$ & $1 / 3$ & 0 & -1 & 0 & -1 & 0 & 1 & $z_{012}$ & $\cdots$ & $t_{012}$ \\
\hline 1 & $1 / 3$ & $1 / 3$ & $1 / 3$ & -1 & -1 & 1 & -1 & 1 & 1 & $z_{022}$ & $\cdots$ & $t_{022}$ \\
\hline 1 & $-2 / 3$ & $1 / 3$ & $1 / 3$ & 0 & 0 & 1 & 0 & -1 & -1 & $z_{100}$ & $\cdots$ & $t_{100}$ \\
\hline 1 & $-2 / 3$ & $-2 / 3$ & $1 / 3$ & 0 & 0 & 0 & 0 & 0 & -1 & $z_{110}$ & $\cdots$ & $t_{110}$ \\
\hline 1 & $-2 / 3$ & $1 / 3$ & $1 / 3$ & 0 & 0 & -1 & 0 & 1 & -1 & $z_{120}$ & $\cdots$ & $t_{12} 0$ \\
\hline 1 & $-2 / 3$ & $1 / 3$ & $-2 / 3$ & 0 & 0 & 0 & 0 & -1 & 0 & $z_{101}$ & $\cdots$ & $t_{101}$ \\
\hline$X=$ & $-2 / 3$ & $-2 / 3$ & $-2 / 3$ & 0 & 0 & 0 & 0 & 0 & 0 & $z \perp 11$ & $\cdots$ & $t_{111}$ \\
\hline 1 & $-2 / 3$ & $1 / 3$ & $-2 / 3$ & 0 & 0 & 0 & 0 & 1 & 0 & $z_{121}$ & $\cdots$ & $t_{121}$ \\
\hline 1 & $-2 / 3$ & $1 / 3$ & $1 / 3$ & 0 & 0 & -1 & 0 & -1 & 1 & $z_{1} 02$ & $\cdots$ & $t_{102}$ \\
\hline 1 & $-2 / 3$ & $-2 / 3$ & $1 / 3$ & 0 & 0 & 0 & 0 & 0 & 1 & $z_{112}$ & $\cdots$ & $t_{112}$ \\
\hline 1 & $-2 / 3$ & $1 / 3$ & $1 / 3$ & 0 & 0 & 1 & 0 & 1 & 1 & $z_{122}$ & $\cdots$ & $t_{122}$ \\
\hline 1 & $1 / 3$ & $1 / 3$ & $1 / 3$ & -1 & -1 & 1 & 1 & -1 & -1 & $z_{2} 00$ & $\cdots$ & $t_{200}$ \\
\hline 1 & $1 / 3$ & $-2 / 3$ & $1 / 3$ & 0 & -1 & 0 & 1 & 0 & -1 & $z_{210}$ & $\cdots$ & $t_{210}$ \\
\hline 1 & $1 / 3$ & $1 / 3$ & $1 / 3$ & 1 & -1 & -1 & 1 & 1 & -1 & $z_{22} 20$ & $\cdots$ & $t_{220}$ \\
\hline 1 & $1 / 3$ & $1 / 3$ & $-2 / 3$ & -1 & 0 & 0 & 1 & -1 & 0 & $z_{2} 01$ & $\cdots$ & $t_{201}$ \\
\hline 1 & $1 / 3$ & $-2 / 3$ & $-2 / 3$ & 0 & 0 & 0 & 1 & 0 & 0 & $z_{211}$ & $\cdots$ & $t_{211}$ \\
\hline 1 & $1 / 3$ & $1 / 3$ & $-2 / 3$ & 1 & 0 & 0 & 1 & 1 & 0 & $z_{221}$ & $\cdots$ & $t_{221}$ \\
\hline 1 & $1 / 3$ & $1 / 3$ & $1 / 3$ & -1 & 1 & -1 & 1 & -1 & 1 & $z_{2} 02$ & $\cdots$ & $t_{202}$ \\
\hline 1 & $1 / 3$ & $-2 / 3$ & $1 / 3$ & 0 & 1 & 0 & 1 & 0 & 1 & $z_{212}$ & $\cdots$ & $t_{212}$ \\
\hline 1 & $1 / 3$ & $1 / 3$ & $1 / 3$ & 1 & 1 & 1 & 1 & 1 & 1 & $z_{222}$ & $\cdots$ & $t_{222}$ \\
\hline
\end{tabular}




\section{b. ESTIMATIVAS DOS PARÁMETROS}

O sistema de equações normais obtido através do método dos quadrados minimos, serä: $X^{\prime} X \bar{B}=X^{\prime} Y$, ou seja,

$$
\left[\begin{array}{cc}
X_{1}^{\prime} X_{1} & X_{1}^{\prime} X_{2} \\
X_{2}^{\prime} X_{1} & X_{2}^{\prime} X_{2}
\end{array}\right]\left[\begin{array}{c}
\bar{\tau} \\
\bar{a}
\end{array}\right]=\left[\begin{array}{c}
X_{1}^{\prime} Y \\
X_{2}^{\prime} Y
\end{array}\right]
$$

onde:

$Y$ : vetor das observações, de dimensão $(\mathrm{N} \times 1)$;

$X$ : matriz da forma $\left[\begin{array}{ll}X_{1} & X_{2}\end{array}\right]$;

$\mathrm{X}_{1}$ : matriz dos valores assumidos por $\mathrm{x}_{1}, \mathrm{x}_{2}$ e $\mathrm{x}_{3}$, de dimensão(Nxp);

$\mathrm{X}_{2}$ : matriz dos valores das variáveis auxiliares, de dimensão (Nxt);

$\beta^{\prime}$ : vetor da forma $\left[\tau^{\prime}, a^{\prime}\right]$;

$\tau$ : vetor dos efeitos de parâmetros, de dimensão ( $\mathrm{p} \times 1)$;

a : vetor dos coeficientes de regressão, de dimensão (tx1);

$\varepsilon$ : vetor dos erros experimentais, de dimensão (Nx1);

$\mathrm{N}$ : número de observações;

$\mathrm{p}$ : nümero de parâmetros do modelo polinomial, em relação à variá vel respostas;

$\mathrm{t}$ : nümero de variäveis auxiliares (ou coeficientes de regressão).

Representando o sistema de equações de (b.1) por

$$
\left[\begin{array}{cc}
\mathrm{R} & \mathrm{T}_{\mathrm{X}} \\
\mathrm{T}_{\mathrm{X}}^{\prime} & \mathrm{L}
\end{array}\right]\left[\begin{array}{c}
\bar{\tau} \\
\overline{\mathrm{a}}
\end{array}\right]=\left[\begin{array}{l}
\mathrm{T} \\
\mathrm{z}
\end{array}\right]
$$


onde:

$R=X_{1}^{\prime} X_{1}=r\left[\begin{array}{cccccccccc}27 & 0 & 0 & 0 & 0 & 0 & 0 & 0 & 0 & 0 \\ 0 & 6 & 0 & 0 & 0 & 0 & 0 & 0 & 0 & 0 \\ 0 & 0 & 6 & 0 & 0 & 0 & 0 & 0 & 0 & 0 \\ 0 & 0 & 0 & 6 & 0 & 0 & 0 & 0 & 0 & 0 \\ 0 & 0 & 0 & 0 & 12 & 0 & 0 & 0 & 0 & 0 \\ 0 & 0 & 0 & 0 & 0 & 12 & 0 & 0 & 0 & 0 \\ 0 & 0 & 0 & 0 & 0 & 0 & 12 & 0 & 0 & 0 \\ 0 & 0 & 0 & 0 & 0 & 0 & 0 & 18 & 0 & 0 \\ 0 & 0 & 0 & 0 & 0 & 0 & 0 & 0 & 18 & 0 \\ 0 & 0 & 0 & 0 & 0 & 0 & 0 & 0 & 0 & 18\end{array}\right]$ dos coeficientes

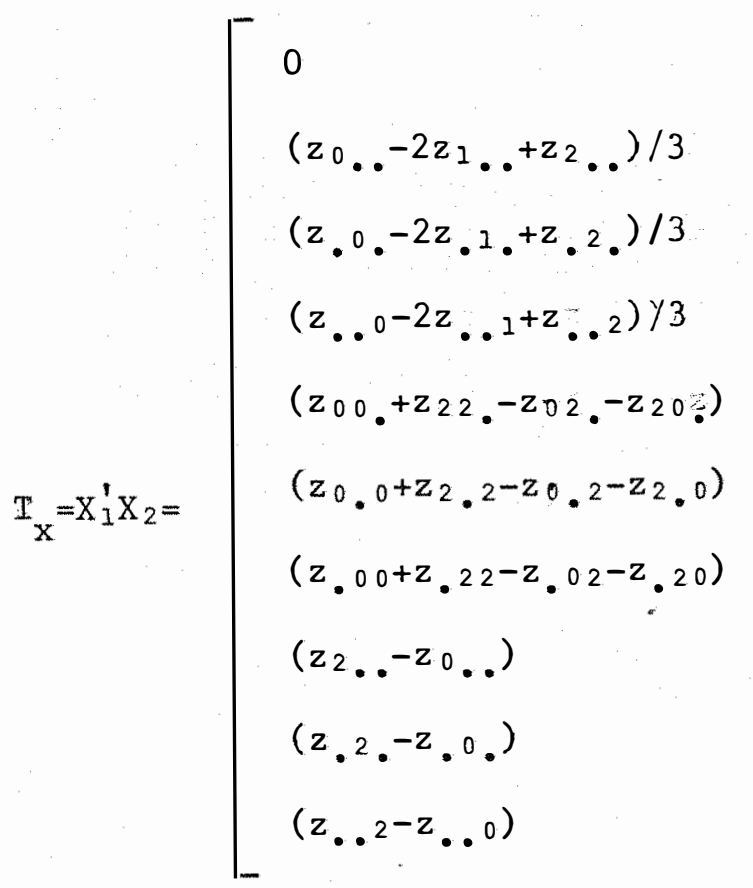

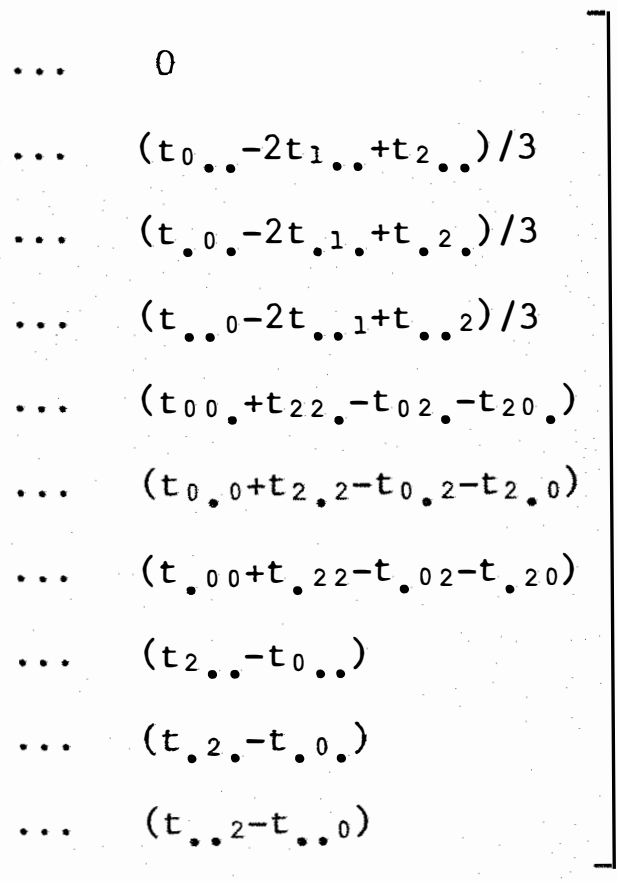

(matriz dos totais de tratamen tos relativos às variäveis au xiliares; 


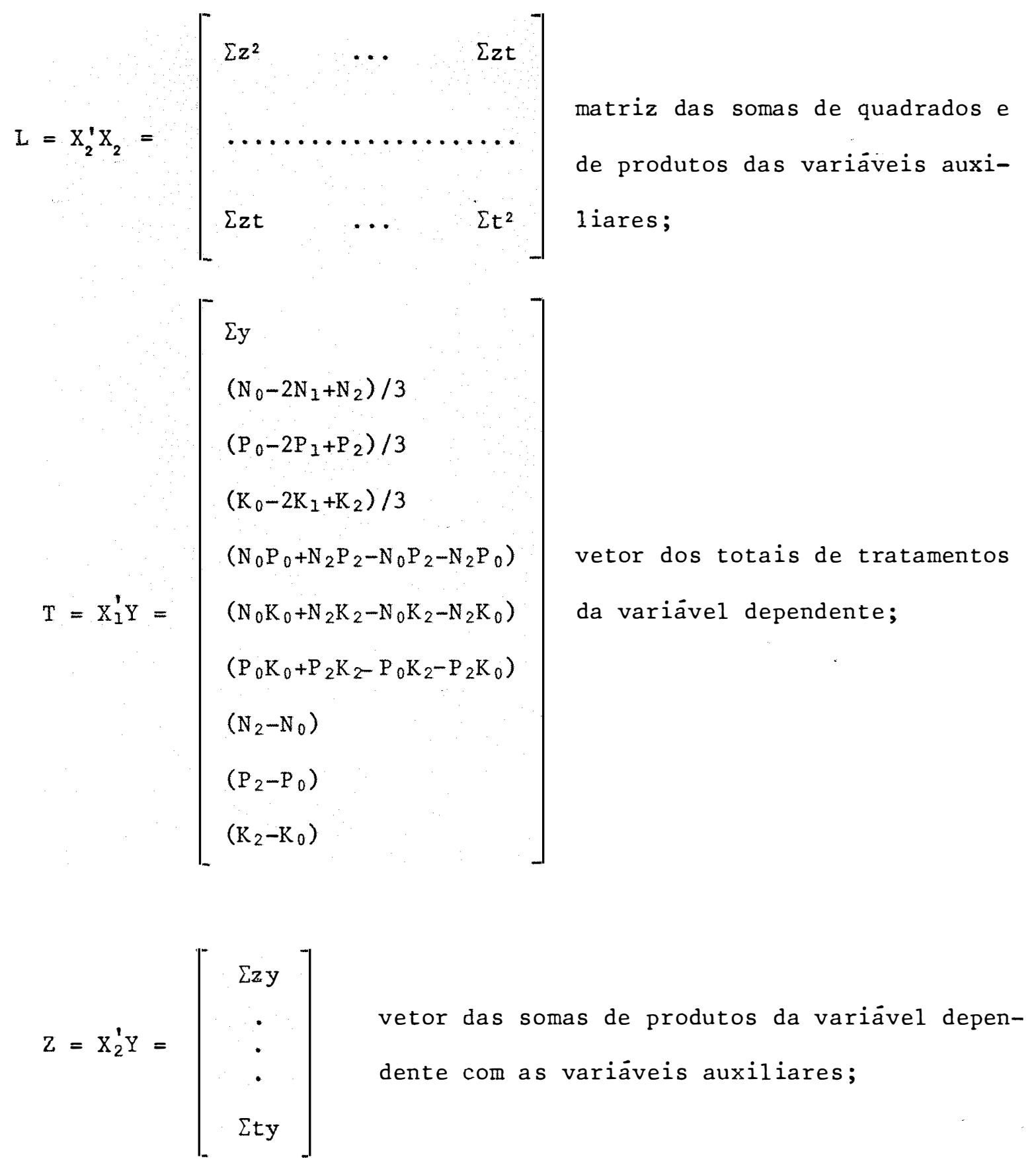


33.

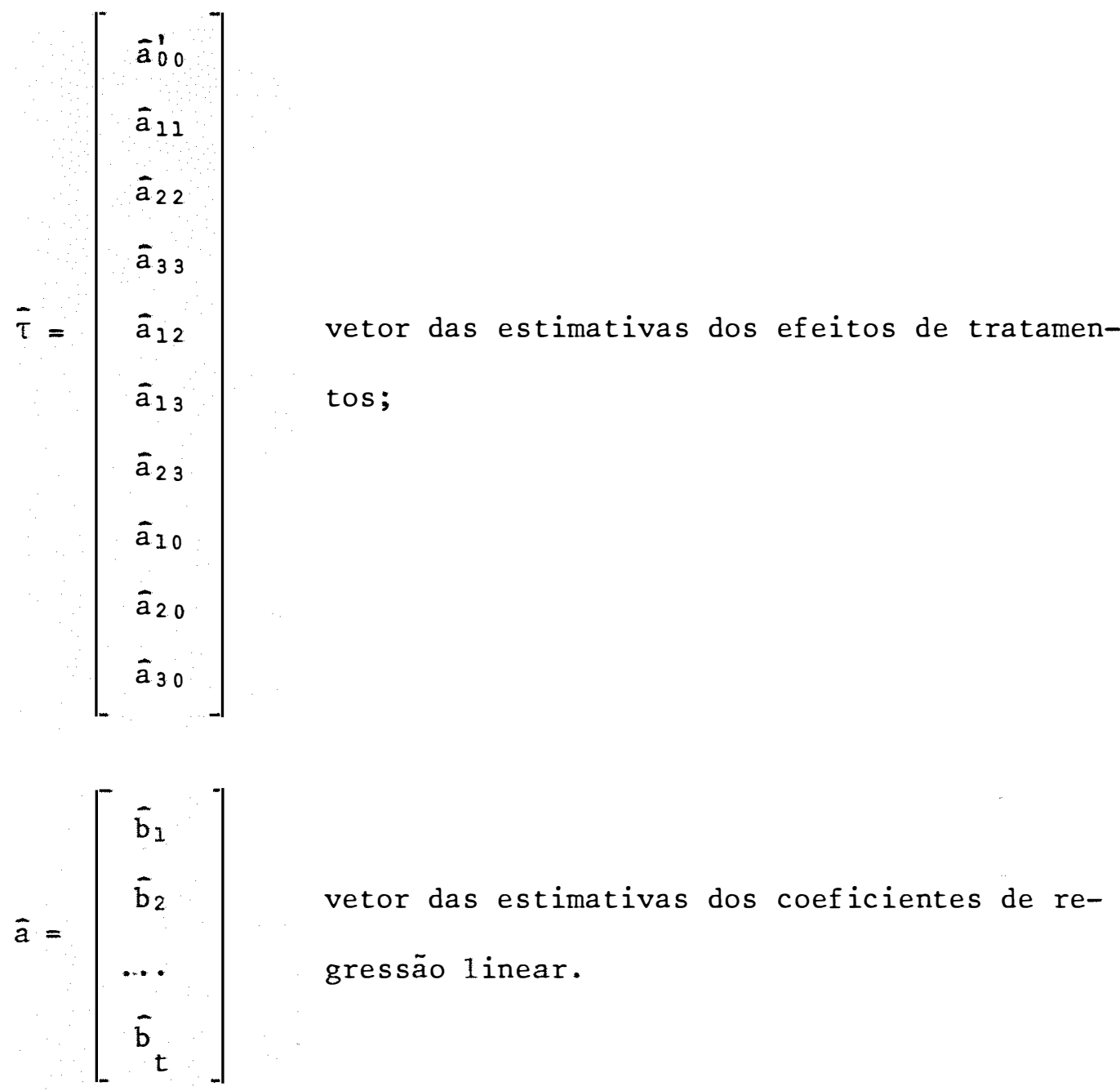

Observação: Quando do uso dos termos "efeitos de tratamentos" ou simples mente "tratamentos" referem-se aos parämetros (a $a_{0}, a_{11}, a_{22}$, $a_{12}, a_{13}, a_{23}, a_{10}, a_{20}$ e $\left.a_{30}\right)$. 
Do sistema de equações normais (b.2), obtëm-se:

$$
\begin{cases}\mathrm{R} \bar{\tau}+\mathrm{T}_{\mathrm{x}} \overline{\mathrm{a}}=\mathrm{T} & (\mathrm{b} \cdot 3) \\ \mathrm{T}_{\mathrm{x}}^{\prime} \bar{\tau}+\mathrm{L}_{\mathrm{a}}=\mathrm{z} & (\mathrm{b} \cdot 4)\end{cases}
$$

Considerando, por hipötese, que a matriz $R$ è não singular, de (b.3), tem-se:

$$
R^{-1} R \bar{\tau}+R^{-1} T_{x} \bar{a}=R^{-\bar{z}} T
$$

logo

$$
\bar{\tau}=R^{-1} T-R^{-1} T_{x} \bar{a} \quad(b .5)
$$

que é o vetor das estimativas dos efeitos de tratamentos ajustados para a regressão linear.

$$
\text { Substituindo o valor de } \hat{\tau} \text { de }(b .5) \text { em (b.4), tem-se }
$$

$$
\begin{aligned}
& T_{x}^{\prime}\left(R^{-1} T-R^{-1} T_{x} \bar{a}\right)+L \bar{a}=Z \\
& \left(L-T_{x}^{\prime} R^{-1} T_{x}\right) \bar{a}=Z-T_{x}^{\prime} R^{-1} T
\end{aligned}
$$

fazendo: $\quad L-T_{x}^{\prime} R^{-1} T_{x}=E_{1}$

$$
Z-T_{x}^{\prime} R^{-1} T=E_{0}
$$

obtēm-se:

$$
E_{1} \bar{a}=E_{0}
$$


sendo: El uma matriz não-singular, de dimensão (txt), tem-se:

$$
\bar{a}=E_{I}^{-1} E_{0} \quad(b .6)
$$

que è o vetor das estimativas dos coeficientes de regressão.

\section{c. ANÁLISE DA VARIÂNCIA}

c.1. Soma de quadrados de parämetros

A soma de quadrados de parâmetros $\left(\mathrm{SQP}_{0}\right)$, é obtida por:

$$
\begin{aligned}
& \mathrm{SQP}_{0}=\bar{B}^{\prime} \mathrm{X}^{\prime} \mathrm{Y}=\left[\begin{array}{ll}
\bar{\tau} & \hat{a}^{\prime}
\end{array}\right]\left[\begin{array}{l}
\mathrm{T} \\
\mathrm{Z}
\end{array}\right]=\bar{\tau}^{\prime} \mathrm{T}+\overline{\mathrm{a}}^{\prime} \mathrm{Z} \quad(\mathrm{c} \cdot 1 \cdot 1) \\
& \text { Em (b.5) tem-se que } \bar{\tau}=R^{-1} T-R^{-1} T x^{\bar{a}} \text {. } \\
& \text { Logo, a soma de quadrados de parāmetros em (c.1.1) fica } \\
& S Q P_{0}=\left(T^{\prime} R^{-1}-\bar{a}^{\prime} T_{x}^{\prime} R^{-1}\right) T+\bar{a}^{\prime} Z \\
& =T^{\prime} R^{-1} T+\hat{a}^{\prime}\left(Z-T_{x}^{\prime} R^{-1} T\right) \\
& =T^{\prime} R^{-1} T+\hat{a}^{\prime} E_{0} \quad \operatorname{com}(p+t) g \cdot l \cdot, \quad(c \cdot 1.2),
\end{aligned}
$$

onde: $\mathrm{T}^{\prime} \mathrm{R}^{-1} \mathrm{~T}$ : soma de quadrados de parāmetros (tratamentos);

$\hat{a}^{\prime} E_{0}$ : soma de quadrados de regressão linear. 


\section{c.2. Soma de quadrados de residuo ajustada}

A soma de quadrados de resíduo ajustada para regressão $\left.\operatorname{lSQRES}_{(a j)}\right]$, è obtida por:

$$
\begin{aligned}
\operatorname{SQRES}_{(a j)} & =Y^{\prime} Y-S P_{0}=Y^{\prime} Y-T^{\prime} R^{-1} T-\bar{a}^{\prime} E_{0} \\
& =R\left(y^{2}\right)-\bar{a}^{\prime} E_{0} \quad \text { com }(N-p-t) g \cdot l \cdot, \quad(c .2 \cdot 1),
\end{aligned}
$$

onde: $R\left(y^{2}\right)=Y^{\prime} Y-T^{\prime} R^{-1} T$.

\section{d. SOMA DE QUADRADOS DE PARAMETROS AJUSTADA}

A soma de quadrados de parámetros ajustada para regressão, pode ser obtida, utilizando o princípio do resíduo condicional. Considerando o modelo matemático seguinte, onde não aparecem o efeito de parāmetros (tratamentos):

$$
y=a_{00}+b_{1} z+\ldots+b_{t} t+e
$$

onde: $y, a_{00}, b_{1}, b_{t}, z, t$ e e possuem as mesmas especificações às do mo delo em (a.2)

A forma matricial do modelo (d.1) reduzido é:

$$
Y=X \beta+\varepsilon
$$

onde: $X=\left[X_{11}, X_{2}\right]$, sendo $X_{11}$ um vetor coluna de 1 (uns);

$$
\beta^{\prime}=\left[\bar{a}_{00}, a^{\prime}\right] \text {. }
$$



sistema de equações normais, seguinte: $X^{\prime} X \beta=X^{\prime} Y$, ou seja:

$$
\left[\begin{array}{ll}
X_{11}^{\prime} X_{12} & X_{11}^{\prime} X_{2} \\
X_{2}^{\prime} X_{12} & x_{2}^{\prime} X_{2}
\end{array}\right]\left[\begin{array}{l}
\bar{a}_{00} \\
\bar{a}
\end{array}\right]=\left[\begin{array}{l}
x_{11}^{\prime} Y \\
X_{2}^{\prime} Y
\end{array}\right]
$$

ou ainda:

$$
\left[\begin{array}{ll}
N & \Phi \\
\Phi^{\prime} & L
\end{array}\right]\left[\begin{array}{c}
\bar{a}_{00} \\
\bar{a}
\end{array}\right]=\left[\begin{array}{c}
\Sigma y \\
z
\end{array}\right]
$$

onde: $\mathrm{N}$ : número de observações;

$\Phi$ : vetor de zeros, de dimensão ( $t \times 1)$;

$\bar{a}$ : vetor dos coeficientes de regressão, de dimensão (tx 1$)$;

$\overline{\mathrm{a}}_{00}:$ média geral;

L e Z: são semelhantes às do modelo completo em (b.2).

Desenvolvendo (d.2), obtèm-se:

$$
\left\{\begin{array}{l}
N \overline{\mathrm{a}}_{00}+\Phi \overline{\mathrm{a}}=\sum \mathrm{y} \\
\Phi^{\prime} \overline{\mathrm{a}}_{00}+\mathrm{L} \overline{\mathrm{a}}=\mathrm{Z}
\end{array}\right.
$$

ou simplesmente:

$$
\left\{\begin{aligned}
\overline{\mathrm{a}}_{00} & =\Sigma \mathrm{y} \\
\mathrm{L} \overline{\mathrm{a}} & =\mathrm{Z}
\end{aligned}\right.
$$

Sendo L uma matriz não-singular, de dimensão (txt), as estimativas dos parāmetros $\left(a_{0}\right.$ e a $)$ serão: 
38.

$$
\bar{a}_{00}=(\Sigma y) / N \quad \text { e } \quad \bar{a}=L^{-1} z \text {. }
$$

A soma de quadrados dos parâmetros $\left(a_{00}, b_{1}, \ldots, b_{t}\right)$ relativo ao modelo $\left(d_{.1}\right)$ reduzido, $\left(\mathrm{SQP}_{1}\right)$, onde $\mathrm{SQP}_{1}\left(\bar{a}_{0}, \bar{a}\right)$, serä:

$$
\mathrm{SQP}_{1}=\left[\begin{array}{lll}
\bar{a}_{0} & 0 & \bar{a}^{\prime}
\end{array}\right]\left[\begin{array}{c}
\Sigma y \\
z
\end{array}\right]=\bar{a}_{00} \Sigma y+\bar{a}^{\prime} z ; \quad(d .5) .
$$

Assim, a soma de quadrados de tratamentos, [SQTRA $(a j)]$, ajustada para regressão linear é obtida pela diferença entre (c.1.2) e (d.5), ou seja:

$$
\begin{aligned}
\operatorname{SQTRA}_{(a j)} & =\mathrm{SQP}_{0}-\mathrm{SQP}_{1}= \\
& =T^{\prime} R^{-1} \mathrm{~T}+\bar{a}^{\prime} E_{0}-\bar{a}_{00} \Sigma y-\bar{a}^{\prime} Z, \operatorname{com}(p-1) g . l ., \quad(d .6)
\end{aligned}
$$

ou também:

$$
\operatorname{SQTRA}_{(a j)}=\operatorname{SQTRA}+\bar{a}^{\prime} E_{0}-\bar{a} \cdot Z,
$$

onde: $\quad$ SQTRA $=T^{\prime} R^{-1} T-\bar{a}_{00} \sum y$. 
Tabela 1 - Esquema de anālise da variāncia.

\begin{tabular}{lcc}
\hline Fontes de Variação & G.L. & S.Q. \\
$R\left(a_{00}, a_{11}, \ldots, a_{23}, a\right)$ & $p+t$ & $T^{\prime} R^{-1} T+a^{\prime} E_{0}$ \\
$R\left(a_{00}, a\right)$ & $t+1$ & $\bar{a}_{00} \sum y+\bar{a}^{\prime} Z$ \\
Tratamento $(a j)$ & $p-1$ & $T^{\prime} R^{-1} T+\bar{a}^{\prime} E_{0}-\bar{a}_{00} \sum y-\bar{a}^{\prime} Z$ \\
Residuo $(a j)$ & $N-p-t$ & $Y^{\prime} Y-T^{\prime} R^{-1} T-\bar{a}^{\prime} E_{0}$ \\
Total & $N$ & $Y^{\prime} Y$ \\
\hline
\end{tabular}

e. SOMA DE QUADRADOS DE NITROGÊNIO QUADRÁTICO AJUSTADA PARA REGRESSÃO

A soma de quadrados de nitrogênio quadrātico, ajustada de acordo com a regressão linear, pode ser obtida, utilizando o método do resíduo condicional.

Considerando o modelo matemätico seguinte, onde não apa rece o efeito de nitrogênio quadrático:

$$
\begin{aligned}
y= & a_{00}+a_{22} x_{2}+a_{33} x_{3}+a_{12} x_{1} x_{2}+a_{13} x_{1} x_{3}+a_{23} x_{2} x_{3}+a_{10} x_{1}+a_{20} x_{2}+ \\
& +a_{30} x_{3}+b_{1} z+\ldots+b_{t} t+e
\end{aligned}
$$

com as mesmas especificações do modelo completo em (a.1). 
40.

Usando a forma matricial ao modelo (e.1) tèm-se:

$$
\mathrm{Y}=\mathrm{X} \beta+\varepsilon,
$$

onde: $\mathrm{X}$ : matriz da forma $\left[\mathrm{X}_{0} \cdot \mathrm{X}_{2}\right]$;

$\mathrm{X}_{0}$ : matriz formada por exclusão da coluna relativa ao efeito nitro gênio quadrätico da matriz $\mathrm{X}_{1}$;

$B^{\prime}:$ vetor da forma $\left[\tau_{0}^{\prime}, a_{0}^{\prime}\right]$;

$\tau_{0}$ : vetor $\tau$ sem o efeito de nitrogēnio quadrático.

Utilizando o método dos quadrados mínimos, obtém-se o sistema de equações normais, seguinte: $X^{\prime} X \tilde{\beta}=X^{\prime} Y$, ou seja:

$$
\left[\begin{array}{cc}
\mathrm{x}_{0}^{\prime} \mathrm{x}_{0} & \mathrm{x}_{0}^{\prime} \mathrm{x}_{2} \\
\mathrm{x}_{2}^{\prime} \mathrm{x}_{0} & \mathrm{x}_{2}^{\prime} \mathrm{x}_{2}
\end{array}\right]\left[\begin{array}{c}
\tilde{\tau} \\
\tilde{\mathrm{a}}
\end{array}\right]=\left[\begin{array}{l}
\mathrm{X}_{0}^{\prime} \mathrm{Y} \\
\mathrm{X}_{2}^{\prime} \mathrm{Y}
\end{array}\right],
$$

ou sendo representado da seguinte maneira:

$$
\left[\begin{array}{cc}
\mathrm{R}_{0} & \mathrm{~T}_{\mathrm{x}_{0}} \\
\mathrm{~T}_{\mathrm{x}_{0}}^{\prime} & \mathrm{L}
\end{array}\right]\left[\begin{array}{c}
\tilde{\mathrm{\tau}} \\
\tilde{\mathrm{a}}
\end{array}\right]=\left[\begin{array}{c}
\mathrm{T}_{0} \\
\mathrm{Z}
\end{array}\right], \quad(\mathrm{e} .2)
$$

onde: 


$$
\mathrm{R}_{0}=\mathrm{X}_{0}^{\mathrm{N}} \mathrm{X}_{0}=\mathrm{r}\left[\begin{array}{ccccccccc}
27 & 0 & 0 & 0 & 0 & 0 & 0 & 0 & 0 \\
0 & 6 & 0 & 0 & 0 & 0 & 0 & 0 & 0 \\
0 & 0 & 6 & 0 & 0 & 0 & 0 & 0 & 0 \\
0 & 0 & 0 & 12 & 0 & 0 & 0 & 0 & 0 \\
0 & 0 & 0 & 0 & 12 & 0 & 0 & 0 & 0 \\
0 & 0 & 0 & 0 & 0 & 12 & 0 & 0 & 0 \\
0 & 0 & 0 & 0 & 0 & 0 & 18 & 0 & 0 \\
0 & 0 & 0 & 0 & 0 & 0 & 0 & 18 & 0 \\
0 & 0 & 0 & 0 & 0 & 0 & 0 & 0 & 18 \\
\text { matriz diagonal dos } \\
\text { coeficientes do mo- } \\
\text { delo original sem } 0 \\
\text { efeito nitrogenio } \\
\text { quadrático; }
\end{array}\right.
$$

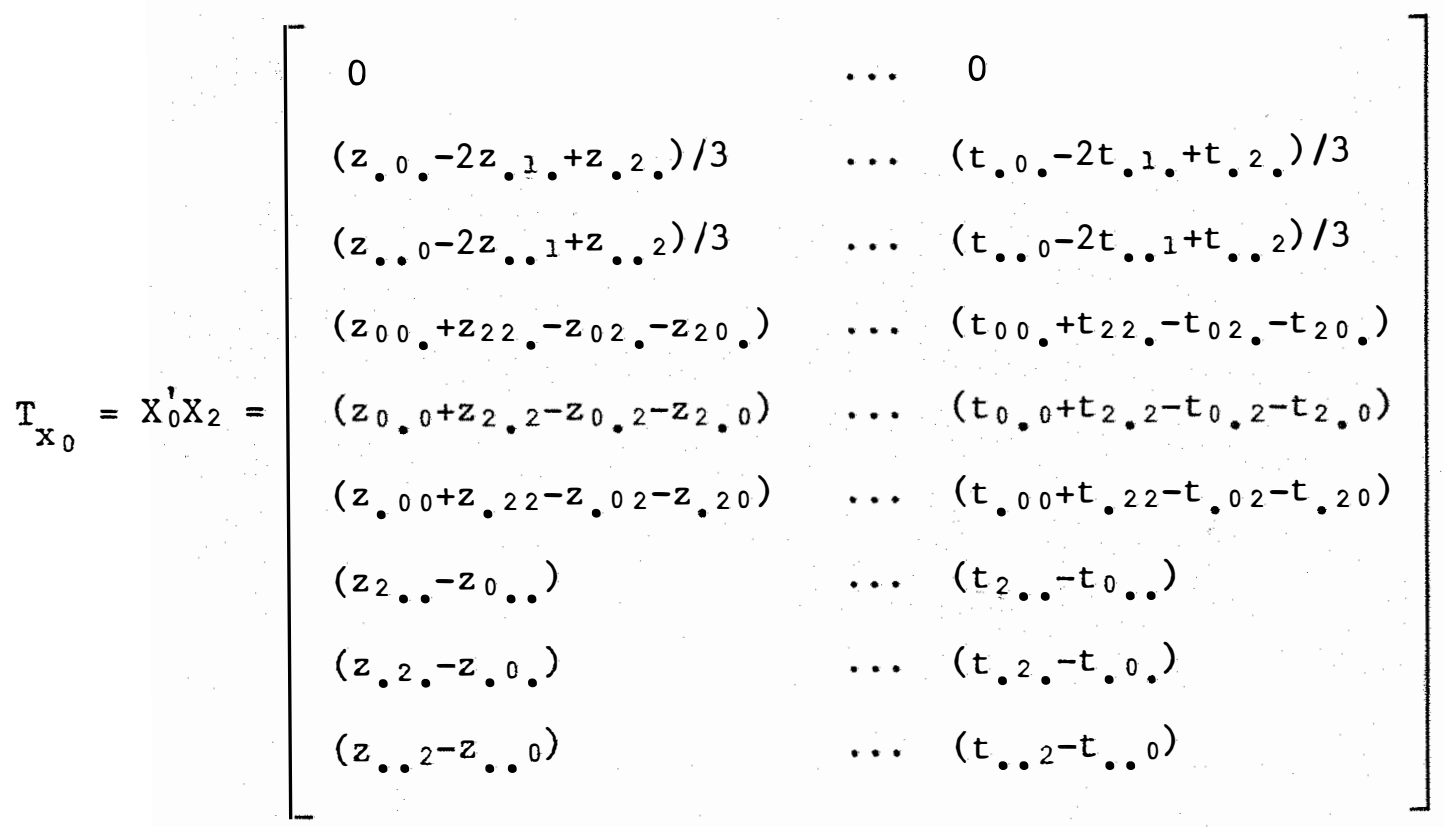

$$
\begin{aligned}
& \text { matriz dos totais de tratamentos } \\
& \text { relativos às variáveis auxiliares, } \\
& \text { na ausencia de nitrogēnio quadrä- } \\
& \text { tico; }
\end{aligned}
$$


42.

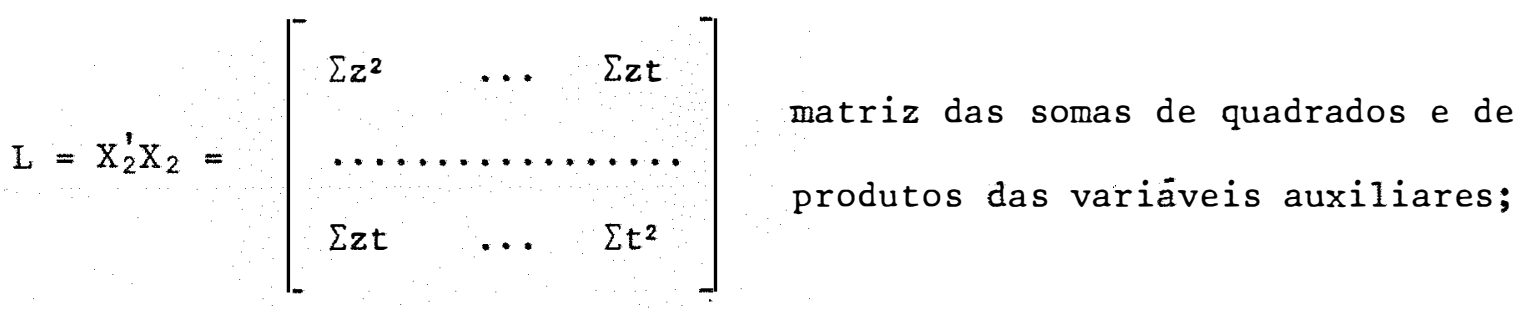

$\mathrm{T}_{0}=\mathrm{X}_{0}^{\prime} \mathrm{Y}=\left[\begin{array}{l}\Sigma \mathrm{y} \\ \left(\mathrm{P}_{0}-2 \mathrm{P}_{2}+\mathrm{P}_{2}\right) / 3 \\ \left(\mathrm{~K}_{0}-2 \mathrm{~K}_{1}+\mathrm{K}_{2}\right) / 3 \\ \left(\mathrm{~N}_{0} \mathrm{P}_{0}+\mathrm{N}_{2} \mathrm{P}_{2}-\mathrm{N}_{0} \mathrm{P}_{2}-\mathrm{N}_{2} \mathrm{P}_{0}\right) \\ \left(\mathrm{N}_{0} \mathrm{~K}_{0}+\mathrm{N}_{2} \mathrm{~K}_{2}-\mathrm{N}_{0} \mathrm{~K}_{2}-\mathrm{N}_{2} \mathrm{~K}_{0}\right) \\ \left(\mathrm{P}_{0} \mathrm{~K}_{0}+\mathrm{P}_{2} \mathrm{~K}_{2}-\mathrm{P}_{0} \mathrm{~K}_{2}-\mathrm{P}_{2} \mathrm{~K}_{0}\right) \\ \left(\mathrm{N}_{2}-\mathrm{N}_{0}\right) \\ \left(\mathrm{P}_{2}-\mathrm{P}_{0}\right) \\ \left(\mathrm{K}_{2}-\mathrm{K}_{0}\right) \\ \end{array}\right]$ vetor dos totais de tratamen-

$Z=X_{2}^{\prime} Y=\left[\begin{array}{c}\sum z y \\ \cdot \\ \cdot \\ \sum t y\end{array}\right]$ te com as variáveis auxiliares; 


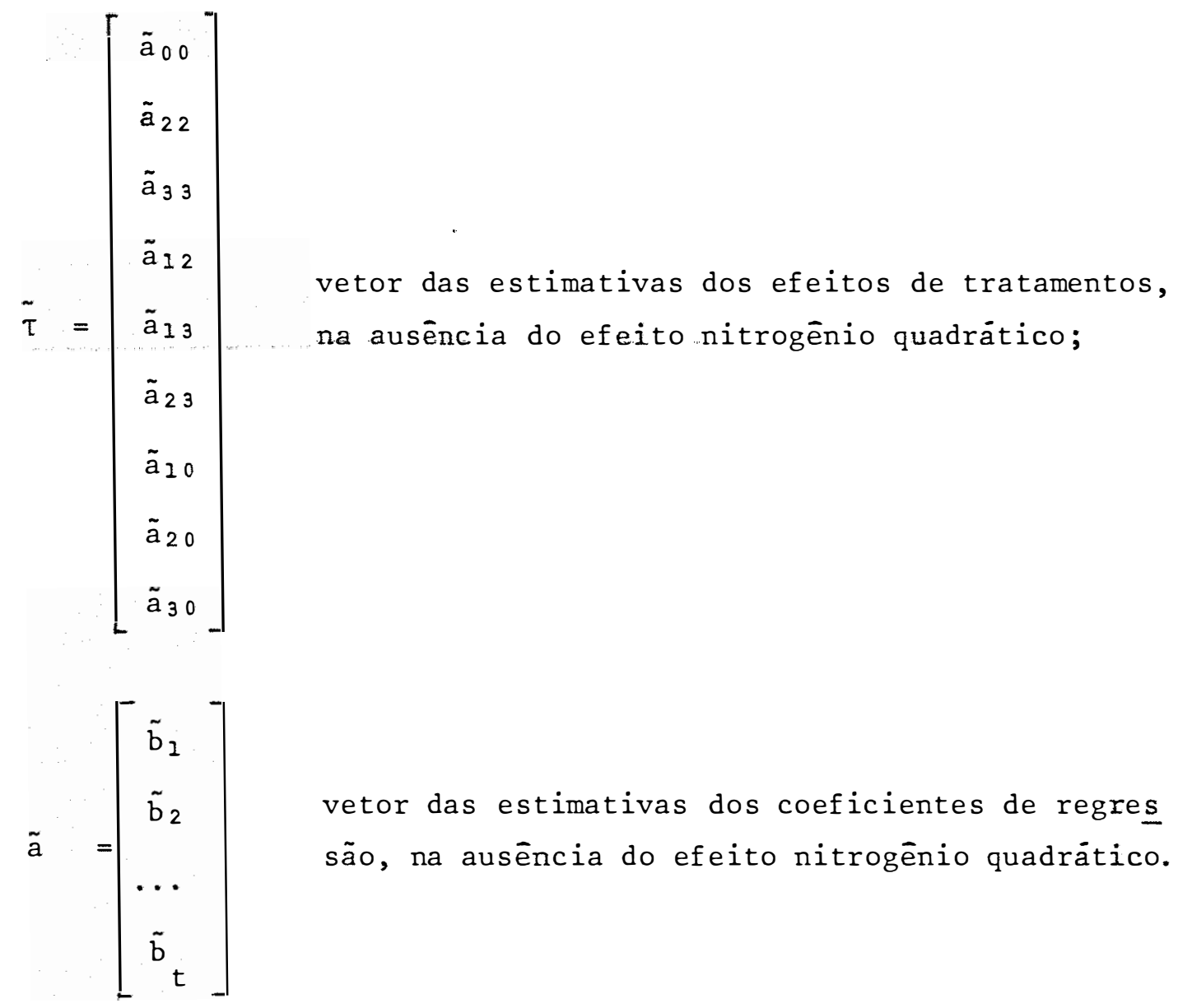

Do sistema de equações normais em (e.2), obtém-se:

$$
\left\{\begin{array}{l}
\mathrm{R}_{0} \tilde{\tau}+\mathrm{T}_{\mathrm{x}_{0}} \tilde{\mathrm{a}}=\mathrm{T}_{0} \\
\mathrm{~T}_{\mathrm{x}_{0}}^{\prime} \tilde{\tau}+\mathrm{La}=2
\end{array}\right.
$$

Considerando que a matriz $R_{0}$ é não-singular, de (e.3),

tem-se:

$$
\tilde{\tau}=R_{0}^{-I} T_{0}-R_{0}^{-1} T_{x_{0}} \tilde{a} . \quad(e .5)
$$

que é o vetor das estimativas dos efeitos de tratamentos ajustados para a regressão linear. Substituindo o valor de $\tilde{\tau}$ em (e.4) tem-se: 


$$
\begin{aligned}
& T_{X_{0}}^{\prime}\left(R_{0}^{-I} T_{0}-R_{0}^{-1} T_{X_{0}} \tilde{a}\right)+L \tilde{a}=2 \\
& \left(L-T_{X_{0}}^{\prime} R_{0}^{-1} T_{X_{0}}\right) \tilde{a}=Z-T_{X_{0}}^{\prime} R_{0}^{-1} T_{0}
\end{aligned}
$$

fazendo: $\quad L-T_{x_{0}}^{\prime} R_{0}^{-1} T_{x_{0}}=E_{1}^{\prime \prime}$

$$
Z-T_{x_{0}}^{\prime} R_{0}^{-1} T_{0}=E_{0}^{\prime \prime}
$$

obtëm-se:

$$
E_{1}^{\prime \prime} \tilde{a}=E_{0}^{\prime \prime}
$$

Sendo $E_{1}^{\prime \prime}$ uma matriz não singular, de dimensão (txt),

tem-se:

$$
\tilde{a}=\left(E_{1}^{\prime \prime}\right)^{-1} E_{0}^{\prime \prime}
$$

que é o vetor das estimativas dos coeficientes de regressão, quando estä ausente o efeito de nitrogénio quadrático.

A soma de quadrados de parámetros $\left(\mathrm{SQP}_{2}\right)$ relativo ao mo delo (e.1) reduzido, serä:

$$
\begin{aligned}
& \mathrm{SQP}_{2}=\mathrm{SQP}_{2}(\tilde{\tau}, \tilde{\mathrm{a}}) \\
& \mathrm{SQP}_{2}=\tilde{\beta^{\prime}} \mathrm{X}^{\prime} Y=\left[\begin{array}{ll}
\tilde{\tau}^{\prime} & \tilde{a}^{\prime}
\end{array}\right]\left[\begin{array}{c}
\mathrm{T}_{0} \\
\mathrm{Z}
\end{array}\right]=\tilde{\tau}^{\prime} \mathrm{T}_{0}+\tilde{\mathrm{a}}^{\prime} \mathrm{Z}, \quad \text { (e.6) } \\
& \text { De (e.5), tem-se que: } \tilde{\tau}=R_{0}^{-1} T_{0}-R_{0}^{-1} T_{x_{0}} \tilde{a} \text {. Logo: } \\
& \mathrm{SQP}_{2}=\left(\mathrm{T}_{0}^{\prime} \mathrm{R}_{0}^{-1}-\tilde{\mathrm{a}}^{\prime} \mathrm{T}_{\mathrm{x}_{0}^{\prime}}^{\prime} \mathrm{R}_{0}^{-1}\right) \mathrm{T}_{0}+\tilde{\mathrm{a}}^{\prime} \mathrm{Z}= \\
& =\mathrm{T}_{0}^{\prime} \mathrm{R}_{0}^{-1} \mathrm{~T}_{0}+\tilde{\mathrm{a}}^{\prime}\left(\mathrm{Z}-\mathrm{T}_{\mathrm{x}_{0}}^{\prime} \mathrm{R}_{0}^{-1} \mathrm{~T}_{0}\right) \\
& =\mathrm{T}_{0}^{\prime} \mathrm{R}_{0}^{-1} \mathrm{~T}_{0}+\tilde{\mathrm{a}}^{\prime} \mathrm{E}_{0}^{\prime \prime} \quad \operatorname{com}(\mathrm{p}-1+\mathrm{t}) \mathrm{g} \cdot \mathrm{l} \cdot \quad(\mathrm{e} \cdot 7)
\end{aligned}
$$


onde: $\mathrm{T}_{0}^{\prime} \mathrm{R}_{0}^{-1} \mathrm{~T}_{0}$ : a soma de quadrados dos parāmetros $\left(\mathrm{a}_{00}, \mathrm{a}_{22}, \mathrm{a}_{33}, \mathrm{a}_{12}\right.$, $\left.a_{13}, a_{23}, a_{10}, a_{20}, a_{30}\right) ;$

$\tilde{a}^{\prime} E_{0}^{\prime}$ : soma de quadrados de regressão linear corrigida para ausência de nitrogēnio quadrätico.

Desse modo, a soma de quadrados de nitrogênio quadrätico [SQN"(aj)], ajustada de acordo com a regressão linear, é obtida pela diferença entre (c.1.2) e (e.7), ou seja:

$$
\begin{aligned}
\operatorname{SQN}^{\prime \prime}(a j) & =\operatorname{SQP}_{0}-\mathrm{SQP}_{2}= \\
& =T^{\prime} R^{-1} \mathrm{~T}+\bar{a}^{\prime} E_{0}-T_{0}^{\prime} R_{0}^{-1} T_{0}-\tilde{a}^{\prime} E_{0}^{\prime \prime}, \operatorname{com} 1 \mathrm{~g} \cdot \ell
\end{aligned}
$$

Usando-se o seguinte artifício, somando e subtraindo

$R\left(y^{2}\right)$ ao segundo membro, tem-se:

$$
\operatorname{SQN}^{\prime \prime}(a j)=\left[R\left(y^{2}\right)+T^{\prime} R^{-1} T\right]-\tilde{a}^{\prime} E_{0}^{\prime \prime}-\left[R\left(y^{2}\right)-\hat{a}^{\prime} E_{0}\right]-T_{0}^{\prime} R_{0}^{-1} T_{0},
$$

ou

$$
\operatorname{SQN}^{\prime \prime}(a j)=R^{\prime}\left(y^{2}\right)-\tilde{a}^{\prime} E_{0}^{\prime \prime}-\operatorname{SQRES}(a j)-T_{0}^{\prime} R_{0}^{-1} T_{0},
$$

onde: $R^{\prime}\left(y^{2}\right)=R\left(y^{2}\right)+T^{\prime} R^{-1} T$

ou ainda

$$
\operatorname{SQN}^{\prime \prime}(a j)=\operatorname{SQN}^{\prime \prime}+\bar{a}^{\prime} E_{0}-\tilde{a} E_{0}^{\prime \prime},
$$

que são as expressões da soma de quadrados de nitrogēnio quadrático ajustada pela regressão linear. 
Para $P^{\prime \prime}, K^{\prime \prime}, N^{\prime} x P^{\prime}, N^{\prime} x K^{\prime}, P^{\prime} x K^{\prime}, N^{\prime}, P^{\prime}$ e $K^{\prime}$ procede-se de maneira anäloga.

\section{f. ESPERANÇA MATEMÁTICA DAS SOMAS DE QUADRADOS}

f.1. Esperança matemātica da soma de quadrados total

Tem-se que:

$$
Y^{\prime} Y=\left(\beta^{\prime} X^{\prime}+\varepsilon^{\prime}\right)(X \beta+\varepsilon)=\beta^{\prime} X^{\prime} X \beta+\beta^{\prime} X^{\prime} \varepsilon+\varepsilon^{\prime} X \beta+\varepsilon^{\prime} \varepsilon .
$$

Aplicando a esperança matemätica, e, considerando as hi póteses: os erros experimentais são independentes, as variāncias dos erros constantes e os valores das variáveis auxiliares fixos, tem-se:

$$
E\left(Y^{\prime} Y\right)=\beta^{\prime} X^{\prime} X \beta+N \sigma^{2}=\left[\tau^{\prime} a^{\prime}\right]\left[\begin{array}{l}
X_{1}^{\prime} \\
X_{2}^{\prime}
\end{array}\right]\left[\begin{array}{ll}
X_{2} & X_{2}
\end{array}\right]\left[\begin{array}{l}
\tau \\
a
\end{array}\right]+N \sigma^{2}
$$

Fazendo as multiplicações e substituições, obtém-se:

$$
E\left(Y^{\prime} Y\right)=\tau^{\prime} R T+2 a^{\prime} T_{X}^{\prime} T+a^{\prime} L a+N \sigma^{2}, \quad(f .1 .1)
$$

f.2. Esperança matemática da soma de quadrados de residuo ajustado $\operatorname{SQRES}(\mathrm{aj})$

Tem-se que:

$$
\begin{aligned}
& E[\operatorname{SQRES}(a j)]=E\left(Y^{\prime} Y\right)-E\left(T^{\prime} R^{-1} T\right)-E\left(\hat{a}^{\prime} E_{0}\right) \cdot \\
& \text { Inicialmente, determinaremos: } E\left(T^{\prime} R^{-1} T\right) \text { e } E\left(\hat{a}^{\prime} E_{0}\right) .
\end{aligned}
$$




$$
\begin{aligned}
& \text { Sendo, } T^{\prime} R^{-1} T=Y^{\prime} X_{1} R^{-1} X_{1}^{\prime} Y=\left(\beta^{\prime} X^{\prime}+\varepsilon^{\prime}\right) X_{1} R^{-1} X_{1}^{\prime}(X \beta+\varepsilon)= \\
& =\beta^{\prime} X^{\prime} X_{1} R^{-1} X_{1}^{\prime} X \beta+\beta^{\prime} X^{\prime} X_{1} R^{-1} X_{1}^{\prime} \varepsilon+\varepsilon^{\prime} X_{1} R^{-1} X_{1}^{\prime} X \beta+\varepsilon^{\prime} X_{1} R^{-1} X_{1}^{\prime} \varepsilon .
\end{aligned}
$$

Aplicando a esperança matemática e considerando as hipō.:-

teses anteriores, em ( $f .1)$, tem-se:

$$
E\left(T^{\prime} \bar{R}^{-1} T\right)=\beta^{\prime} X^{\prime} X_{1} R^{-1} X_{1}^{\prime} X \beta+\operatorname{tr} X_{1} R^{-1} X_{1}^{\prime} \sigma_{1}^{2},
$$

substituindo convenientemente e aplicando propriedades de álgebra de matrizes, virá:

$$
E\left(T^{\prime} R^{-1} T\right)=\left(\tau^{\prime} X_{1}^{\prime}+a^{\prime} X_{2}^{\prime}\right) X_{1} R^{-1} X_{1}^{\prime}\left(X_{1} \tau+X_{2} a\right)+t_{r} I_{p} \sigma_{1}^{2} .
$$

Desenvolvendo e simplificando, obtém-se:

$$
E\left(T R^{-1} T\right)=\tau^{\prime} R \tau+2 a^{\prime} T_{x}^{\prime} \tau+a^{\prime} T_{x}^{\prime} R^{-1} T_{x} a+p \sigma_{I}^{2},(f .2 .1) .
$$

Sendo,

$$
\bar{a}^{\prime} E_{0}=E_{0}^{\prime} E_{1}^{-1} E_{0}=\left(Z^{\prime}-T^{\prime} R^{-1} T_{x}\right) E_{1}^{-1}\left(Z-T_{x}^{\prime} R^{-1} T\right)
$$

Desenvolvendo e sabendo que $Z^{\prime} E^{-1} T_{x}^{\prime} R^{-1} T=T^{\prime} R^{-1} T_{X} E^{-1} Z$, pois são matrizes de dimensão $(1 \times 1)$ e, uma a transposta da outra, e ain da, que $\mathrm{R}^{-1}$ e $\mathrm{E}_{1}^{-1}$ são matrizes simétricas, tem-se:

$$
\bar{a}^{\prime} E_{0}=Z^{\prime} E_{I}^{-1} Z-2 T^{\prime} R^{-1} T_{x} E_{I}^{-I} Z+T^{\prime} R^{-I} T_{x} E_{I}^{-1} T_{x}^{\prime} R^{-1} T .
$$

Substituindo os valores de algumas matrizes e desenvolvendo, virä: 


$$
\begin{aligned}
& a^{\prime} E_{0}=\beta^{\prime} X^{\prime} X_{2} E_{1}^{-1} X_{2}^{\prime} X \beta+\beta^{\prime} X^{\prime} X_{2} E_{1}^{-1} X_{2}^{\prime} \varepsilon+\varepsilon^{\prime} X_{2} E^{-1} X_{2}^{\prime} X \beta+\varepsilon^{\prime} X_{2} E_{1}^{-1} X_{2}^{\prime} \varepsilon- \\
& -2 \beta^{\prime} X^{\prime} X_{1} R^{-1} T_{X} E_{1}^{-1} X_{2}^{\prime} X \beta-2 \beta^{\prime} X^{\prime} X_{1} R^{-1} T_{X_{1}} E_{1}^{-1} X_{2}^{\prime} \varepsilon-2 \varepsilon^{\prime} X_{1} R^{-1} T_{X} E_{1}^{-1} X_{2}^{\prime} X \beta- \\
& -2 \varepsilon^{\prime} X_{1} R^{-1} T_{X} E_{1}^{-1} X_{2}^{\prime} \varepsilon+\beta^{\prime} X^{\prime} X_{1} R^{-1} T_{X^{\prime}} E_{1}^{-} T_{X}^{\prime} R^{-1} X_{1}^{\prime} X \beta+\beta^{\prime} X^{\prime} X_{1} R^{-1} T_{X} E_{1}^{-1} T_{X}^{\prime} R^{-1} X_{1}^{\prime} \varepsilon+ \\
& +\varepsilon^{\prime} X_{1} R^{-1} T_{x} E_{1}^{-1} T_{x}^{\prime} R^{-1} X_{1}^{\prime} X \beta+\varepsilon^{\prime} X_{1} R^{-1} T_{x} E_{1}^{-1} T_{x}^{\prime} R^{-1} X_{1}^{\prime} \varepsilon \text {. }
\end{aligned}
$$

Aplicando a esperança matemática, considerando as hipóte ses em (f.1), substituindo algumas matrizes e simplificando, obtëm-se:

$$
\begin{aligned}
& E\left(\hat{a}^{\prime} E_{0}\right)=a^{\prime} E_{1} a+t \sigma_{1}^{2},(f .2 .2) \\
& \text { Assim, } \\
& E[\operatorname{SQRES}(a j)]=(f .1 .1)-(f .2 .1)-(f .2 .2),
\end{aligned}
$$

logo,

$$
\operatorname{E}[\operatorname{SQRES}(a j)]=(N-p-t) \sigma_{1}^{2} .
$$

\section{f.3. Esperança matemātica de correção - C}

Tem-se que:

$\left(\sum y\right)^{2}=W^{\prime} Y W^{\prime} Y$, onde $W e ̈$ um vetor coluna de 1 (uns), de dimensão (Nx1). Desenvolvendo virä:

$$
(\Sigma \mathrm{y})^{2}=\mathrm{W}^{\prime} \mathrm{X} \beta \mathrm{W}^{\prime} \mathrm{X} \beta+\mathrm{W}^{\prime} \mathrm{X} \beta \mathrm{W}^{\prime} \varepsilon+\mathrm{W}^{\prime} \varepsilon \mathrm{X} \beta+\mathrm{W}^{\prime} \varepsilon \mathrm{W}^{\prime} \varepsilon .
$$

Aplicando a esperança matemätica e simplificando, tem -

-se : 


$$
\begin{aligned}
& E\left[\left(\sum y\right)^{2}\right]=\left(W^{\prime} X \beta\right)^{2}+N \sigma_{I}^{2} . \\
& \text { Logo, } \\
& E(C)=\frac{E\left[\left(\sum y\right)^{2}\right]}{N}=\left(W^{\prime} X \beta\right)^{2} / N+\sigma_{I}^{2},(f \cdot 3 \cdot 1) .
\end{aligned}
$$

f.4. Esperança matemática da soma de quadrados de nitrogênio quadrätico ajustada - SQN"( $(\mathrm{j})$

Tem-se que:

$$
\begin{gathered}
E\left[S Q N^{\prime \prime}(a j)\right]=E\left(T^{\prime} R^{-1} T\right)+E\left(\bar{a}^{\prime} E_{0}\right)-E\left(T_{0}^{\prime} R_{0}^{-1} T_{0}\right)-E\left(\tilde{a}^{\prime} E_{0}^{\prime \prime}\right) \cdot \\
\text { Inicialmente, determinaremos: } \\
E\left(T_{0}^{\prime} R_{0}^{-1} T_{0}\right) \text { e } E\left(\tilde{a}^{\prime} E_{0}^{\prime \prime}\right) .
\end{gathered}
$$

Sendo,

$$
\mathrm{T}_{0}^{\prime} \mathrm{R}_{0}^{-1} \mathrm{~T}_{0}=\mathrm{Y}^{\prime} \mathrm{X}_{0} \mathrm{R}_{0}^{-1} \mathrm{X}_{0}^{\prime} \mathrm{Y}=\left(\beta^{\prime} \mathrm{X}^{\prime}+\varepsilon^{\prime}\right) \mathrm{X}_{0} \mathrm{R}_{0}^{-1} \mathrm{X}_{0}^{\prime}(\mathrm{X} \beta+\varepsilon) .
$$

De modo anālogo, ao obtido em (f.2.1), obtém-se:

$$
\mathrm{E}\left(\mathrm{T}_{0}^{\prime} \mathrm{R}_{0}^{-1} \mathrm{~T}_{0}\right)=\tau_{0}^{\prime} \mathrm{R}_{0} \tau_{0}+2 \mathrm{a}_{0}^{\prime} \mathrm{T}_{\mathrm{x}_{0}}^{\prime} \tau_{0}+\mathrm{a}_{0}^{\prime} \mathrm{T}_{\mathrm{x}_{0}}^{\prime} \mathrm{R}_{0}^{-1} \mathrm{~T}_{\mathrm{x}_{0}} \mathrm{a}_{0}+(\mathrm{p}-1) \sigma_{1}^{2},(\mathrm{f} \cdot 4 \cdot 1) .
$$

Sendo que:

$$
\begin{aligned}
\tilde{\mathrm{a}}^{\prime} \mathrm{E}_{0}^{\prime \prime}=\left(\mathrm{E}_{0}^{\prime \prime}\right)^{\prime}\left(\mathrm{E}_{1}^{\prime \prime}\right)^{-1} \mathrm{E}_{0}^{\prime \prime} & =\left(\mathrm{Z}^{\prime}-\mathrm{T}_{0}^{\prime} \mathrm{R}_{0}^{-1} \mathrm{~T}_{\mathrm{x}_{0}}\right)\left(\mathrm{E}_{1}^{\prime \prime}\right)^{-1}\left(\mathrm{Z}-\mathrm{T}_{\mathrm{x}_{0}}^{\prime} \mathrm{R}_{0}^{-1} \mathrm{~T}_{0}\right) \cdot \\
& \text { De modo anälogo, ao obtido em (f.2.2), obtém-se: }
\end{aligned}
$$




$$
\begin{aligned}
& E\left(\tilde{a}^{\prime} E_{0}^{\prime \prime}\right)=a_{0}^{\prime} E_{1}^{\prime \prime} a_{0}+t \sigma_{I}^{2},(f .4 .2) . \\
& \text { Assim, } \\
& \left.\left.E\left[S Q N^{\prime \prime}\right) a j\right)\right]=(f .2 .1)+(f .2 .2)-(f .4 .1)-(f .4 .2) .
\end{aligned}
$$

Substituindo as expressões pelos seus valores e simpli-

ficando, obtém-se:

$$
\begin{aligned}
& E\left[\operatorname{SQN}^{\prime \prime}(a j)\right]=\tau^{\prime} R \tau+2 a^{\prime} T_{x}^{\prime} \tau+a^{\prime} T_{x}^{\prime} R^{-1} T_{x} a+a^{\prime} E_{1} a- \\
& -\left(\tau{ }_{0}^{\prime} R_{0} \tau_{0}+2 a_{0}^{\prime} T_{x_{0}}^{\prime} \tau_{0}+a_{0}^{\prime} T_{x_{0}}^{\prime} R_{0}^{-1} T_{x_{0}} a_{0}+a_{0}^{\prime} E_{1}^{\prime \prime} a_{0}\right)+\sigma_{1}^{2} \ldots \\
& \text { Para obter-se as esperanças matemáticas das somas de }
\end{aligned}
$$

quadrados ajustadas de $P^{\prime \prime}, K^{\prime \prime}, N^{\prime} x P^{\prime}, N^{\prime} x K^{\prime}, P^{\prime} x K^{\prime}, N^{\prime}, P^{\prime}$ e $K^{\prime}$, procede-se de maneira análoga.

f.5. Esperança matemática da soma de quadrados de tratamentos ajusta da - SQTRA $(a j)$

Tem-se que

$$
\begin{aligned}
& E[\operatorname{SQTRA}(a j)]=E\left(T^{\prime} R^{-1} T\right)+E\left(\bar{a}^{\prime} E_{0}\right)-E(C)-E\left(\bar{a}^{\prime} Z\right) . \\
& \text { Inicialmente, determinaremos } E\left(\bar{a}^{\prime} Z\right) . \\
& \text { Sendo, } \\
& \bar{a}^{\prime} Z=Z^{\prime} L^{-1} Z=Y^{\prime} X_{2} L^{-1} X_{2}^{\prime} Y=\left(\beta^{\prime} X^{\prime}+\varepsilon^{\prime}\right) X_{2} L^{-1} X_{2}^{\prime}(X \beta+\varepsilon) . \\
& \text { Desenvolvendo e aplicando a esperança matemática, virá: } \\
& E\left(\bar{a}^{\prime} Z\right)=\beta^{\prime} X^{\prime} X_{2} L^{-1} X_{2}^{\prime} X \beta+\operatorname{trX} X_{2} L^{-1} X_{2}^{\prime} \sigma_{1}^{2} .
\end{aligned}
$$

Substituindo algumas matrizes e simplificando, obtém-se: 


$$
\begin{aligned}
& E\left(a^{-1} z\right)=\tau^{\prime} T_{x} L^{-1} T_{x}^{\prime} \tau+2 a^{\prime} T_{x}^{\prime} \tau+a{ }^{\prime} L a+t \sigma_{1}^{2},(f .5 .1) \\
& \text { Assim, } \\
& E[\operatorname{SQTRA}(a j)]=(f .2 .1)+(f \cdot 2.2)-(f .3 .1)-(f .5 .1)
\end{aligned}
$$

Substituindo as expressões pelos seus valores e simplificando, obtém-se:

$$
E[\operatorname{SQTRA}(a j)]=\tau^{\prime} C \tau-\left(W^{\prime} X \beta\right)^{2} / N+(p-1) \sigma_{1}^{2},(f .5: 1)
$$

\section{g. ESPERANCA MATEMÁTICA DOS QUADRADOS MÉDIOS A.JUSTADOS}

A esperança matemática dos quadrados médios ajustados é obtida tomando-se como divisor das somas de quadrados de cada fonte de vạ riação, o indice da variāncia residual ajustada $\left(\sigma_{1}^{2}\right)$, e são mostradas na Tabela 2 . 
Tabela 2 - Esquema de anälise da variancia para os efeitos de tratamentos ajustados de acordo com a regressão linear, com suas respectivas esperanças matemáticas de quadrados médios.

\begin{tabular}{|c|c|c|c|}
\hline Fontes de Variação & G.L. & Q.M. & $E(Q . M)$. \\
\hline (Tratamento) & $(p-1)$ & $\mathrm{V}_{10}$ & $\sigma_{1}^{2}+\left[\tau^{\prime} C \tau-\left(W^{\prime} X B\right)^{2} / N\right] /(p-1)$ \\
\hline Nitrog.Quad.(aj) & 1 & $\mathrm{~V}_{0}$ & $\sigma_{1}^{2}+K_{0}$ \\
\hline Fösf.Quad.(aj) & 1 & $v_{2}$ & $\sigma_{1}^{2}+K_{1}$ \\
\hline Potās.Quad. (aj) & 1 & $\mathrm{~V}_{2}$ & $\sigma_{1}^{2}+K_{2}$ \\
\hline Nit.LinxFösf.Lin. (aj) & 1 & $\mathrm{~V}_{3}$ & $\sigma_{1}^{2}+K_{3}$ \\
\hline Nit.LinxPot.Lin. $(a j)$ & 1 & $\mathrm{~V}_{4}$ & $\sigma_{1}^{2}+K_{4}$ \\
\hline Fösf.Lin.xPot.Lin. (aj) & 1 & $\mathrm{~V}_{5}$ & $\sigma_{1}^{2}+K_{5}$ \\
\hline Nitrog.Lin. (aj) & 1 & $\mathrm{v}_{6}$ & $\sigma_{1}^{2}+K_{6}$ \\
\hline Fösf. Lin. $(a j)$ & 1 & $\mathrm{~V}_{7}$ & $\sigma_{1}^{2}+K_{7}$ \\
\hline Potās.Lin. (aj) & 1 & $\mathrm{~V}_{8}$ & $\sigma_{1}^{2}+K_{8}$ \\
\hline Resíduo ( $a j$ ) & $N-p-t$ & $\mathrm{~V}_{9}$ & $\ldots \ldots$ \\
\hline
\end{tabular}

onde:

$$
k_{i}=k-\left(\tau_{i}^{\prime} R_{i} \tau_{i}+2 a_{i}^{\prime} \mathrm{T}_{x_{i}}^{\prime} \tau_{i}+a_{i}^{\prime} \mathrm{T}_{x_{i}}^{\prime} \mathrm{R}_{i}^{-1} \mathrm{~T}_{\mathrm{x}_{i}} a_{i}+a_{i}^{\prime} \mathrm{E}_{j}^{\prime \prime} \mathrm{a}_{i}\right)
$$

sendo: $(i=0,1, \ldots, 8$ e $j=i+1)$;

$$
K=\tau^{\prime} R \tau+2 a^{\prime} T_{x}^{\prime} \tau+a^{\prime} T_{x}^{\prime} R^{-1} T_{x} a+a^{\prime} E_{l} a
$$


h. MATRIZ DE DISPERSÃO DOS EFEITOS DOS TRATAMENTOS AJUSTADOS

$$
\begin{aligned}
& \text { De (b.5) tem-se que: } \\
& \bar{\tau}=R^{-1} T-R^{-1} T_{x} \bar{a}
\end{aligned}
$$

substituindo os vetores $\mathrm{T}$ e $\mathrm{a}$ e desenvolvendo, tem-se:

$$
\begin{aligned}
\bar{\tau}= & R^{-1} X_{I}^{\prime} X \beta+R^{-1} X_{I}^{\prime} \varepsilon-R^{-1} T_{X} E_{I}^{-1} X_{2}^{\prime} X \beta-R^{-1} T_{X} E_{I}^{-1} X_{2}^{\prime} \varepsilon+ \\
& +R^{-1} T_{X} E_{I}^{-1} T_{X}^{\prime} R^{-1} X_{I}^{\prime} X \beta+R^{-1} T_{X} E_{I}^{-1} T_{X}^{\prime} R^{-1} X_{I}^{\prime} \varepsilon .
\end{aligned}
$$

Supondo que os valores das variäveis auxiliares são fi-

xos e $E(\varepsilon)=\Phi$, tem-se:

$$
E(\bar{\tau})=R^{-1} X_{I}^{\prime} X \beta-R^{-1} T_{X} E_{I}^{-1} X_{2}^{\prime} X \beta+R^{-1} T_{X} E_{I}^{-} T_{X}{ }^{1} R^{-I} X_{I}^{\prime} X \beta .
$$

Por definição tem-se:

$$
\begin{gathered}
D_{\tau}=E\left\{[\bar{\tau}-E(\bar{\tau})][\bar{\tau}-E(\bar{\tau})]^{\prime}\right\} . \\
\text { Assim: } \\
\tilde{\tau}-E(\bar{\tau})=R^{-1} X_{1}^{\prime} \varepsilon-R^{-1} T_{X} E_{I}^{-1} X_{2}^{\prime} \varepsilon+R^{-1} T_{X} E_{I}^{-1} T_{X}^{\prime} R^{-1} X_{I}^{\prime} \varepsilon
\end{gathered}
$$

então:

$$
\begin{aligned}
D_{\tau}= & E\left\{( R ^ { - 1 } X _ { 1 } ^ { \prime } \varepsilon - R ^ { - 1 } T _ { X } E _ { I } ^ { - 1 } X _ { 2 } ^ { \prime } \varepsilon + R ^ { - 1 } T _ { X } E _ { I } ^ { - 1 } T _ { X } ^ { \prime } R ^ { - 1 } X _ { 1 } ^ { \prime } \varepsilon ) \left(\varepsilon^{\prime} X_{1}^{\prime} R^{-1}-\varepsilon^{\prime} X_{2} E_{I}^{-1} T_{X}^{\prime} R^{-1}+\right.\right. \\
& \left.\left.+\varepsilon^{\prime} X_{I} R^{-1} T_{X} E_{I}^{-1} T_{X}^{\prime} R^{-1}\right)\right\}
\end{aligned}
$$


sendo as matrizes $R^{-1}$ e $E_{1}^{-1}$ simétricas. Desenvolvendo e considerando-se, por hipötese, que os erros são independentes e com variāncia constante, ou seja $E\left(\varepsilon \varepsilon^{\prime}\right)=\hat{\sigma}_{I}^{2} I_{N}$, obtēm-se:

$D_{\tau}=\sigma_{I}^{2}\left[\begin{array}{l}R^{-1}-R^{-1} T_{x} E_{I}^{-1} T_{x}^{\prime} R^{-1}+R^{-1} T_{x} E_{I}^{-1} T_{x}^{\prime} R^{-1}-R^{-1} T_{x} E_{I}^{-1} T_{x}^{\prime} R^{-1}+ \\ +R^{-1} T_{x} E_{I}^{-1} L_{I}^{-1} T_{x}^{\prime} R^{-1}-R^{-1} T_{x} E_{I}^{-1} T_{x}^{\prime} R^{-1} T_{x} E_{I}^{-1} T_{x}^{\prime} R^{-1}+R^{-1} T_{x} E_{I}^{-1} T_{x}^{\prime} R^{-1}- \\ -R^{-1} T_{x} E_{I}^{-1} T_{x}^{\prime} R^{-1} T_{x} E_{I}^{-1} T_{x}^{\prime} R^{-1}+R^{-1} T_{x} E_{I}^{-1} T_{x}^{\prime} R^{-1} T_{x} E_{I}^{-1} T_{x}^{\prime} R^{-1}\end{array}\right]$

Simplificando obtém-se:

$$
D_{\tau}=\sigma_{I}^{2}\left(R^{-1}+R^{-1} T_{x} E_{1}^{-1} T_{x}^{\prime} R^{-1}\right), \quad(h .1)
$$

No caso particular, de uma variável auxiliar, a matriz de dispersão dos efeitos de tratamentos ajustados pela regressão ë mostra da na Tabela 3 , onde:

- $\operatorname{Cor}=\left(\sum z\right)^{2} / 27$ è a correção relativa à variāvel auxiliar;

- SQn", ..., SQk' são as somas de quadrados dos tratamentos relativos à variảvel auxiliar;

$\begin{aligned} \cdot n^{\prime \prime}= & z_{0},-2 z_{1} \ldots+z_{2} \ldots, n^{\prime} x p^{\prime}=z_{00}+z_{22},-z_{02}-z_{20}, \\ & n^{\prime}=z_{2} \ldots-z_{0} \ldots, \text { os demais valores obtém-se por analogia; }\end{aligned}$

- $R\left(z^{2}\right)$ é a soma de quadrados de resíduo relativa à variável auxiliar;

- as expressões na diagonal principal representam as variāncias dos efeitos de tratamentos ajustados e, às fora da diagonal principal as cova $\hat{\sim}$ riāncas. 


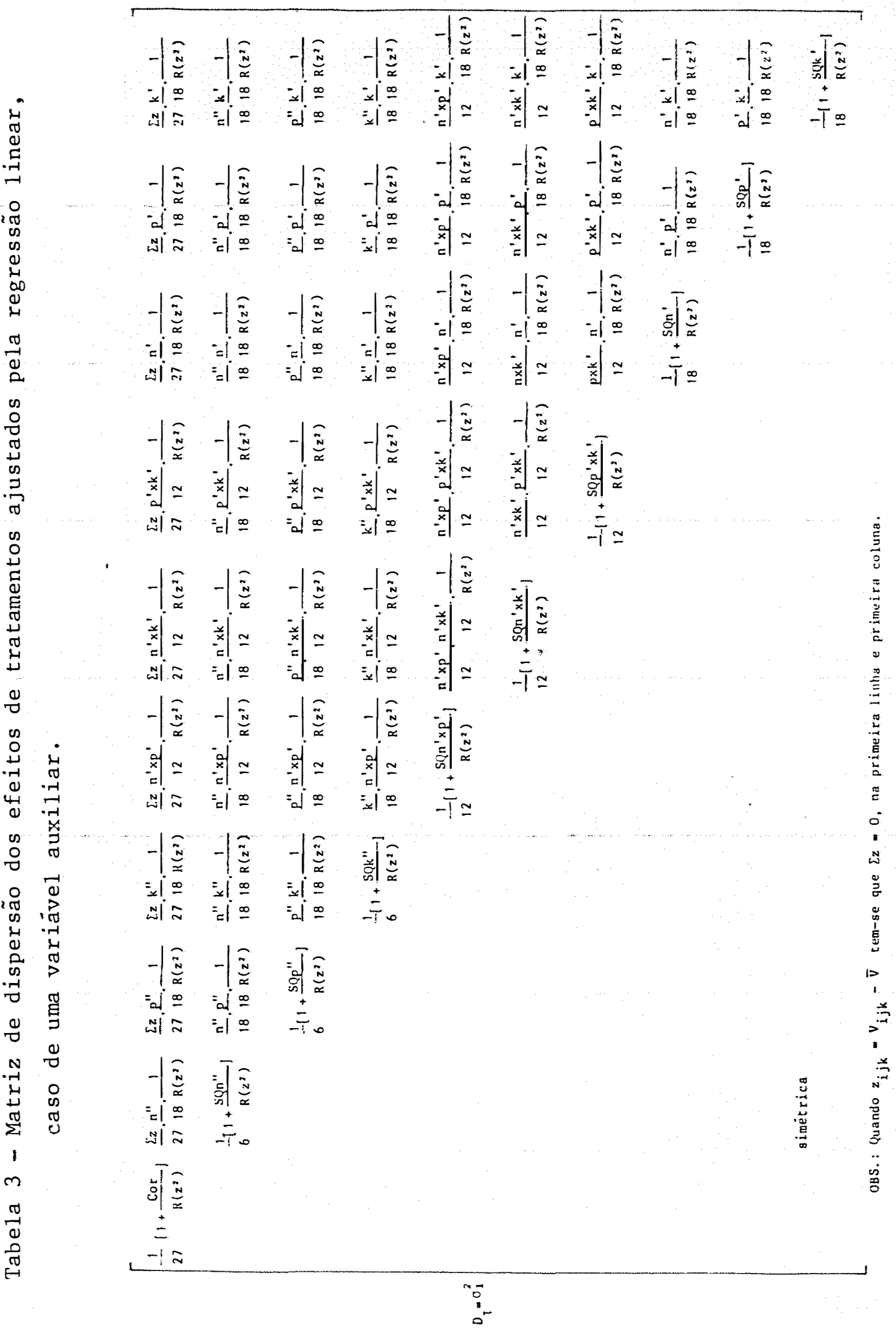


56.

\section{i. MATRIZ DE DISPERSÃO DOS COEFICIENTES DE REGRESSÃO}

De $(b .6)$ tem-se que $\bar{a}=E_{\mathcal{I}}^{-1} E_{0}$. Substituindo o vetor $E_{0}$

e desenvolvendo tem-se:

$$
\begin{aligned}
\bar{a}=E_{1}^{-1} X_{2}^{\prime} X \beta+E_{1}^{-1} X_{2}^{\prime} \varepsilon-E_{1}^{-1} I_{X}^{\prime} R^{-1} X_{1}^{\prime} X \beta-E_{1}^{-1} T_{X}^{\prime} R^{-1} X_{1}^{\prime} \varepsilon \cdot \\
\text { Por definição: } D_{r}=E\left\{[\bar{a}-E(\bar{a})][\bar{a}-E(\bar{a})]^{\prime}\right\} \text {. Assim }
\end{aligned}
$$
considerando os valores das variáveis auxiliares fixos e $E(\varepsilon)=\Phi$, tem-se

$$
\bar{a}-E(\bar{a})=E_{1}^{-1} X_{2}^{\prime} \varepsilon-E_{1}^{-1} T_{x}^{\prime} R^{-1} X_{1}^{\prime} \varepsilon,
$$

então

$$
D_{r}=E\left\{\left(E_{1}^{-1} X_{2}^{\prime} \varepsilon-E_{1}^{-1} T_{X}^{\prime} R^{-1} X_{1}^{\prime} \varepsilon\right)\left(\varepsilon^{\prime} X_{2} E_{1}^{-1}-\varepsilon^{\prime} X_{1} R^{-1} T_{X} E_{1}^{-1}\right)\right\},
$$

sendo as matrizes $\mathrm{R}^{-1}$ e $\mathrm{E}_{\mathrm{I}}^{-1}$ simëtricas. Desenvolvendo e considerando - se que os erros são independentes e com variāncia constante tem-se, por hipó tes, $E\left(\varepsilon \varepsilon^{\prime}\right)=\sigma_{I}^{2} I_{N}, \log 0$

$$
\begin{aligned}
& D_{r}=\sigma_{1}^{2}\left(E_{1}^{-1} X_{2}^{1} X_{2} E_{1}^{-1}-E_{1}^{-1} X_{2}^{1} X_{1} R^{-1} T_{x} E_{I}^{-1}-E_{1}^{-1} T_{x}^{\prime} R^{-1} X_{1}^{1} X_{2} E_{1}^{-1}+\right. \\
& \left.+E_{1}^{-1} T_{X}^{\prime} R^{-1} X_{1}^{\prime} X_{1} R^{-1} T_{x} E_{1}^{-1}\right)
\end{aligned}
$$

Substituindo algumas matrizes e simplificando, obtém-se

$$
D_{r}=\sigma_{1}^{2} E_{1}^{-1},(i \cdot 1)
$$

No caso de uma variāvel auxiliar, tem-se

$\mathrm{D}_{\mathrm{r}}=\frac{\sigma_{\mathrm{I}}^{2}}{\mathrm{R}\left(\mathrm{z}^{2}\right)}$, onde: $\mathrm{R}\left(z^{2}\right)$ è a soma de quadrados de residuo rela lativo à anālise da variāncia da variāvel auxiliar. 
j. INTERVALO DE CONFIANCA DAS ESTIMATIVAS DOS EFEITOS DE TRATAMENTOS AJUS TADOS

\begin{abstract}
A matriz de dispersão $D_{\tau}$, obtida em (h.1), também chama da "matriz das variāncias e covariāncias de $\tau$ ", mostra que as variāncias e covariancias das estimativas dos efeitos de tratamentos dependem do esquema experimental e do modelo de superficie utilizado.
\end{abstract}

$$
\text { Sendo } \bar{\tau}=R^{-1} T-R^{-1} T_{x} \bar{a}, E(\bar{\tau})=\tau \text { e } E\left(s_{1}^{2}\right)=\sigma_{1}^{2} \text {, tem - se: }
$$

$\vec{\tau} \sim N\left(\tau ; D_{\tau}\right)$, logo cada uma das estimativas dos efeitos de tratamentos te ráa $\bar{a}_{i j} \sim N\left(a_{i j}, d_{i j} \sigma_{1}^{2}\right)$, onde $a_{i j}, i \leqq j=0,1,2,3$, designa o parâmetro e $d_{i j}$ o elemento da diagonal principal de $D_{\tau}$, correspondente ao parāmetro anterior. Sabe-se, por hipötese, que $\bar{\tau}$ e $s_{1}^{2}$ são independentes, logo, $\bar{\tau}$ e $(N-p-t) s_{1}^{2} / \sigma_{1}^{2}$ também o são. Desse modo, o intervalo de confiança do efeito de tratamento $\mathbf{a}_{\mathbf{i j}}$, com probabilidade de confiança $1-\infty \mathrm{e}, \mathbf{t} \operatorname{com}(\mathrm{N}-\mathrm{p}-\mathrm{t})$ graus de liberdade, pode ser obtido por:

$$
\bar{a}_{i j}-t_{\alpha / 2} s_{1} \sqrt{d_{i j}} \leqq a_{i j} \leqq \bar{a}_{i j}+t_{\alpha / 2} s_{1} \sqrt{d_{i j}} \quad,(j \cdot 1)
$$

k. INTERVALO DE CONFIANCA DAS ESTIMATIVAS DOS COEFICIENTES DE REGRESSÃO

De modo análogo, ao item anterior, obtém-se:

$$
\hat{b}_{t}-t_{\alpha / 2} s_{1} \sqrt{d t} \leqq b_{t} \leqq b_{t}+t_{\alpha / 2} s_{1} \sqrt{d_{t t}} \quad,(k \cdot 1)
$$

onde: $\widehat{b}_{t}$ é a estimativa do t-ésimo coeficiente de regressão;

$$
\begin{gathered}
d_{t t}, \operatorname{com} t=1,2, \ldots, t \text {, designa o elemento da diagonal principal } \\
\text { de } D_{r} \text {, correspondente ao coeficiente de regressão } b_{t} .
\end{gathered}
$$




\section{Ł. VARIANCIA E INTERVALOS DE CONFIANÇA DAS ESTIMATIVAS DE PRODUÇÃO}

Para determinar as variāncias dos valores observados, considerou-se que o vetor das estimativas dos valores esperados de $y_{i j k}$, representado por $\bar{y}$, é dado por:

$$
\bar{y}=P^{\prime} \bar{B}
$$

onde $\mathrm{P}^{\prime}$ é o vetor linha cujos elementos correspondem à linha da matriz $\mathrm{X}$ relativa a uma determinada combinação dos niveis dos fatores, ou seja,

$$
P^{\prime}=\left[\begin{array}{lllllllllllll}
1 & x_{1}^{2}-\frac{2}{3} & x_{2}^{2}-\frac{2}{3} & x_{3}^{2}-\frac{2}{3} & x_{1} x_{2} & x_{1} x_{3} & x_{2} x_{3} & x_{1} & x_{2} & x_{3} & z & \ldots & t
\end{array}\right] .
$$

A variāncia de cada valor $\bar{y}$ é

$$
\begin{gathered}
\mathrm{V}(\overline{\mathrm{y}})=\mathrm{V}\left(\mathrm{P}^{\prime} \overline{\bar{B}}\right),(l .1) \\
\text { Desenvolvendo a expressão }(l .1) \text { tem-se: } \\
\mathrm{V}\left(\mathrm{P}^{\prime} \bar{\beta}\right)=\mathrm{E}\left[\mathrm{P}^{\prime} \bar{\beta}-\mathrm{P}^{\prime} \beta\right]^{2}=\mathrm{E}\left[\mathrm{P}^{\prime}(\bar{\beta}-\beta)\right]^{2},
\end{gathered}
$$

como $P^{\prime} \bar{B}$ è uma matriz de um único elemento, segundo HOFFMANN e VIEIRA (1977), obtèm-se:

$$
V\left(P^{\prime} \bar{\beta}\right)=P^{\prime}\left(X^{\prime} X\right)^{-1} P \sigma_{I}^{2}
$$

Como em experimentação $\sigma_{1}^{2}$ é desconhecida, utiliza-se co mo sua estimativa não tendenciosa, $s_{I}^{2}=\operatorname{QMRES}(a j)$. Portanto

$$
\tilde{V}\left(P^{\prime} \bar{B}\right)=P^{\prime}\left(X^{\prime} X\right)^{-1} P^{2}{ }_{1}^{2}
$$


A partir desta förmula pode-se estimar as variāncias dos vinte e sete valores de $y_{i j k}$.

Como $\bar{y} \sim N\left(P B ; P^{\prime}\left(X^{\prime} X\right)^{-1} P \sigma_{I}^{2}\right)$, o intervalo de confiança de $y_{i j k}$, com probabilidade de confiança $1-\alpha e, t$ com $(N-p-t)$ graus de liber dade, pode ser obtido por:

$$
\bar{y}-t_{\alpha / 2} s_{1} \sqrt{P^{\prime}\left(x^{\prime} x\right)^{-1} P} \leqq y_{i j k} \leqq \hat{y}+t_{\alpha / 2} s_{1} \sqrt{P^{\prime}\left(x^{\prime} X\right)^{-1} P}
$$




\section{RESULTADOS E DISCUSSÃO}

Para exemplificar a aplicação da metodologia de superfície de resposta, atravēs do uso de um modelo de regressão polinomial qua drätico, considerando-se algumas variäveis auxiliares adicionais ao mode10, tomou-se dados provenientes de um experimento em esquema fatorial $3^{3}$, de adubação $\mathrm{N}, \mathrm{P}_{2} \mathrm{O}_{5}$ e $\mathrm{K}_{2} \mathrm{O}$, em cafeeiro. Os dados observados de produção (variāvel dependente), altura da planta, diāmetro da copa e nümero de internödios (variäveis auxiliares adicionais) relativos à aplicação das vin te e sete combinações de tratamentos, encontram-se nos Apēndices 7, 8, 9 e 1 , respectivamente.

\subsection{Modelo sem as Variáveis auxiliares adicionais}

Usando a metodologia que se encontra em 3.2., não consi derando-se as variáveis auxiliares adicionais, obtiveram-se os vetores das estimativas dos parâmetros $(\bar{\tau})$, a anälise da variância, as estimativas das 
variāncias das estimativas dos parāmetros e as covariāncias (que são nulas). A partir da estimativa $s^{2}=$ QMRES, da variāncia residual $\left(\sigma^{2}\right)$ ou desvios de regressão, determinou-se os desvios padrões das estimativas dos parāmetros considerando-se o teste $t$ ao nivel de $5 \%$ de probabilidade e 17 graus de liberdade, e ainda os valores calculados de $\mathbf{t}$ para os mesmos parämetros.

Os valores calculados das estimativas dos parāmetros, desvios padrões e de $\mathbf{t}$ encontram-se na Tabela 4, enquanto a anälise da va riāncia na Tabela 5, para os exemplos de aplicação considerados. 


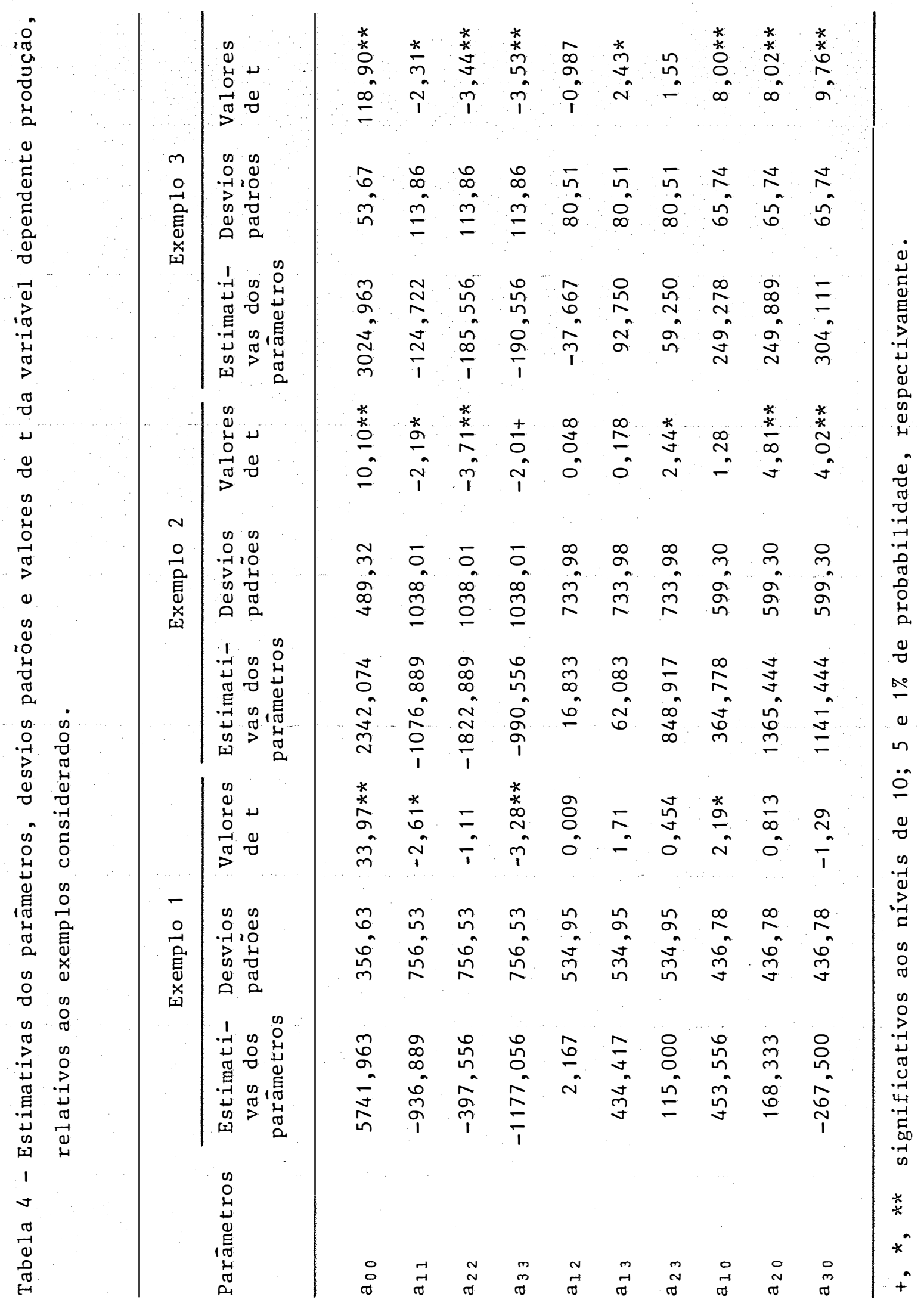


Estimativas das variancias

$\vec{v}\left(\vec{a}_{0} 0\right)$

$28.567,75$

$\bar{v}\left(\bar{a}_{i i}\right)$

$\bar{v}\left(\bar{a}_{i i},\right)$

$\bar{v}\left(\hat{a}_{i_{0}}\right)$

Exemplo 1

$64.277,44$

$42.851,63$
Exemplo 2

$53.780,67$

$242.013,02$
$121.006,51$

$1.456,14$

$80.671,01$

970,76
$2.912,28$

Exemp10 3

$$
647,17
$$


64.

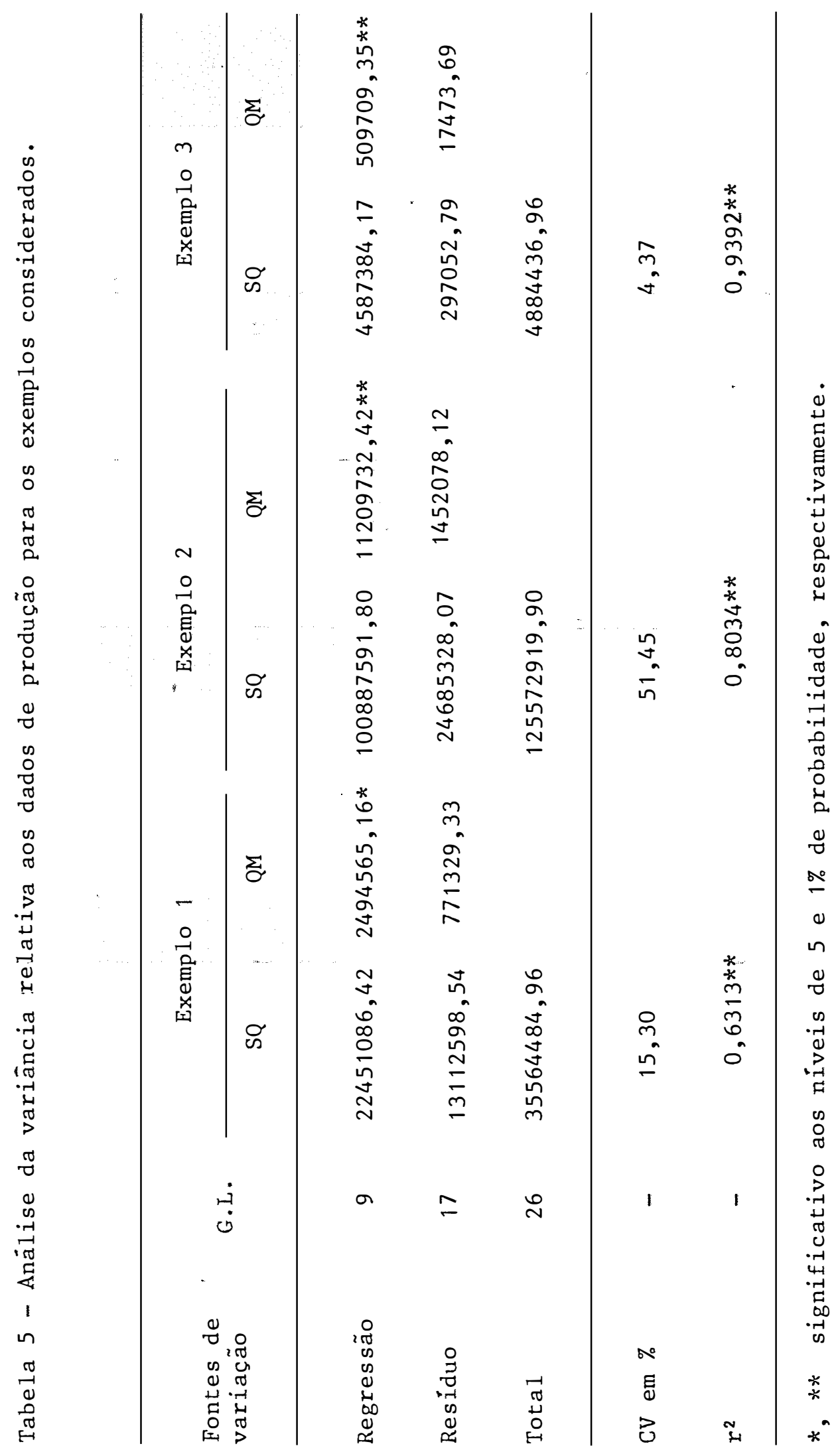


Pelas estimativas das variāncias obtidas nota-se que o parāmetro da média é estimado com mais precisão do que os termos lineares, estes com maior precisão do que os efeitos das interações e estas mais do que os termos quadräticos.

Observa-se na Tabela 4 que os desvios padrões obtidos, em alguns casos são relativamente grandes, em relação aos valores calculą dos das estimativas dos parâmetros e, essa grandeza se acentua nas estima tivas dos parâmetros não significativos. Assim, estimativas de parāmetros que sejam próximas de zero, podem mudar de sinal, concordando com resulta dos obtidos por vários autores, como CAMPOS (1967), MORAIS (1969) e MONTEIRO (1978). Nota-se que não houve efeito significativo das interações lineares, com exceção de $\mathrm{P}^{\prime} \mathrm{xK}^{\prime}$ e $\mathrm{N}^{\prime} \mathrm{xK}^{\prime}$ nos exemplos 2 e 3, respectivamente, ocorrendo uma predomināncia dos efeitos lineares e quadräticos. A não significância dos parāmetros nos evidenciam que estes não diferem signifi cativamente de zero podendo, em alguns casos, serem eliminados do modelo, conforme estudos de CAMPOS e ARAUJO (1971).

0 modelo ajustou-se melhor aos dados do exemplo 3, evidenciado pelos valores dos coeficientes de determinação, os quais mostra ram que $93,92 \%, 80,34 \%$ e $63,13 \%$ da variação são explicadas pela regres são, respectivamente, nos exemplos 3,2 e 1 .

\title{
4.2. MODElO COM as VARIÁVEIS AUXiLiaRes adicionais
}

\author{
Usando a metodologia que se encontra em 3.2., foram fei \\ tas as anälises estatisticas considerando o modelo com uma e com as três
}


variäveis auxiliares adicionais. Os valores obtidos de quadrados médios e do teste $\mathbf{F}$ encontram-se nas Tabelas 6,7 e 8 , respectivamente, para os exemplos 1,2 e 3 .

Observa-se que a adição de uma variävel auxiliar ao modelo diminuiu moderadamente a estimativa da variāncia residual, o que era esperado, exceto quando se considerou as variáveis auxiliares altura da planta e nümero de internódios no exemplo 1 e, nümero de internódios no exemplo 2.

Em termos percentuais, a variāvel auxiliar diāmetro da copa reduziu a variāncia residual em 10,$38 ; 35,97$ e 4,77\%, respectivamente, nos exemplos 1, 2 e 3; a altura da planta em 22,28 e 2,12\%, respectivamente, nos exemplos 2 e 3; o nümero de internódios em 7,54\% no exem plo 3.

Quando são incluidas ou adicionadas variāveis auxiliares ao modelo, a S.Q. de Resíduo e os graus de liberdade do resíduo ficam reduzidos, se o decréscimo da S.Q. de Resíduo é maior proporcionalmente ao decréscimo no nümero de graus de liberdade, os valores da S.Q. de Resi duo ajustada ficam reduzidos e apresentam maior eficiência relativa. 
67.

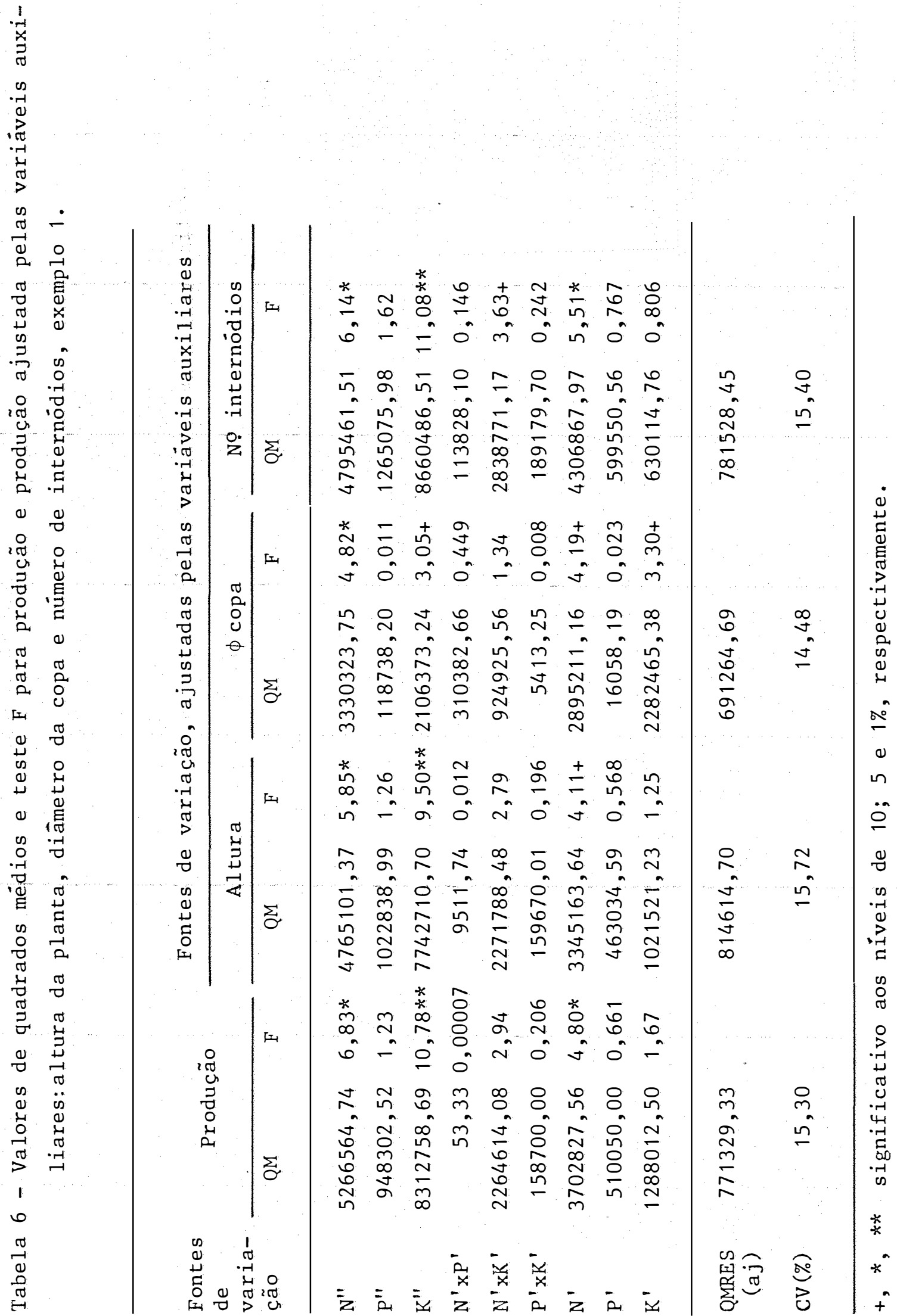


68.

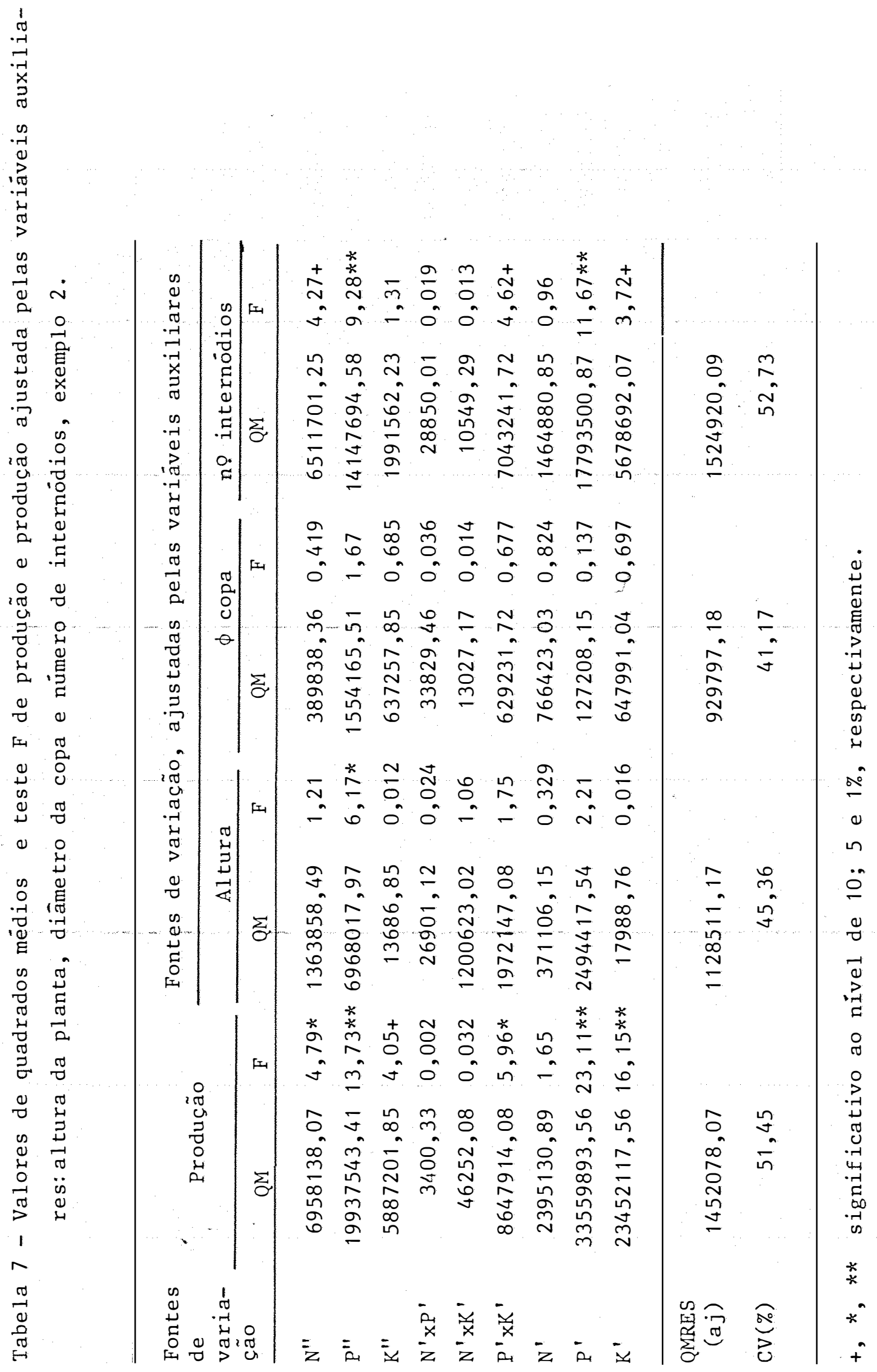


69.

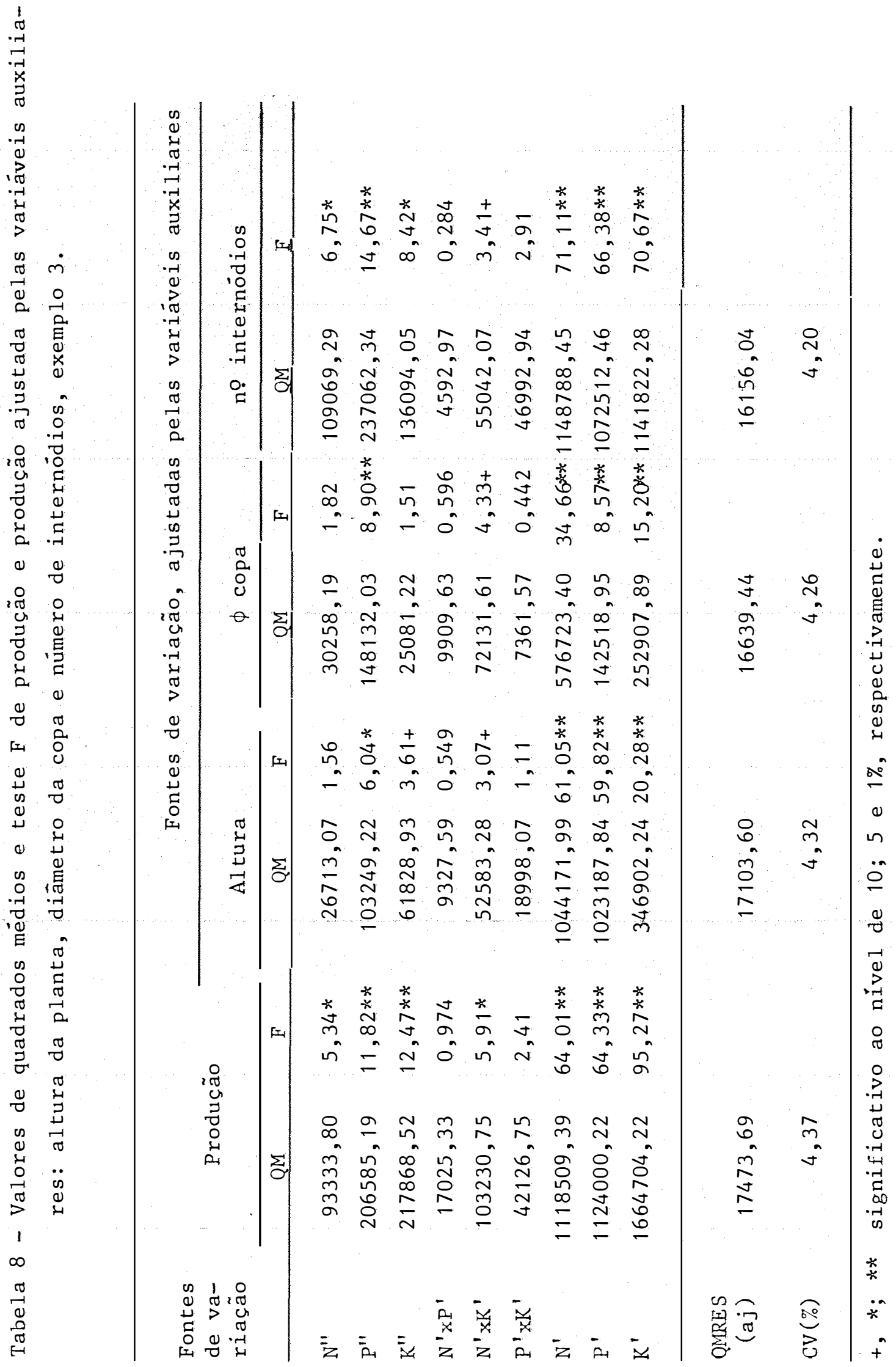


Das variäveis auxiliares adicionais consideradas, os re sultados evidenciam que o diāmetro da copa foi a variāvel que mais contri buiu para a redução da varianncia residual, seguida pela altura da planta. o número de internódios, apesar de ter aumentado a variāncia residual, comportou satisfatoriamente, aumentando alguns valores de fontes de varia ção, como K" e $N^{\prime x K}$ ' no exemplo 1 e, $N^{\prime \prime}$ no exemplo 3.

Observa-se alguns resultados bastante. interessantes, quando da introdução da variável auxiliar ao modelo, em relação aos valores obtidos das S.Q. de Tratamentos ajustadas. Quando da adição da variävel diāmetro da copa ao modelo nota-se que o efeito quadrático de potảs sio ajustado teve seu nivel de significāncia reduzido, de $1 \%$ para $10 \%$ no exemplo 1 e 10\% para um nivel bem inferior a 10\% no exemplo 2 . Nota-se, tambēm, que $N^{\prime} x K^{\prime}$ passou a apresentar significância (10\%) quando se consi derou a variāvel nümero de internódios no modelo, no exemplo 1.

Pelos valores obtidos para o teste $\mathbf{F}$, evidencia-se que a redução nos graus de liberdade foi maior, proporcionalmente, aos decréscimos da S.Q. de Residuo.

As estimativas ajustadas dos parâmetros pelas variäveis auxiliares, desvios padrões, valores de $t$ e coeficientes de regressão encontram-se nas Tabelas 9, 10 e 11, respectivamente, para os exemplos 1, 2 e 3.

Observa-se que os desvios padrões foram relativamente grandes quando comparados aos valores obtidos para as estimativas dos parâmetros e maiores do que os obtidos anteriormente, em 4.1., sem as variā veis auxiliares; o mesmo ocorrendo para os valores calculados para o teste $\boldsymbol{t}$, mas com tendência a serem menores. 


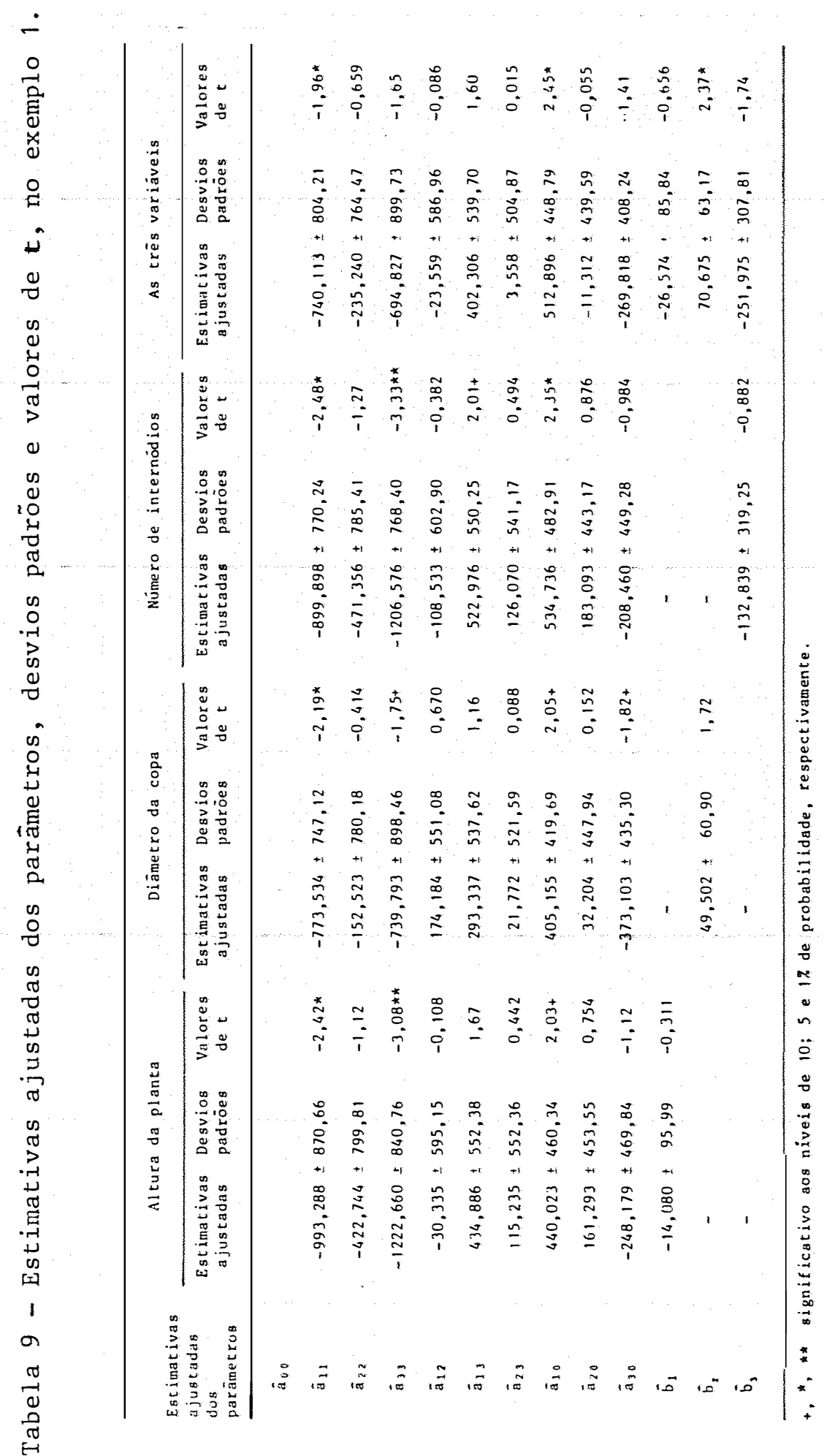




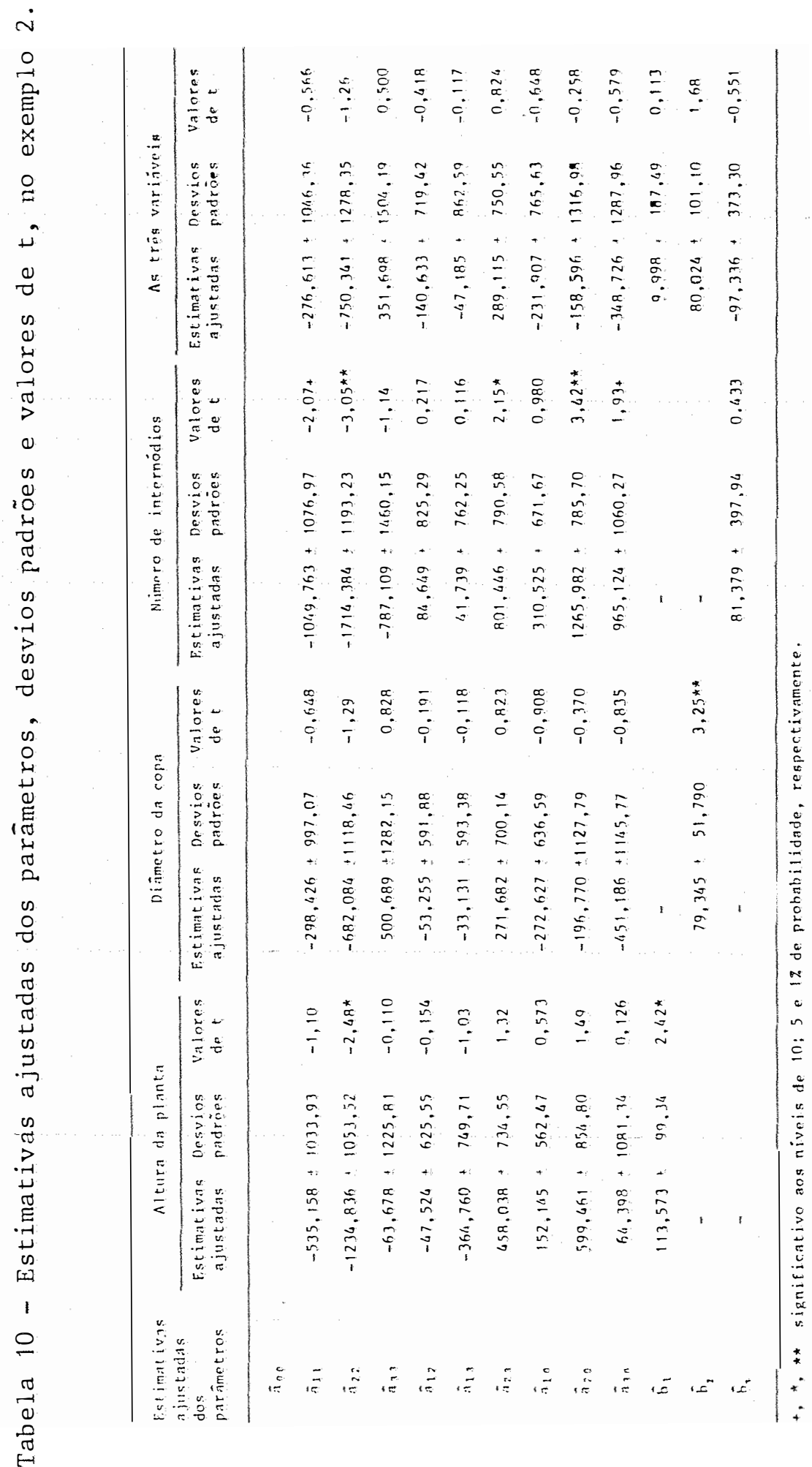




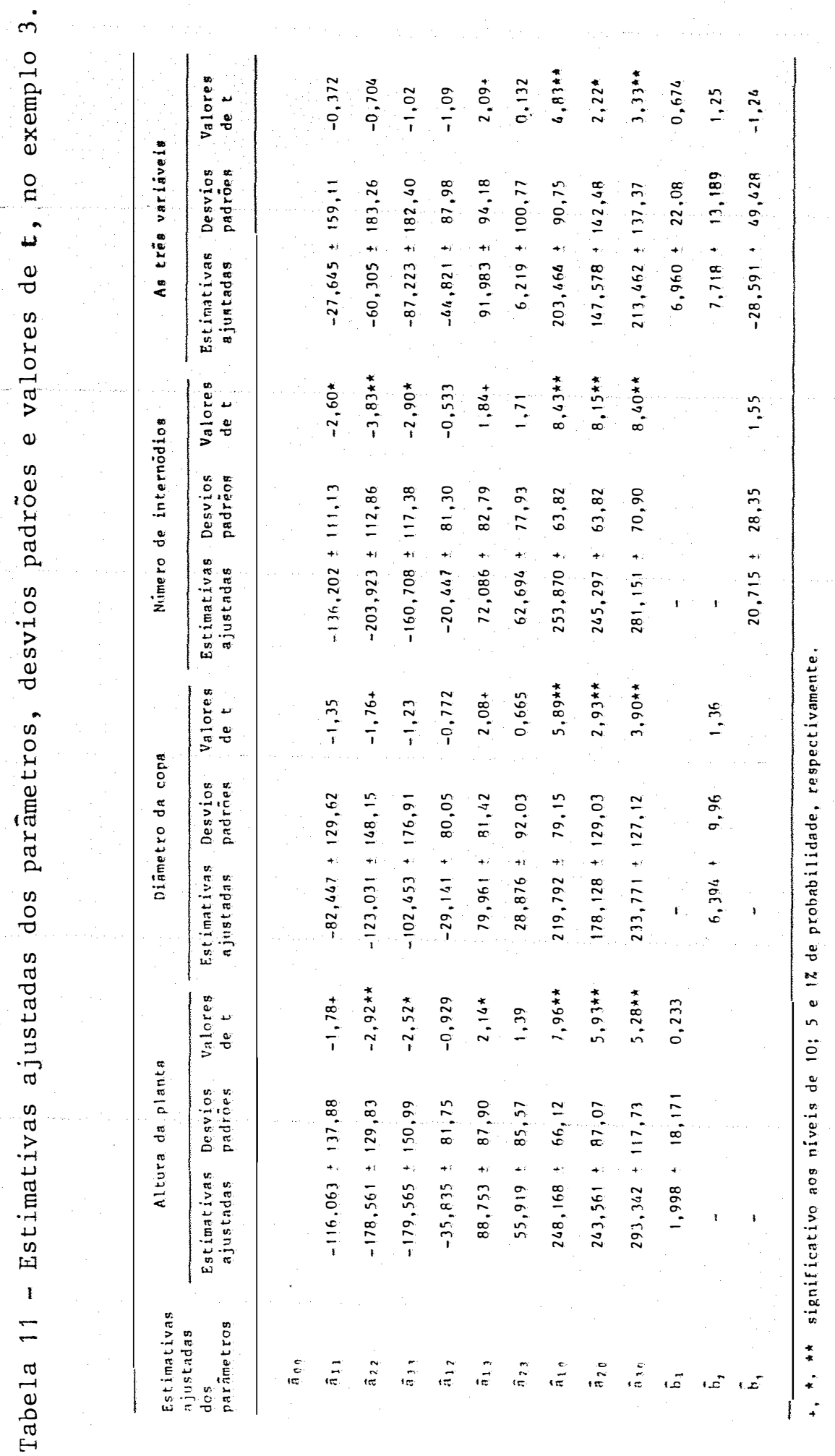


As estimativas ajustadas dos parâmetros, em poucos casos, se aproximam daquelas obtidas sem o ajustamento feito pelas variäveis auxiliares. Nota-se uma maior semelhança no exemplo 3 quando da inclusão da variāvel altura da planta.

As estimativas dos coeficientes de regressão apresentaram significāncia somente para as variáveis auxiliares altura da planta e diâmetro da copa no exemplo 2 e, diāmetro da copa no exemplo 1, evidenciando que estas variäveis auxiliares contribuiram satisfatoriamente na redução da variāncia residual.

De maneira geral, o ajustamento das estimativas dos parāmetros pelas variáveis auxiliares não trouxe resultados plenamente satisfatórios, pois as estimativas dos quadrados médios ajustadas das diver sas fontes de variação, na maioria das vezes, sofreram reduções e, em alguns casos muito acentuados, inibindo assim as reduções ocorridas nas variāncias residuais. Estes fatos devem-se, talvez, à pouca precisão dos exemplos considerados ou que o método não se adapte bem ao estudo de super fícies de resposta, ou ainda, que as variāveis auxiliares altura da planta, diāmetro da copa e número de internódios estão sendo afetadas pelos próprios tratamentos (niveis de $\mathrm{N}, \mathrm{P}_{2} \mathrm{O}_{5}$ e $\mathrm{K}_{2} \mathrm{O}$ ) conforme PIMENTEL GOMES (1978).

As estimativas das variāncias das estimativas ajustadas dos parâmetros se encontram na Tabela 12, para os exemplos em questão. Nota-se, em comparação com as estimativas das variān cias dos parâmetros calculados, em 4.1., que algumas estimativas ajustadas de variāncia dos parāmetros foram inferiores (aquelas onde figuram o 


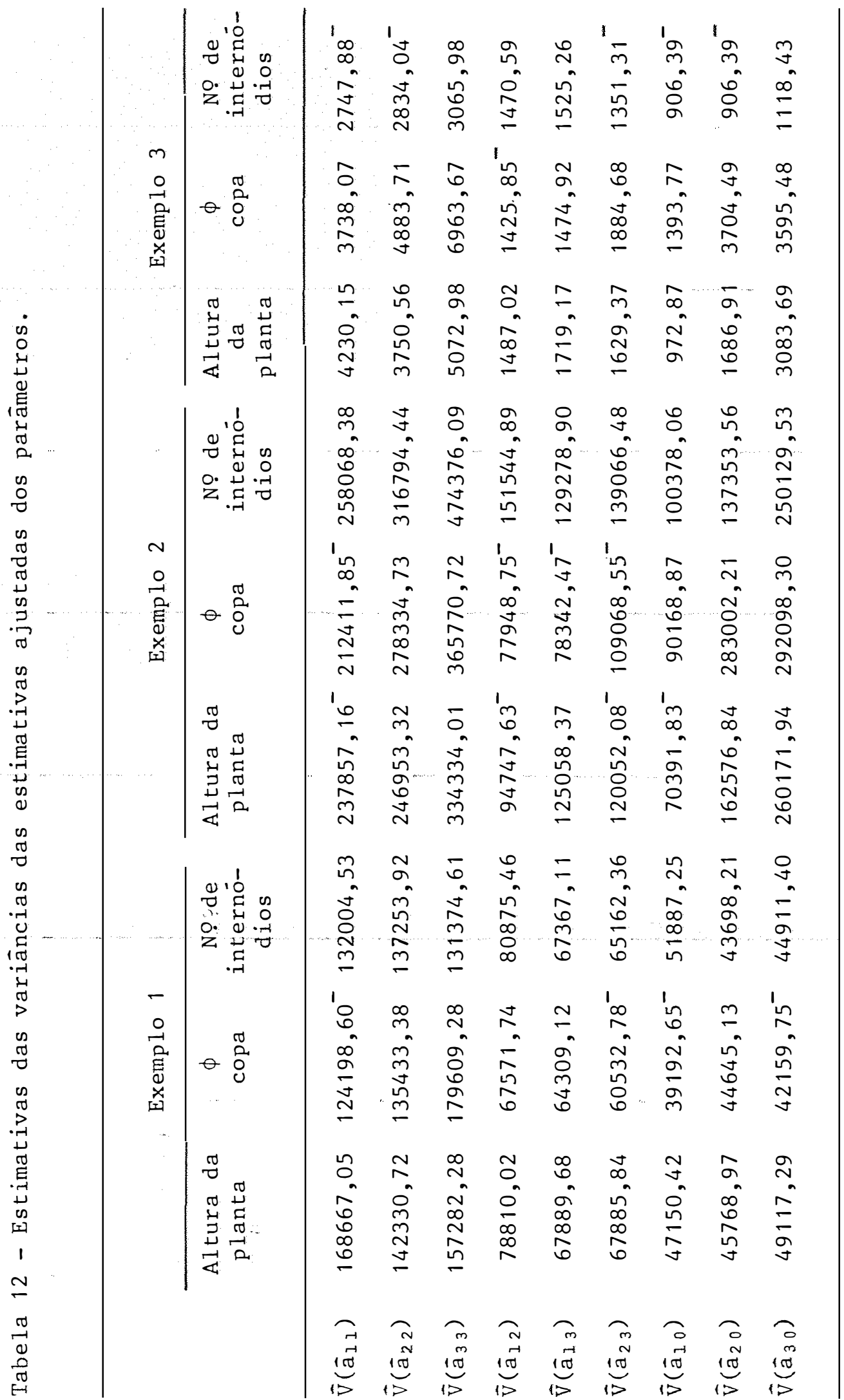


sinal -), evidenciando que os efeitos correspondentes a estas variāncias podem ser obtidas com maior precisão pelo modelo com a variável auxiliar. Os valores estimados de produção, através do modelo ori ginal (sem variáveis auxiliares adicionais) e do modelo com as variáveis auxiliares encontram-se nos Apéndices 7, 8 e 9, respectivamente, para os $\underline{\text { e }}$ xemplos 1,2 e 3.

Observa-se que os valores estimados se aproximam satisfatoriamente dos valores observados, principalmente nos exemplos com menor coeficiente de variação ou maior precisão. 
77.

\section{CONCLUSÕES}

A aplicação da metodologia de superficie de resposta, a través do uso de um modelo de regressão polinomial quadrático, a experi mento planejado em esquema fatorial para três fatores e três niveis eqüidistantes, tendo-se a preocupação de considerar algumas variáveis auxilia res adicionais ao modelo, levou às seguintes conclusões:

1. Os parámetros $\left(a_{i i^{\prime}}, i, i^{\prime}=0,1,2,3\right)$ do modelo com uma variável auxiliar, serão estimados com maior precisão do que no modelo original (sem a variävel auxiliar) quando a redução da variānica residual deste, dada por $\left(\sigma^{2}-\sigma_{1}^{2}\right)$, for maior do que o acréscimo [SQ $\left.a_{i 1}^{\prime}, / R\left(z^{2}\right)\right] \sigma_{1}^{2}$, dado na inclusão da variável auxiliar ao modelo, ou seja,

$$
\frac{\sigma_{1}^{2}}{\sigma_{1}^{2}}>1+\frac{\mathrm{SQa}_{\mathrm{i}^{\prime}}^{\prime}}{\mathrm{R}\left(\mathrm{z}^{2}\right)},
$$


onde: SQa' ${ }_{i i^{\prime}}$ : é a soma de quadrados do parāmetro (a' ${ }_{i i}$ ', $i, i^{\prime}=0$, 1,2,3), relativa à variāvel auxiliar;

$R\left(z^{2}\right)$ : é a soma de quadrados de residuo relativa à variável au xiliar;

$\sigma^{2}$ e $\sigma_{1}^{2}$ : são as variāncias residuais dos modelos sem e com a variāvel auxiliar, respectivamente.

2. As variáveis auxiliares que mais contribuiram para a redução da variân cia residual $\left(\sigma^{2}\right)$ foram: diāmetro da copa seguida da altura da planta, nos exemplos em questão. Consequentemente as estimativas ajustadas dos parämetros se aproximaram mais das estimativas do modelo original (sem a variável auxiliar) ao serem ajustadas pelas variāveis auxiliares: nú mero de internódios e altura da planta.

3. As estimativas da variāncia dos parâmetros $\left(a_{i i}, i, i,=0,1,2,3\right)$ são dadas pela expressão:

$$
\bar{V}\left(a_{i i^{\prime}}\right)=\frac{1}{C_{j}}\left[1+\frac{Q M a_{i i^{\prime}}^{\prime}}{R\left(z^{2}\right)}\right] \sigma_{1}^{2},
$$

onde: QMa! ${ }_{i}^{\prime}$ : quadrado médio do parāmetro $\left(a_{i i}^{\prime}\right)$ relativo à variável auxiliar;

$c_{j}$ : coeficiente dos termos quadráticos, lineares e interações, respectivamente 6,18 e 12 . 
4. A covariāncia entre os efeitos ajustados de dois parāmetros é dada pela soma de produtos desses parāmetros dividida pela soma de quadrados de residuo, relativas à variävel auxiliar. Por exemplo, a covariāncia entre os efeitos ajustados de nitrogēnio e fösforo quadräticos, nos exemplos considerados, é:

$$
\operatorname{Cov}\left(a_{11}, a_{22}\right)=\frac{n^{\prime \prime}}{18} \cdot \frac{p^{\prime \prime}}{18} \frac{\sigma_{1}^{2}}{R\left(z^{2}\right)},
$$

cujos valores foram definidos em $\mathbf{h}$. 
80.

\section{LITERATURA CITADA}

ANDRADE, D.F. de, 1977. Alguns Aspectos da Metodologia de Superficie de Resposta. São Paulo, USP. 87p. [Dissertação de Mestrado]

ARNOLD, B.; L. NELSON; R. VACCARO; C. MORĀN; T. SCHOFIELD; R. ARROYO, 1979. Diseños de Superfícies de Resposta. In: Curso de Estatistica Experimental Avanzada, Tomo 2, Lima. $444 p$.

BALAAM, L.N., 1973. Response Surface Designs. In: Developments in Fields Experimental Design and Analysis. Proceedings of a Symposium held at St. Albert's College, University of New England Armidade, New South Wales, Australia, 3-7 September. Commonwealth Agricultural Bureaux, p. 11-32. 
BOX, G.E.P. e J.S. HUNTER, 1957. Multifactor Experimental Designs for Exploring Response Surfaces. Ann. Math. Stat., Hayward, 28(1): 195-241.

BOX, G.E.P. e K.B. WILSON, 1951. On the Experimental Attainment of Optimum Conditions. J.R. Statist. Soc. B., London, 13: 1-45.

CAMPOS, H., 1967. Aspectos da Aplicação das Superfícies de Resposta a Ensaios Fatoriais $3^{3}$ de Adubação. Piracicaba, ESALQ/USP. 82p. [Tese de Livre-Docência]

CAMPOS, H. e P.F.C. de ARAUJO, 1971. Aspectos Econōmicos da Adubação em Milho. Departamento de Ciēncias Sociais Aplicadas, ESALQ/USP, Piracicaba, 41p. [Mimeografado]

COCHRAN, W.G., 1957. Analysis of Covariance: its nature and uses. Biometrics, Raleigh, 13: 261-281.

COCHRAN, W.G. e G.M. COX, 1957. Experimental Designs. 2å edição. New York, John Wiley. $611 \mathrm{p}$.

COSTA, R.A. da, 1977. Funções de Produção Ajustadas a Ensaios Fatoriais $3^{3}$ de Adubação de Arroz. Piracicaba, ESALQ/USP. 80p. [Dissertação de Mestrado]

DAVIES, O.L., 1960. The Design and Analysis of Industrial Experiments. 2a ed., London, Oliver and Boyd. 636p. 
DÁVILA, L.E.R., 1979. Alguns Diseños para Estüdios de la Superfícies de Respuesta a la Aplicación de Fertilizantes. In: Reunião Internacional de Biometria, Região Brasileira. Piracicaba, 1975. Fundação Cargill, p.131-156.

DÁvIlA, L.E.R. e J. BENIteZ, 1979. Vantajas y Desvantajas del Modelo Polinomial Cuadrático en el Estüdio de la Respuesta a los Fertilizantes. In: Reunião Internacional de Biometria, Região Brasileira. Piracicaba, 1975. Fundação Cargill, p.101-109.

DIAS, J.F.S., 1981. Anālise de Covariāncia Intrablocos, com p variäveis Auxiliares, para Delineamentos em blocos Incompletos Equilibrados. Piracicaba, ESALQ/USP. 96p. [Tese de Doutoramento]

DRAPER, N.R. e H. SMITH, 1981. Applied Regression Analysis. 2à ed., New York, John Wiley. 709p.

ESCOBAR, J.H. e F.B. CADY, 1967. Consideraciones sobre la Comparación de Diseños de Tratamientos. Agrociēncia, Chapingo, 2: 64-75.

GRAYBILL, F.A., 1961. An Introduction to Linear Statistical Models, Vol. 1. New York, McGraw-Hill. 463p. 
GUIMARÃES, P.T.G.; F.M. FREIRE; J.G. de CARVALHO; M.M. de CARVALHO; S.P. de SOUZA; J.M. BRAGA, 1976. Ensaio de Adubação Mineral e Orgānica para a Formação de Cafeeiros em um Latossolo Vermelho Escuro, fase cerrado de Machado-MG. In: Projeto Café - Relatório Anual 74/75. Belo Horizonte, EPAMIG. P.139-146.

HADER, R.J.; M.E. HARWARD; D.D. MASON; D.P. MOORE, 1957. An Investigation of Some of the Relationships of Cooper, Iron and Molybdenum in the Growth and Nutrition of Lettuce: I. Experimental Design and Statistical Methods for Characterizing the Response Surface. Soil Sci. Soc. Amer. Proc., Madison, 21: 59-64.

HEADY, E.O.; J.T. PESEK; W.G. BROWN; J.P. DOLL, 1961. Crop Response Surfaces and Economic Optima in Fertilizer Use. In: Agricultural Production Functions. Ames, Iowa State Univ. Press. 667p.

HOFFMANN, R. e S. VIEIRA, 1977. Anālise de Regressão. Uma Introdução a Econometria. São Paulo, HUCITEC-EDUSP. 339p.

JORGE, J. de P.N., 1980. Delineamento Guadalupe para Três Fatores, Analisado através de Modelo de Regressão Polinomial Quadrātica. Piracicaba, ESALQ/USP. 56p. [Dissertação de Mestrado]

KATTI, S.K., 1965. Multiple Covariate Analysis. Biometrics, Raleigh, 21: $957-974$. 
KEMPTHRONE, O., 1952. The Design and Analysis of Experiments. New York, John Wiley. 631p.

LIMA, A.R.C., 1980. Superficies de Resposta em Experimentos Fatoriais $3^{3}$ Incompletos de Adubação NPK em Mandioca no Estado do Cearā. Piracicaba, ESALQ/USP. 100p. [Dissertação de Mestrado]

MEAD, R. e D.J. PIKE, 1975. A Review of Response Surface Methodology from a Biometric Viewpoint. Biometrics, Raleigh, 31: 803-851.

MENEGUELli, C.A., 1976. Avaliação do Efeito da Escolha de Forma Algébrica Inadequada para Função de Resposta à Adubação. Brasilia, Universidade de Brasília/Departamento de Estatística. 41p. [Dissertação de Mestrado]

MONTEIRO, J.R.A., 1978. Comportamento de Funções de Produção em Ensaios Fatoriais $3^{3}$ de Adubação NPK em Amendoim (Arachis hypogaea L.) no Estado do Maranhão. Piracicaba, ESALQ/USP. 73p. [Dissertação de Mestrado]

MONTGOMERY, D.C., 1976. Design and Analysis of Experiments. New York, John Wiley. $418 \mathrm{p}$. 
MORAES, R.S., 1969. Superficie Polinomial de Resposta num Ensaio de Adubação com Niveis Não Eqüidistantes. Piracicaba, ESALQ/USP. 58p. [Tese de Doutoramento]

MORAIS, O.P. de e V. de P.M. GONTIJO, 1978. Respostas da Cultura de Arroz (Oryza sativa L.) de Sequeiro à Fertilização NPK e à Calagem. In: Projeto Arroz-Relatörio Anual 75/76. Belo Horizonte, EPAMIG. p.93-138.

MYERS, R.H., 1971. Response Surface Methodology, Boston, Allyn e Bacon. $246 p$.

(NAS-NRC) NATIONAL ACADEMY OF SCIENCES - NATIONAL RESEARCH COUNCIL, 1961. Status and Methods of Research in Economic and Agronomic Aspects of Fertilizer Response and use. Publication 918, Washington.

NAGAI, V.; N.M. SILVA e T. IGUE, 1979. Aplicação do Modelo Polinomial Quadrātico ao Estudo de Experimentos de Adubação em Algodoeiro. In: Reunião Internacional de Biometria, Região Brasileira, Piracicaba, 1975. Fundação Cargi11. p.78-100.

NEVES, O.S. e Outros, 1960. Ensaios de Adubação do Algodoeiro. Boletim no 114 do Instituto Agronōmico. Campinas, Instituto Agronómico. 33p.

NICOLELlA, G., 1981. O Uso de Superficie de Resposta na Interpretação de Ensaios de Adubação NPK em Plantações de Cacau (Theobroma cacao L.). Piracicaba, ESALQ/USP. 91p. [Dissertação de Mestrado] 
OLIVEIRA, L.M. de, 1974. Eficiéncia de Delineamentos para Ajustamento de Superfícies de Resposta. Piracicaba, ESALQ/USP. 61p. [Dissertação de Mestrado]

OSTLE, B., 1954. Statistics in Research. Ames, Iowa State College Press, 487p.

PIMENTEL GOMES, F., 1968. Novos Aspectos do Estudo Económico de Adubação. Fertilité, Paris, 34: 3-9.

PIMENTEL GOMES, F., 1978. Curso de Estatistica Experimental. 8ạ ed. São Paulo, Livraria Nobel. 430p.

PIMENTEL GOMES, F. e H. CAMPOS, 1972. The Efficiency of Factorial $3^{3}$ Designs as Compared to a Central Composite Rotatable Design. Potash Review, Berna, Fevereiro. 3p.

PIRES, V.M., 1979. Anālise de Superfície de Resposta em Condições de Risco Quando as Informações são Escassas. Um Exemplo com a Cultura do Milho. Viçosa, U.F.V. 69p. [Tese de Mestrado] 
RIBOLDI, J., 1978. Ajustamento de Duas Superficies de Resposta Usadas em Ensaios de Adubação. Piracicaba, ESALQ/USP. 81p. [Dissertação de Mestrado]

ROJAS, B.A., 1980. Diseño de Experimentos de Fertilizantes. Agrociéncia, Chapingo, 40: 191-202.

SEARLE, S.R., 1971. Linear Models. New York, John Wiley. 532p.

SHIROSE, I.; R. CARVALHO; V.L.P. FERREIRA; R.L. CARVALHO, 1978. Aplicação de metodologia de superficie de resposta na determinação de niveis ötimos de açūcar e sal na paçoca de soja. Coletãnea do Instituto de Tecnologia de Alimentos, Campinas, 9: 239-256.

SILVA, I.P. da, 1978. Interpretação Econōmica de Ensaios de Adubação de Milho em Pernambuco. ESALQ/USP, Piracicaba. 138p. [Dissertação de Mestrado]

SNEDECOR, G.W. e W.G. COCHRAN, 1967. Statistical Methods. 6a ed., Ames, Iowa State College Press. 593p.

TEIXEIRA, T.D., 1969. Superfície Quadrätica e suas Aplicações na Análise Econōmica de Experimentos. Viçosa, U.F.V. 164p. [Tese de Mestrado]

VIEIRA, S., 1970. Aspectos das Funções de Produção Ajustadas aos Ensaios Fatoriais $3^{3}$ de Adubação. Piracicaba, ESALQ/USP. 160p. [Tese de Doutoramento] 
VIEIRA, S., 1978. Estudo Econométrico de Funções de Produção para Adubação. In: Reunião Comemorativa dos Noventa Anos do Instituto Agronōmico. Campinas, Instituto Agronómico. 13p.

VIEIRA, S.; H.V. de ARRUDA e R. HOFFMANN, 1971. Estudo Comparativo de Trēs Funções na Anālise Economëtrica de Experimentos de Adubação. Convēnio ESCO-MA/ESALQ-USP, Piracicaba. $111 \mathrm{p}$.

WINER, B.J., 1970. Statistical Principles in Experimental Design. New York, McGraw-Hill. 672p.

ZELLEN, M., 1957. The Analysis of Covariance for Incomplete Block Design. Biometrics, Raleigh, 13: 309-332. 
89.

7. APENDICE 
Apēndice 1 - Valores observados, relativos às variäveis auxiliares nos exemplos considerados.

\begin{tabular}{|c|c|c|c|c|c|c|c|c|c|}
\hline \multirow{2}{*}{$\begin{array}{l}\text { Trata- } \\
\text { mentos }\end{array}$} & \multicolumn{3}{|c|}{ Altura da planta } & \multicolumn{3}{|c|}{ Diämetro da copa } & \multicolumn{3}{|c|}{ NO de internödios } \\
\hline & 1 & 2 & 3 & 1 & 2 & 3 & 1 & 2 & 3 \\
\hline 000 & 90,6 & 70,6 & 81 & 115,4 & 58,1 & 87 & 19 & 15 & 34 \\
\hline 010 & 96,6 & 76,2 & 86 & 137,8 & 84,0 & 111 & 23 & 18 & 35 \\
\hline 020 & 91,9 & 83,4 & 88 & 132,3 & 89,0 & 110 & 23 & 20 & 35 \\
\hline 001 & 92,8 & 76,0 & 84 & 137,2 & 85,6 & 111 & 22 & 20 & 35 \\
\hline 011 & 96,2 & 88,5 & 92 & 136,5 & 114,2 & 125 & 24 & 23 & 31 \\
\hline 021 & 104,4 & 89,6 & 97 & 141,0 & 124,8 & 133 & 22 & 24 & 36 \\
\hline 002 & 95,5 & 76,7 & 86 & 113,6 & 88,9 & 101 & 20 & 19 & 3.1 \\
\hline 012 & 103,9 & 88,8 & 96 & 134,9 & 119,4 & 127 & 23 & 23 & 35 \\
\hline 022 & 91,6 & 91,9 & 92 & 142,6 & 128,2 & 135 & 22 & 25 & 36 \\
\hline 100 & 99,2 & 78,4 & 89 & 144,2 & 86,2 & 115 & 24 & 22 & 28 \\
\hline 110 & 94,0 & 73,5 & 84 & 130,6 & 85,5 & 108 & 23 & 19 & 31 \\
\hline 120 & 100,0 & 71,5 & 86 & 134,5 & 94,6 & 115 & 21 & 18 & 33 \\
\hline 101 & 107,0 & 81,4 & 94 & 132,5 & 86,4 & 109 & 21 & 21 & 39 \\
\hline 111 & 95,8 & 103,0 & 99 & 145,3 & 151,8 & 149 & 21 & 24 & 33 \\
\hline 121 & 101,4 & 99,0 & 100 & 141,0 & 145,9 & 143 & 23 & 25 & 33 \\
\hline 102 & 94,1 & 84,2 & 89 & 136,7 & 96,1 & 116 & 22 & 20 & 35 \\
\hline 112 & 99,8 & 105,5 & 103 & 135,1 & 153,1 & 144 & 23 & 25 & 33 \\
\hline 122 & 99,6 & 104,9 & 102 & 130,1 & 153,2 & 142 & 23 & 22 & 36 \\
\hline 200 & 94,9 & 62,0 & 78 & 122,2 & 72,8 & 98 & 22 & 16 & 33 \\
\hline 210 & 89,9 & 71,2 & 81 & 127,4 & 90,5 & 109 & 22 & 20 & 29 \\
\hline 220 & 87,8 & 76,2 & 82 & 120,1 & 96,2 & 108 & 21 & 19 & 32 \\
\hline 201 & 94,1 & 85,9 & 90 & 136,6 & 102,9 & 120 & 24 & 24 & 34 \\
\hline 211 & 105,6 & 103,8 & 105 & 152,1 & 149,1 & 151 & 24 & 25 & 37 \\
\hline 221 & 88,8 & 94,6 & 92 & 141,0 & 145,9 & 143 & 23 & 23 & 35 \\
\hline 202 & 97,8 & 81,4 & 90 & 132,0 & 96,6 & 114 & 26 & 22 & 36 \\
\hline 212 & 95,8 & 93,4 & 95 & 140,2 & 132,5 & 136 & 23 & 25 & 35 \\
\hline 222 & 91,5 & 106,9 & 99 & 137,5 & 150,2 & 144 & 24 & 25 & 33 \\
\hline
\end{tabular}




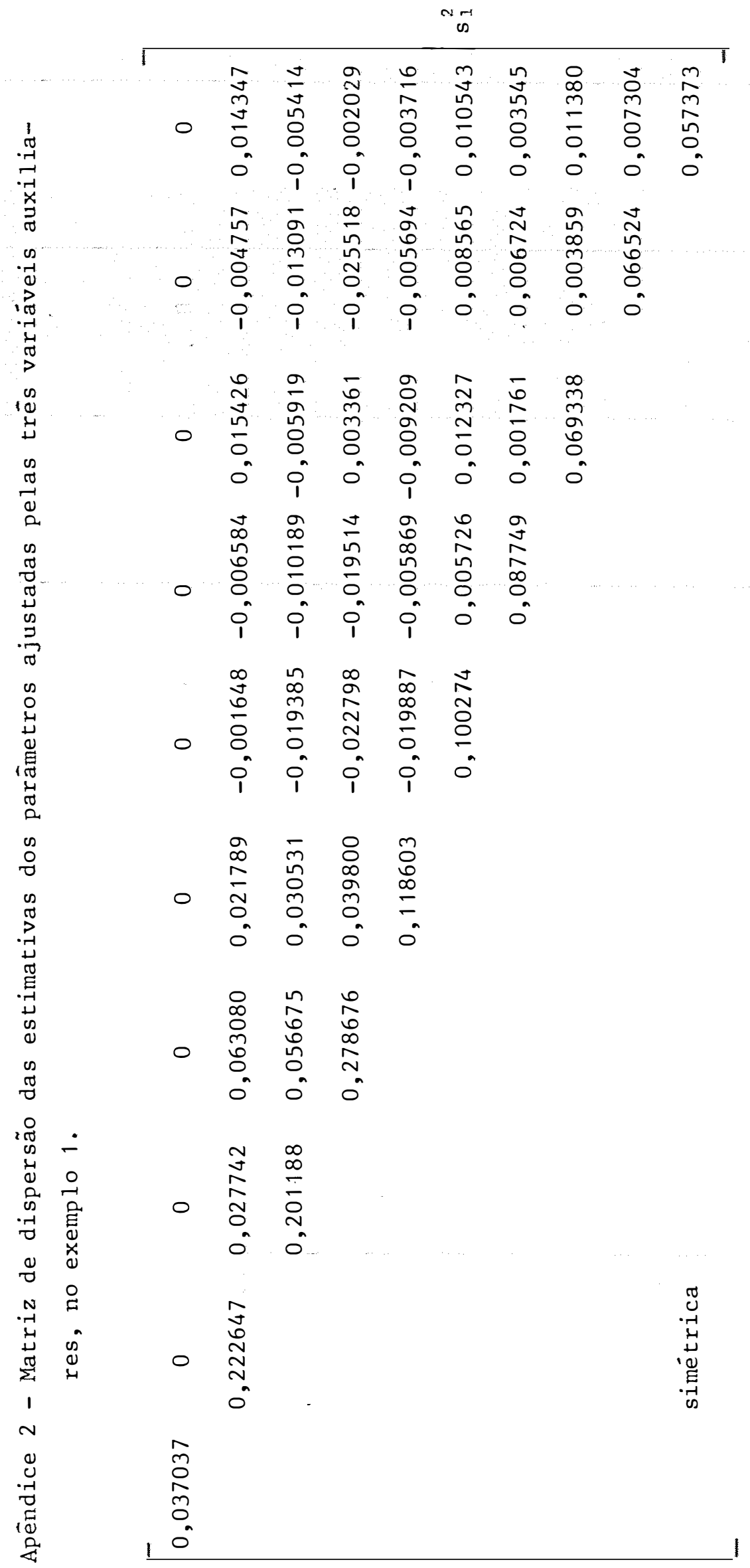

91. 


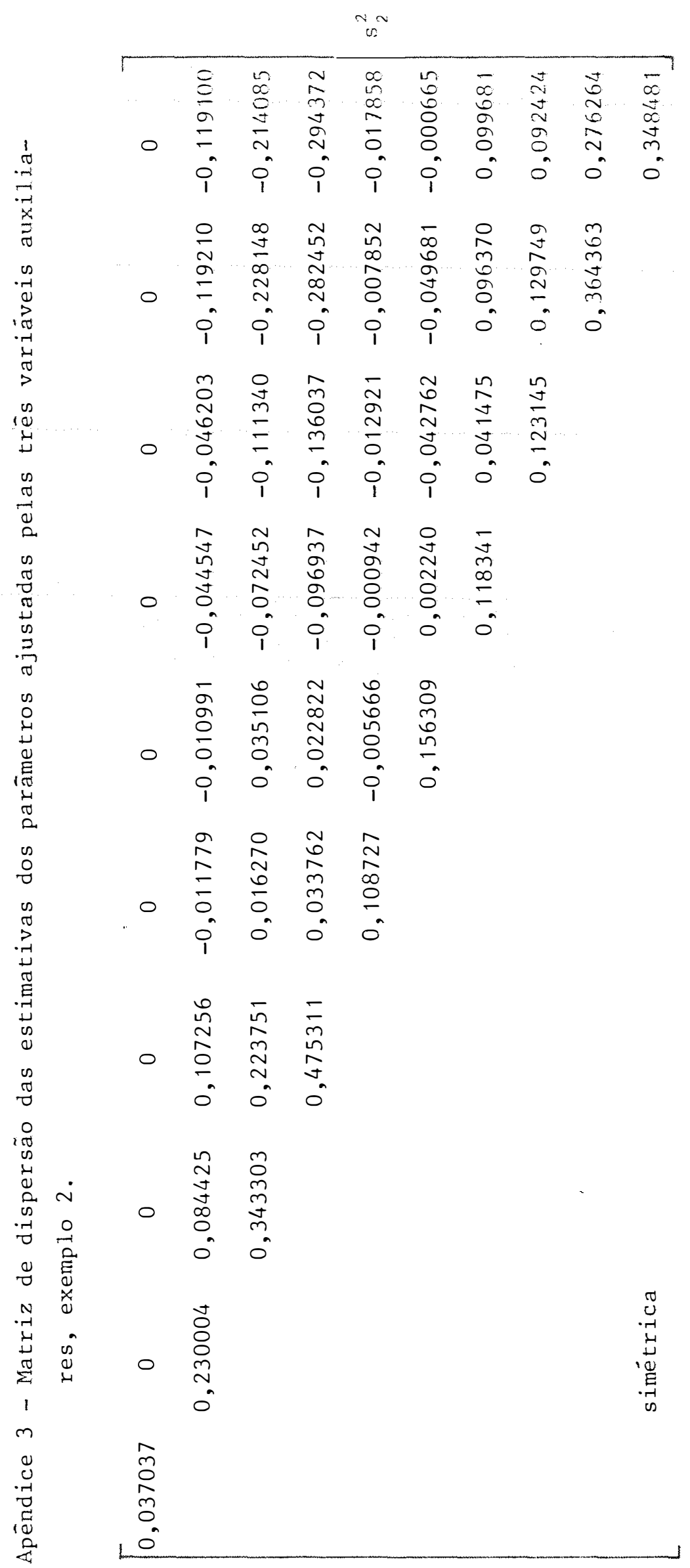

92. 


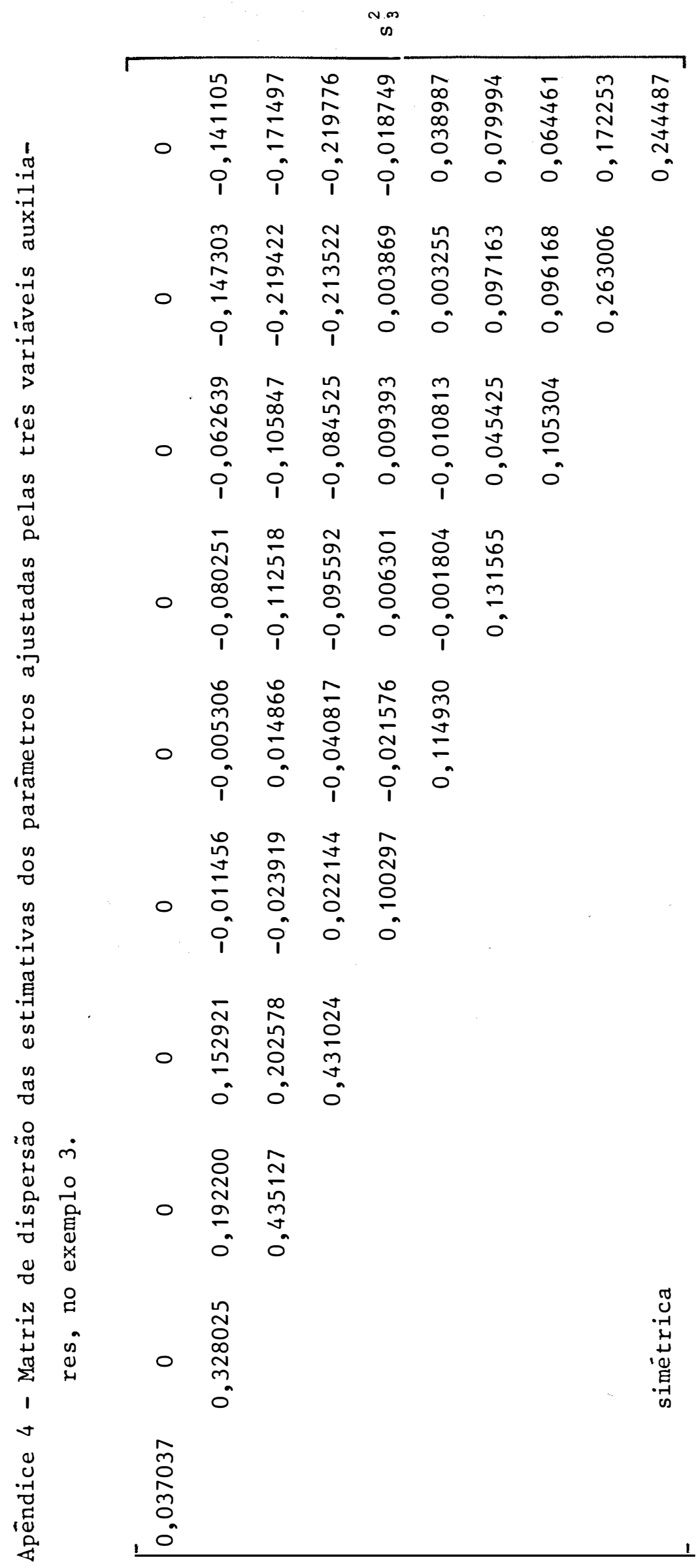




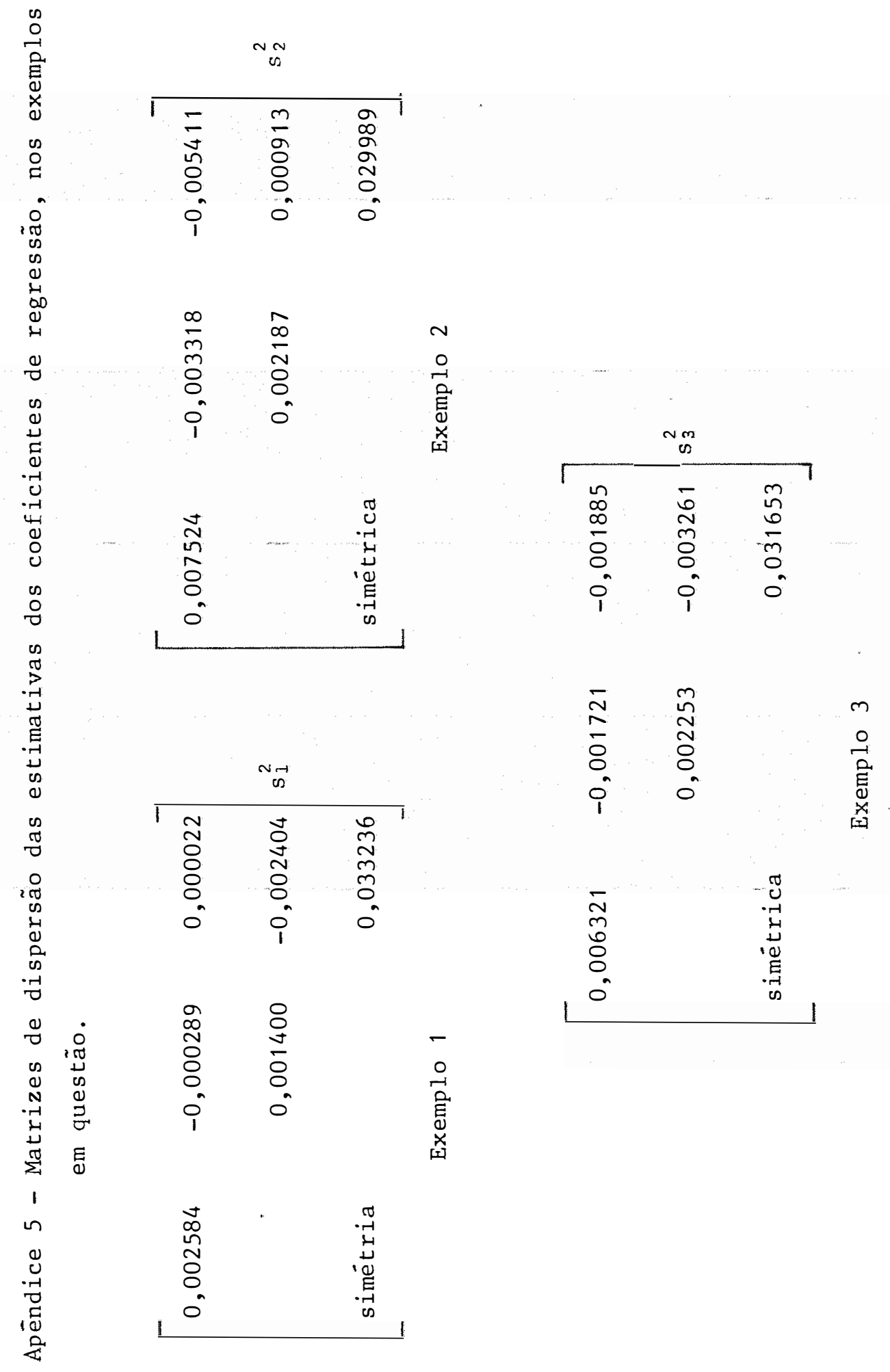



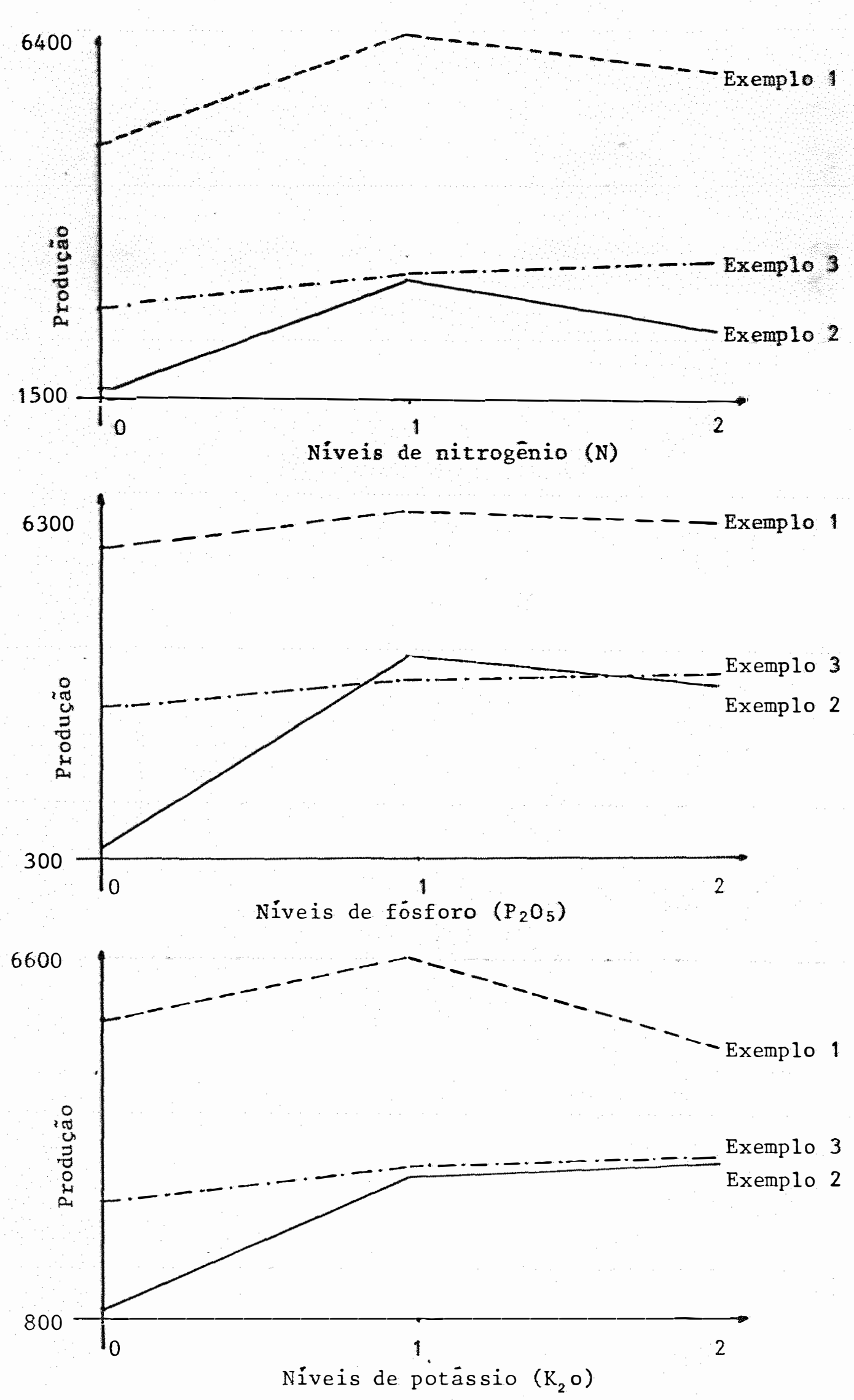

Apēndice 6 - Representação gräfica das produções mëdias nos trēs níveis de $\mathrm{N}, \mathrm{P}_{2} \mathrm{O}_{5}$ e $\mathrm{K}_{2} \mathrm{O}$. 
Apēndice 7 - Valores observados e estimados da produção, no exemplo 1.

\begin{tabular}{|c|c|c|c|c|c|}
\hline \multirow{3}{*}{$\begin{array}{l}\text { Valores } \\
\text { obser- } \\
\text { vados }\end{array}$} & \multicolumn{5}{|c|}{ Valores estimados } \\
\hline & \multirow{2}{*}{$\begin{array}{l}\text { Sem variäveis } \\
\text { auxiliares }\end{array}$} & \multicolumn{4}{|c|}{ Com variäveis auxiliares } \\
\hline & & Altura & Diāmetro & Nümero & as trēs \\
\hline 4436 & $5102,6 \pm 1322,4$ & 5109,3 & 4671,2 & 5378,7 & 5026,2 \\
\hline 6030 & $5551,0 \pm 1084,6$ & 5523,9 & 5763,8 & 5484,3 & 5679,0 \\
\hline 5090 & $5102,6 \pm 1322,4$ & 5243,8 & 5447,5 & 5178,5 & 5188,6 \\
\hline 5855 & $5462,3 \pm 1084,6$ & 5502,7 & 5796,9 & 5329,3 & 5764,7 \\
\hline 5935 & $6026,0 \pm 943,5$ & 6069,2 & 5502,8 & 5826,6 & 5368,5 \\
\hline 5680 & $5794,6 \pm 1084,6$ & 5722,6 & 5701,1 & 5913,5 & 5749,6 \\
\hline 3620 & $3468,1 \pm 1322,4$ & 3443,7 & 3215,6 & 3530,9 & 3156,9 \\
\hline 3344 & $4146,8 \pm 1084,6$ & 4055,0 & 4287,4 & 4021,4 & 3935,8 \\
\hline 4795 & $4030,4 \pm 1322,4$ & 4112,3 & 4395,8 & 4100,6 & 4839,4 \\
\hline 6034 & $6056,1 \pm 1084,6$ & 6017,0 & 6803,0 & 5734,8 & 6440,6 \\
\hline 6305 & $6506,9 \pm 943,5$ & 6559,0 & 6292,8 & 6396,0 & 6089,8 \\
\hline 6835 & $6162,7 \pm 1084,6$ & 6097,8 & 6348,7 & 6247,4 & 6467,0 \\
\hline 7080 & $6850,4 \pm 943,5$ & 6766,4 & 6568,8 & 7005,4 & 6583,8 \\
\hline 7010 & $7416,3 \pm 943,5$ & 7508,1 & 7387,1 & 7660,0 & 8010,0 \\
\hline 7295 & $7187,0 \pm 943,5$ & 7167,8 & 7053,9 & 7105,9 & 6806,8 \\
\hline 6760 & $5290,6 \pm 1084,6$ & 5362,0 & 5642,0 & 5331,4 & 6542,8 \\
\hline 4540 & $5971,5 \pm 943,5$ & 5980,9 & 5769,3 & 5979,1 & 5714,2 \\
\hline 5440 & $5857,3 \pm 1084,6$ & 5837,6 & 5641,1 & 5816,9 & 5123,1 \\
\hline 5195 & $5136,0 \pm 1322,4$ & 5119,6 & 4883,1 & 5220,8 & 4904,9 \\
\hline 6079 & $5589,1 \pm 1084,6$ & 5628,6 & 5472,6 & 5640,6 & 5595,1 \\
\hline 4550 & $5246,9 \pm 1322,4$ & 5251,1 & 5148,4 & 5250,6 & 5120,3 \\
\hline 6275 & $6364,8 \pm 1084,6$ & 6425,1 & 6229,2 & 6350,2 & 6256,7 \\
\hline 7345 & $6932,8 \pm 943,5$ & 6816,9 & 6214,1 & 6896,1 & 7247,0 \\
\hline 6265 & $6705,8 \pm 1084,6$ & 6761,6 & 6859,7 & 6632,1 & 6890,8 \\
\hline 3715 & $5239,4 \pm 1322,4$ & 5221,8 & 5160,2 & 5066,3 & 4763,4 \\
\hline 7475 & $5922,5 \pm 1084,6$ & 5918,9 & 5946,7 & 6136,9 & 6356,0 \\
\hline 6050 & $5810,4 \pm 1322,4$ & 5798,7 & 5893,7 & 5733,3 & 5760,0 \\
\hline
\end{tabular}


Apēndice 8 - Valores observados e estimados da produção, no exemplo 2.

\begin{tabular}{|c|c|c|c|c|c|}
\hline \multirow{3}{*}{$\begin{array}{l}\text { Valores } \\
\text { obser- } \\
\text { vados }\end{array}$} & \multicolumn{5}{|c|}{ Valores estimados } \\
\hline & \multirow{2}{*}{$\begin{array}{l}\text { Sem variáveis } \\
\text { auxiliares }\end{array}$} & \multicolumn{4}{|c|}{ Com variáveis auxiliares } \\
\hline & & Altura & Diāmetro & Nümero & as très \\
\hline 298 & $-898,5 \pm 1814,4$ & $-777,0$ & $-861,4$ & $-991,9$ & $-1216,1$ \\
\hline 692 & $1424,0 \pm 1488,2$ & 1282,4 & 1460,3 & 1020,3 & 1667,0 \\
\hline 958 & $100,8 \pm 1814,6$ & 1054,2 & 759,7 & 174,7 & 547,6 \\
\hline 235 & $322,5 \pm 1488,2$ & $-129,2$ & 130,0 & 323,4 & $-160,6$ \\
\hline 2407 & $3494,0 \pm 1294,6$ & 3172,1 & 2937,6 & 3463,2 & 2979,3 \\
\hline 3215 & $3019,7 \pm 1488,2$ & 2709,2 & 2953,0 & 3011,5 & 3078,9 \\
\hline 470 & $-437,7 \pm 1814,4$ & $-271,0$ & 202,7 & $-422,5$ & 1,9 \\
\hline 2895 & $3582,8 \pm 1488,2$ & 3571,7 & 3432,8 & 3599,5 & 3500,6 \\
\hline 3395 & $395,7 \pm 1814,4$ & 3793,9 & 752,6 & 4031,2 & 3649,9 \\
\hline 206 & $464,2 \pm 1488,2$ & 1209,1 & 1480,1 & 810,9 & 897,6 \\
\hline 752 & $2803,6 \pm 1294,6$ & 2028,9 & 1638,3 & 2745,7 & 1380,2 \\
\hline 912 & $1497,3 \pm 1488,2$ & 708,3 & 1209,7 & 1414,5 & 1078,7 \\
\hline-673 & $1747,3 \pm 1294,6$ & 1219,8 & 272,5 & 1680,4 & 53,4 \\
\hline 6695 & $4935,6 \pm 1294,6$ & 3565,2 & 2662,0 & 4709,6 & 2792,2 \\
\hline 6255 & $4478,2 \pm 1294,6$ & 4417,6 & 4599,7 & 4537,9 & 4879,1 \\
\hline 372 & $1049,3 \pm 1488,2$ & 1080,5 & 819,9 & 975,6 & 765,8 \\
\hline 6345 & $5086,5 \pm 1294,6$ & 5791,8 & 6099,3 & 5164,3 & 6504,1 \\
\hline 5330 & $5478,0 \pm 1488,2$ & 5546,4 & 5498,3 & 5273,2 & 6179,3 \\
\hline 477 & $-326,8 \pm 1814,4$ & $-625,2$ & $-67,6$ & $-542,2$ & $-209,3$ \\
\hline 2460 & $2029,4 \pm 1488,2$ & 1748,3 & 1497,0 & 2046,1 & 1238,7 \\
\hline 1079 & $413,1 \pm 1814,4$ & 1175,2 & 745,4 & 800,2 & 570,4 \\
\hline 267 & $1018,4 \pm 1488,2$ & 1394,3 & 1063,8 & 1100,6 & 923,8 \\
\hline 5115 & $4223,5 \pm 1294,6$ & 5214,1 & 6169,3 & 4243,6 & 5624,5 \\
\hline 2160 & $3782,9 \pm 1488,2$ & 3486,3 & 3975,3 & 3720,5 & 4380,6 \\
\hline 323 & $795,5 \pm 1814,4$ & 61,2 & 308,6 & 356,8 & 173,1 \\
\hline 4655 & $4436,5 \pm 1488,2$ & 3668,8 & 3860,7 & 4466,8 & 3973,0 \\
\hline 4595 & $4844,8 \pm 1814,4$ & 4977,2 & 4604,5 & 4905,1 & 4941,0 \\
\hline
\end{tabular}


Apéndice 9 - Valores observados e estimados da produção, no exemplo 3.

\begin{tabular}{|c|c|c|c|c|}
\hline \multirow{3}{*}{$\begin{array}{l}\text { Valores } \\
\text { observados }\end{array}$} & \multicolumn{4}{|c|}{ Valores estimados } \\
\hline & \multirow{2}{*}{$\begin{array}{l}\text { Sem variäveis } \\
\text { auxiliares }\end{array}$} & \multicolumn{3}{|c|}{ Com variäveis auxiliares } \\
\hline & & Altura & Diāmetro & Nümero \\
\hline 2166 & $2169 \pm 199$ & 2171 & 2147 & 2192 \\
\hline 2657 & $2583 \pm 163$ & 2583 & 2601 & 2620 \\
\hline 2586 & $2626 \pm 199$ & 2628 & 2650 & 2619 \\
\hline 2423 & $2482 \pm 163$ & 2505 & 2527 & 2520 \\
\hline 2953 & $2985 \pm 142$ & 2979 & 2947 & 2907 \\
\hline 3102 & $3057 \pm 163$ & 3090 & 3083 & 3072 \\
\hline 2559 & $2473 \pm 199$ & 2478 & 2486 & 2423 \\
\hline 2855 & $3006 \pm 163$ & 3012 & 2992 & 3038 \\
\hline 3306 & $3167 \pm 199$ & 3161 & 3176 & 3183 \\
\hline 2532 & $2488 \pm 163$ & 2498 & 2577 & 2406 \\
\hline 2768 & $2864 \pm 142$ & 2854 & 2805 & 2855 \\
\hline 3012 & $2869 \pm 163$ & 2857 & 2875 & 2875 \\
\hline 3028 & $2923 \pm 142$ & 2925 & 2846 & 3013 \\
\hline 2451 & $3359 \pm 142$ & 3357 & 3403 & 3338 \\
\hline 3131 & $3423 \pm 142$ & 3424 & 3420 & 3380 \\
\hline 2915 & $2978 \pm 163$ & 2973 & 2993 & 2988 \\
\hline 3546 & $3472 \pm 142$ & 3479 & 3502 & 3459 \\
\hline 3590 & $3596 \pm 163$ & 3598 & 3573 & 3625 \\
\hline 2577 & $2557 \pm 199$ & 2555 & 2555 & 2576 \\
\hline 2734 & $2896 \pm 163$ & 2892 & 2868 & 2859 \\
\hline 2884 & $2863 \pm 199$ & 2867 & 2859 & 2879 \\
\hline 3002 & $3056 \pm 163$ & 3085 & 3083 & 3048 \\
\hline 3685 & $3483 \pm 142$ & 3501 & 3553 & 3539 \\
\hline 3593 & $3480 \pm 163$ & 3504 & 3528 & 3518 \\
\hline 3217 & $3232 \pm 199$ & 3231 & 3227 & 3219 \\
\hline 3689 & $3690 \pm 163$ & 3684 & 3668 & 3690 \\
\hline 3713 & $3776 \pm 199$ & 3777 & 3774 & 3732 \\
\hline
\end{tabular}

